\title{
Recent Advances in Modeling and Simulation of Nanofluid Flows-Part I: Fun Jamental and
} Theory

Omid Mahian ${ }^{a, b, c^{*}}$, Lioua Kolsi ${ }^{d, e}$, Mohammad Amani ${ }^{f}$, Patrice Estellé ${ }^{g}$, Good ‘rz / hmadi ${ }^{h}$, Clement

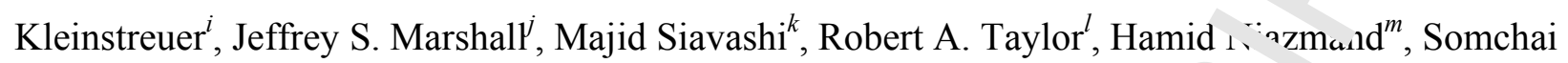
Wongwises $^{c, n}$, Tasawar Hayat ${ }^{o, p}$, Arun Kolanjiyil ${ }^{i}$, Alibakhsh Kasaeian ${ }^{q}$, Ir an $)_{\sim_{1}}{ }^{r}$

*Corresponding author email: omid.mahian@gmail.com

${ }^{a}$ School of Chemical Engineering and Technology, Xi'an Jiaotong Unive vity, Aı un, Shaanxi 710049, China

${ }^{b}$ Center for Advanced Technologies, Ferdowsi University of Mashhad, $\Lambda_{\ldots . .}$ hhar, Iran

${ }^{c}$ Fluid Mechanics, Thermal Engineering and Multiphase Flow Research Lu' 'oratory(FUTURE Lab.), Department of Mechanical Engineering, Faculty of Engineering, Kı. Mor skut's University of Technology Thonburi, Bangmod, Bangkok 10140, Thailand

${ }^{d}$ Dept. Mech. Engineering, College of Engineering, Hail Univer itv, Hail City, Saudi Arabia

${ }^{e}$ Laboratory of metrology and energy system, National eng. 'eel , school, Monastir, University of Monastir, Tunisia

${ }^{f}$ Mechanical and Energy Engineering Department, Shahic Ber.eshti University, Tehran, Iran

${ }^{g}$ Univ Rennes, LGCGM, EA3913, F-35000 Rennes, Fra»'”

${ }^{h}$ Department of Aeronautical and Mechanical I ngine ring, Clarkson University, NY, USA

${ }^{i}$ Department of Mechanical and Aerospace Fngm sri g, North Carolina State University, Raleigh, USA.

${ }^{j}$ Department of Mechanical Engineering, Ini, zrsit of Vermont, Burlington VT, USA

${ }^{k}$ Applied Multiphase Fluid Dynamics I. horatory, School of Mechanical Engineering, Iran University of Science and Technology, Tehran, Iran

${ }^{l}$ School of Mechanical and Manu xctu ing Engineering, School of Photovoltaics and Renewable Energy Engineering, University of New Sou.' Wales, Kensington, New South Wales, Australia

${ }^{m}$ Department of Mechanical ing leer $n g$, Ferdowsi University of Mashhad, Mashhad, Iran

${ }^{n}$ The Academy of Science, ine Rrvaı Institute of Thailand, Sanam Suea Pa, Dusit, Bangkok 10300, Thailand

${ }^{\circ}$ Nonlinear Analysis and $A_{t}$ nlied Mathematics (NAAM) Research Group, Department of Mathematics, Faculty of Science, King Abd ıaziz Iniversity, Jeddah 121589, Saudi Arabia

${ }^{p}$ Department of Mathe. 'ntic', Quaid-i-Azam University 45320, Islamabad 44000, Pakistan

${ }^{q}$ Faculty of New Sc ier es and Technologies, University of Tehran, Tehran, Iran

${ }^{r}$ Faculty of Mathematus, University of Cluj, R-3400 Cluj, CP 253, Romania 


\section{Abstract}

It has been more than two decades since the discovery of nanofluids-mixtures of common. liquids and solid nanoparticles less than $100 \mathrm{~nm}$ in size. As a type of colloidal suspension, anr iluids are typically employed as heat transfer fluids due to their favorable thermal and fluid prop - ties. There have been numerous numerical studies of nanofluids in recent years (more than $1^{r} j 0$. hoth 2016 and 2017, based on Scopus statistics). Due to the small size and large numbers of nanu ${ }_{r}$ rticles that interact with the surrounding fluid in nanofluid flows, it has been a major challeng to cap ure both the macro-scale and the nano-scale effects of these systems without incurring extr? sndinany high computational costs. To help understand the state of the art in modeling nanofluids ...1d $t^{\prime}$ discuss the challenges that remain in this field, the present article reviews the latest developme. ${ }^{+} \mathrm{s}$ in modeling of nanofluid flows and heat transfer with an emphasis on $3 \mathrm{D}$ simulations. $\mathrm{I}_{\boldsymbol{n}} \mathrm{p}_{\boldsymbol{c}}{ }^{+}{ }^{*}$, a brief overview of nanofluids (fabrication, applications, and their achievable thermo nest..... Next, various forces that exist in particulate flows such as dras, lift (Magnus and Saffman), Brownian, thermophoretic, van der Waals, and electrostatic dc sle layer forces and their significance in nanofluid flows are discussed. Afterwards, the ma $\eta$. odels used to calculate the thermophysical properties of nanofluids are reviewed. This will $\iota$ toruwwed with the description of the main physical models presented for nanofluid flows and hent transfer, from single-phase to Eulerian and Lagrangian two-phase models. In part II, various omput tional fluid dynamics (CFD) techniques will be presented. Next, the latest studies $0^{+} .3 \Gamma$ sululation of nanofluid flow in various regimes and configurations are reviewed. The pr selı rev ew is expected to be helpful for researchers working on numerical simulation of nanoflu is and also for scholars who work on experimental aspects of nanofluids to understand the un err ing physical phenomena occurring during their experiments.

Keywords: Nanofluids, the nonhys zal properties, dynamics of nanoparticles, physical models 


\section{Table of Contents}

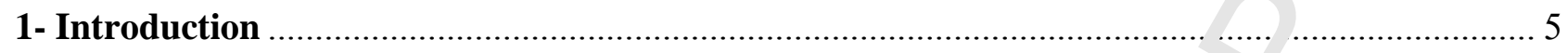

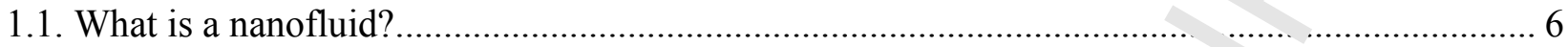

1.2. How has the research on nanofluids evolved? ................................................................... 7

1.3. What applications are suitable for nanofluids? ................................................................. 8

1.4. What are the advantages and disadvantages of nanofluids? ........................................... 9

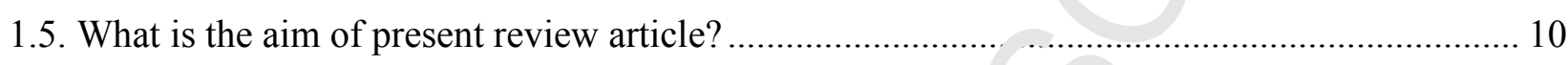

2. Dynamics of nanoparticle motion in a liquid ............................................................... 12

2.1. Forces acting on a nanoparticle by the base liquid ......................................................... 14

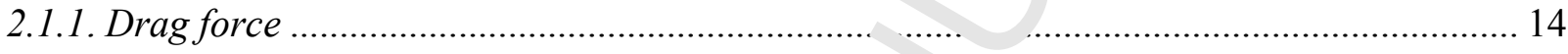

2.1.1.1. Wall effect on drag coefficient .................................................................. 15

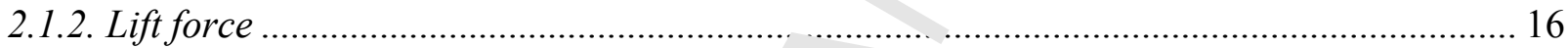

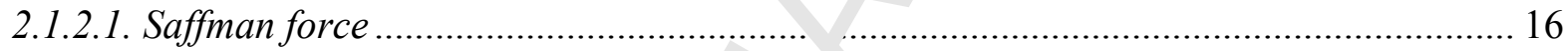

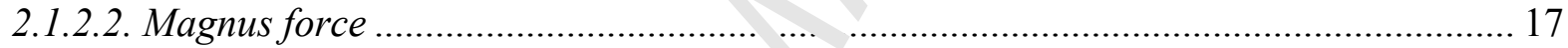

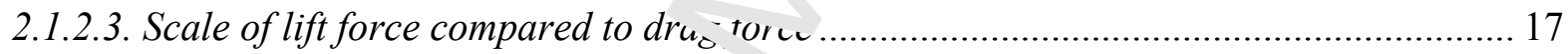

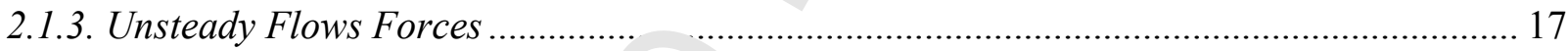

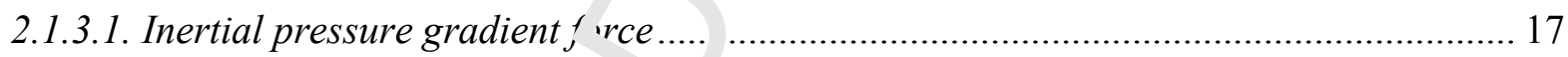

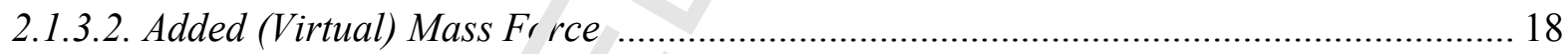

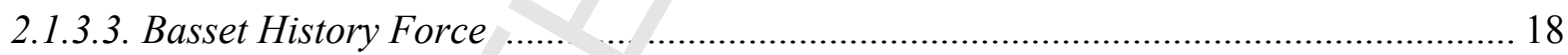

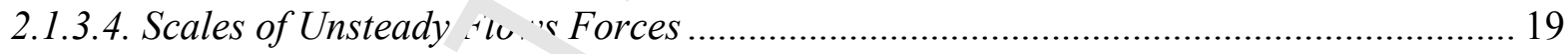

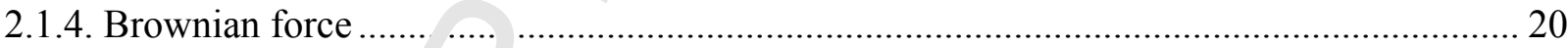

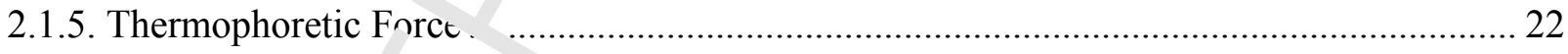

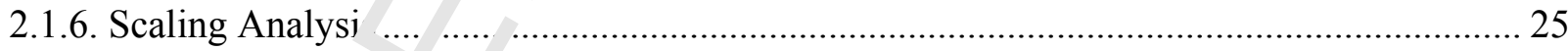

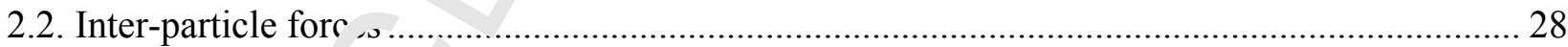

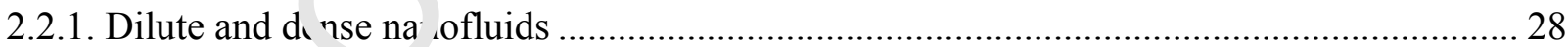

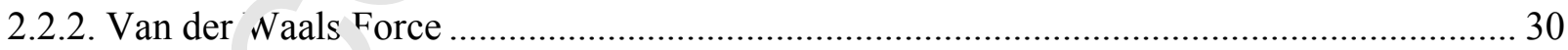

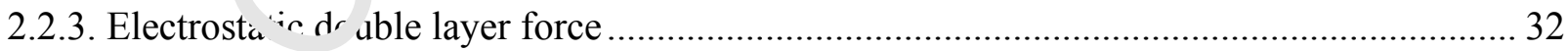

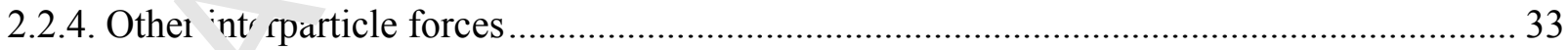

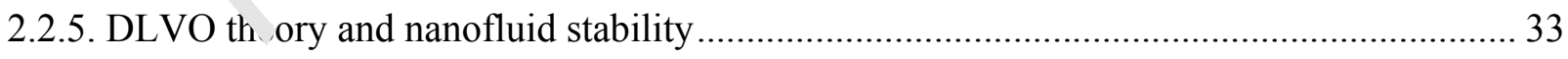

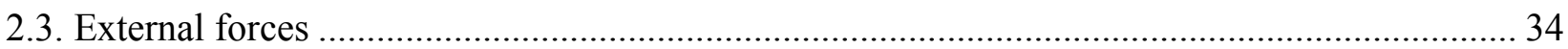




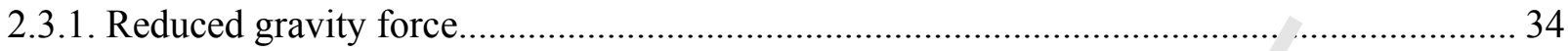

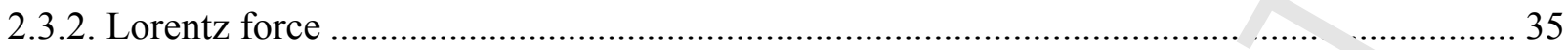

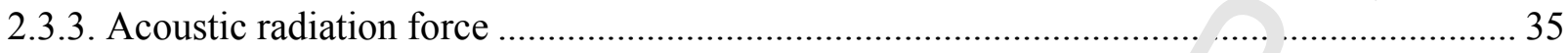

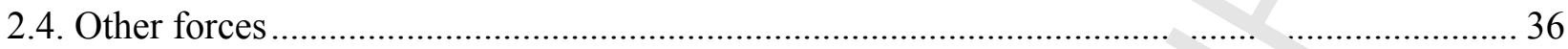

3. An overview of nanofluids thermophysical properties........................................... 37

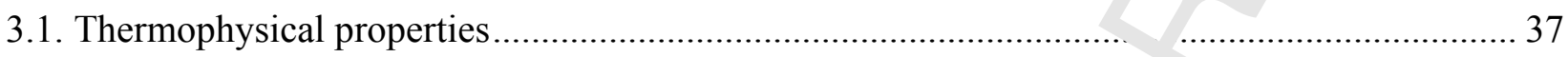

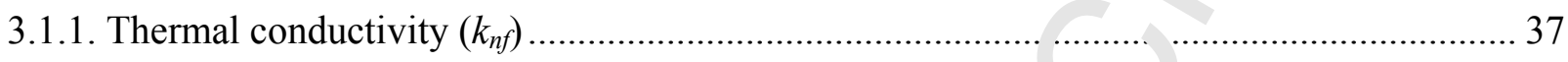

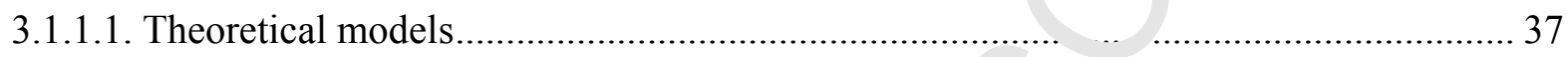

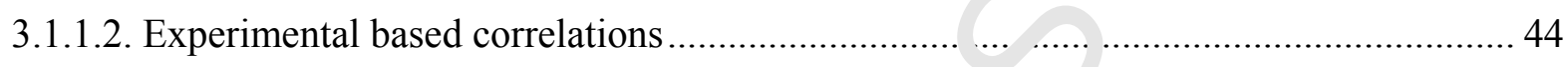

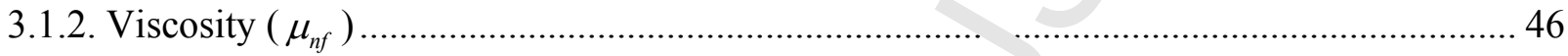

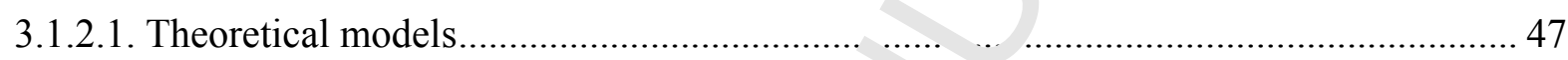

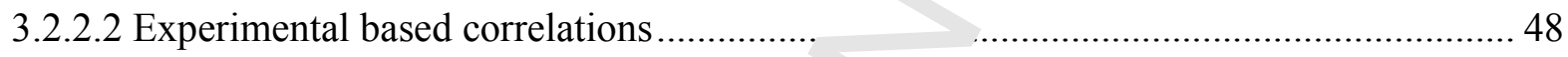

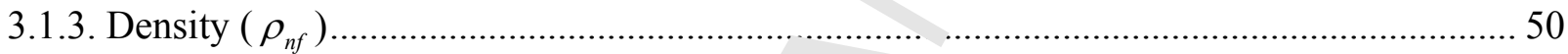

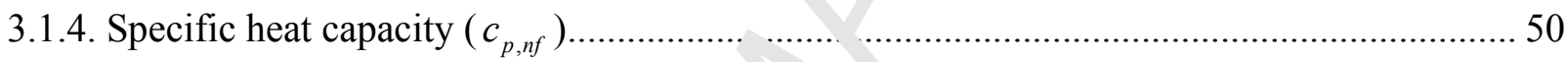

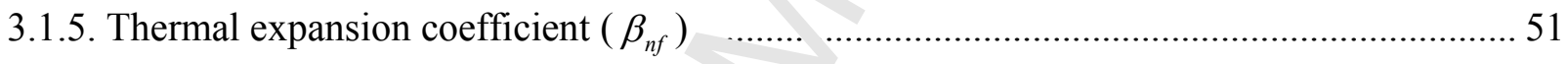

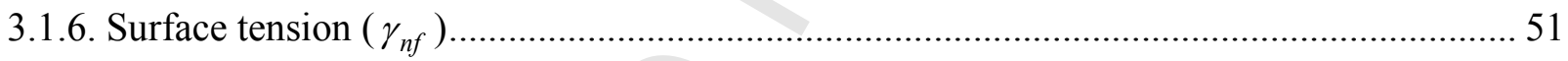

3.2. On the importance of thermophysic 1 mode $s$ in modeling ................................................. 52

4. Physical models for nanofluid flow and he transfer .......................................................... 54

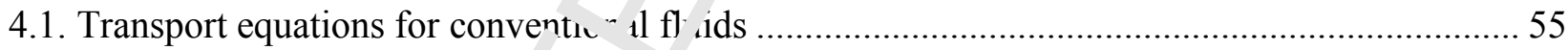

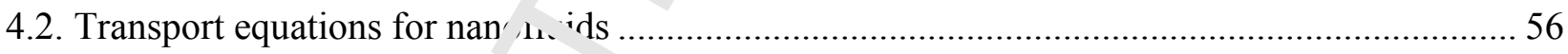

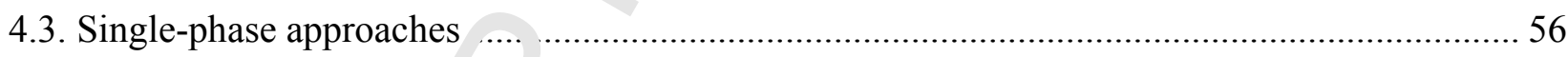

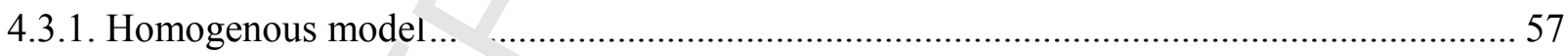

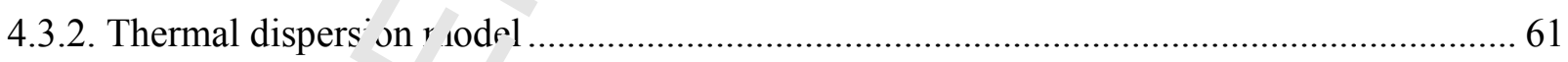

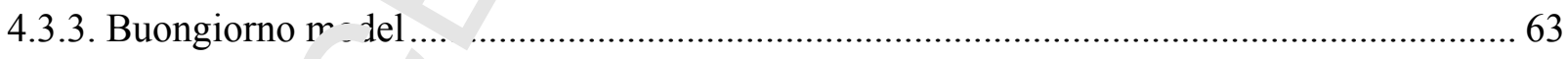

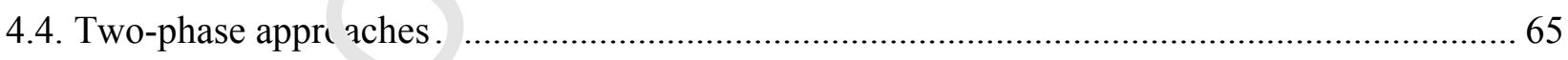

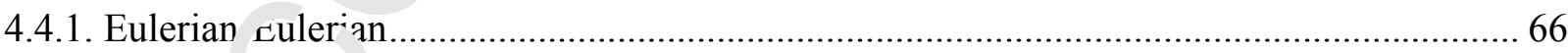

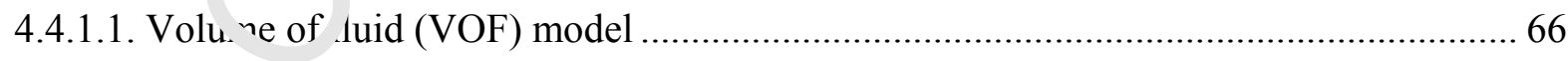

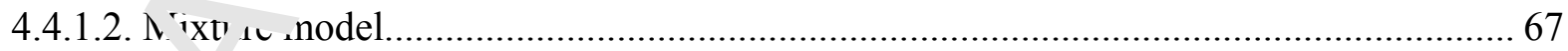

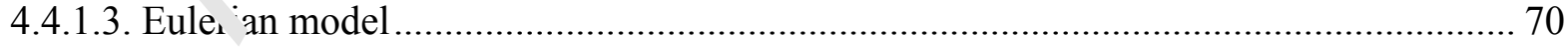

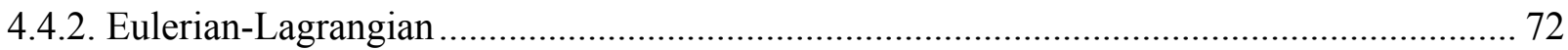


4.5. Comparison of different approaches 76

5. Conclusions 78

Acknowledgment. 80

Appendix A: Extended form of transport equations 81

References. 85

\section{1- Introduction}

Amelioration of heat transfer rate in thermal systems has been alwn.'s one of the primary concerns of scientists. Let's start with a simple example. Consider the t. rir $;$ of an automobile. The friction between moving and stationary parts in the engine lends a mperature rise in the system, so a lubricant (Engine oil) is used for cooling the components. Thu engine performance improves if we can increase the lubricant ability in heat removal. But the $q^{*}{ }^{*}$ stion is, how can this be done? One solution is the augmentation of oil thermal conductivity; in $i$ 'ts vay its ability for cooling purposes increases. The thermal conductivity of solids is much gren ${ }^{+}$r crun that of fluids. Figure 1 has been drawn to show the difference between thermal conductivity of liquids including water and oil with some solids such as ceramics, metals, and grapher. (whic 1 is known as a semi-metal). As seen, thermal conductivity of metals and graphene a e bındı ds of times higher than that of liquids. As shown in Fig. 1, some solids like graphene have $v, v f$ gh thermal conductivity (thousands of times higher than liquids) which makes them a suita $1 t$. ntion to employ in thermal systems.

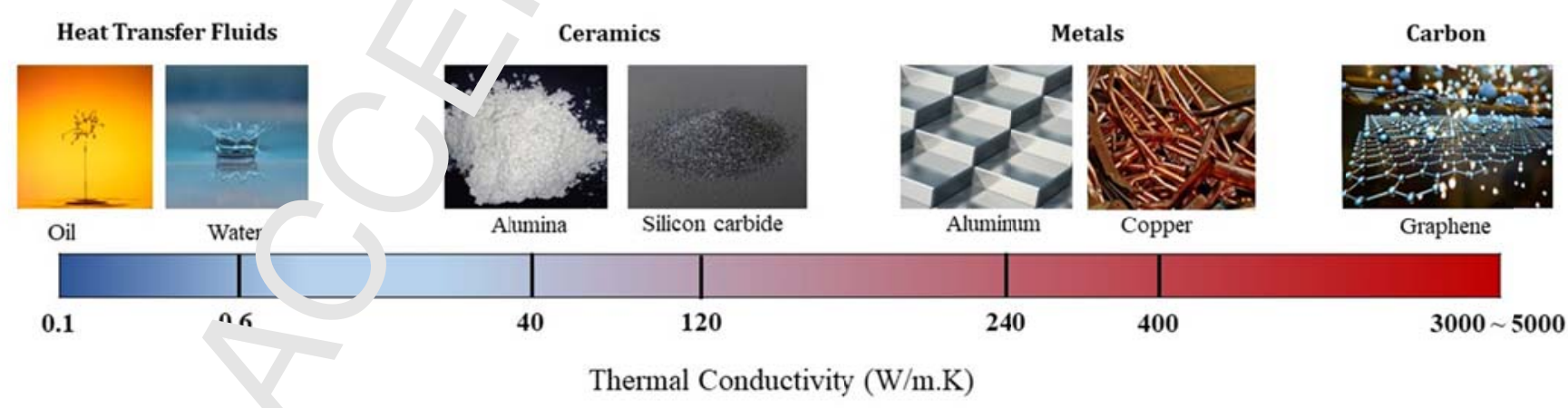


Figure 1. Thermal conductivity of some common liquids and solids, the high thermal conauctivity f solids gives the idea to mix them with liquids to enhance the effective thermal conr ucti ity.

From the above discussion, one idea for thermal conductivity enhancement $v_{\text {i }}$ il could be adding solid particles at low concentrations to the base fluid to augment the ef ecti e i.ermal conductivity. However, what sizes of particles are most suitable? Using particles wi $\mathbf{t}^{{ }^{\prime}}$. diamu ars in the millimeter or even micrometer range results in the eventual sedimentation of susper ted pa icles unless the particles are perfectly neutrally buoyant. Gravitational effects are minimiz $\mathrm{dd}^{\mathrm{d}} \mathrm{b}^{\prime}$ 'se of solid particles with the smallest possible size, in the nanoscale size range. The stabilitr or nan sarticle-based liquids is much greater than that of microparticle-based liquids; moreover at a $\mathrm{g}$ ven mass of solid particles, the contact surface area between nanoparticles is bigger than $t_{1 .}{ }^{+}$ot milcroparticles, which leads to faster thermal response of the particles to change in liquid ten $n_{{ }_{\mathrm{r}}}$ rature in mixtures containing nanoparticles. Figure 2 compares the diameter of typical carbon nar , hos with the size of some well-known things such as an ant and a single grain of salt to better visu ize the size of a nanoparticle. As seen, the diameter of a carbon nanotube can be 1 million times . mailer than that of a single grain of salt.

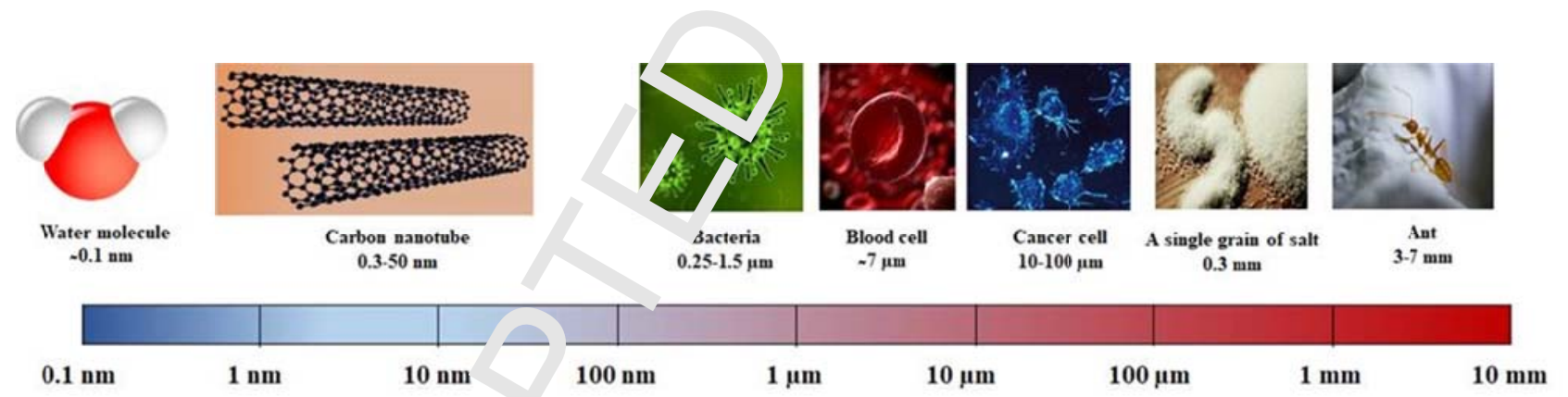

Figure 2. Comparison ${ }^{+} \mathrm{w}$ en: zes of carbon nanotubes as a typical nanoparticle with other things

\subsection{What is a nan sfluid:}

In 1993, Masua et ،. [1] measured thermal conductivity and viscosity of three different water-based suspensions contair $7 \mathrm{Al}_{2} \mathrm{O}_{3}, \mathrm{TiO}_{2}$, and $\mathrm{SiO}_{2}$ nanoparticles (particles with a size between 1 and 100 $\mathrm{nm}$ ). They reported that both thermal conductivity and viscosity of the water become greater than 
before by adding nanoparticles. Later in 1995, Choi [2] selected the name "nanoflı id" for a mixture of nanoparticles and a liquid. It should be kept in mind that nanofluids are not $\mathrm{pr}_{\mathrm{r}}{ }^{\mathrm{r}} \mathrm{red}$ simply by adding nanoparticles to water or oil and stirring the mixture, similar to mixing s' gal and tea, but rather the formation of a nanofluid requires special physical and chemical processes 1 . order to produce a uniform and efficient dispersion of particles for long-term application. 'Jse $\_$surfactant (noncovalent functionalization), functionalization of nanoparticles, control of $i_{i} \mathrm{H}$ and sonication are some primary approaches for increasing the stability of nanofluids [3]. Fig are 3 nresents the main physical and chemical approaches that might be used to prepare stable nanofı. ids. 7 he most suitable method for preparing stable nanofluids is determined based on the nan partis s type and the choice of the base liquid.

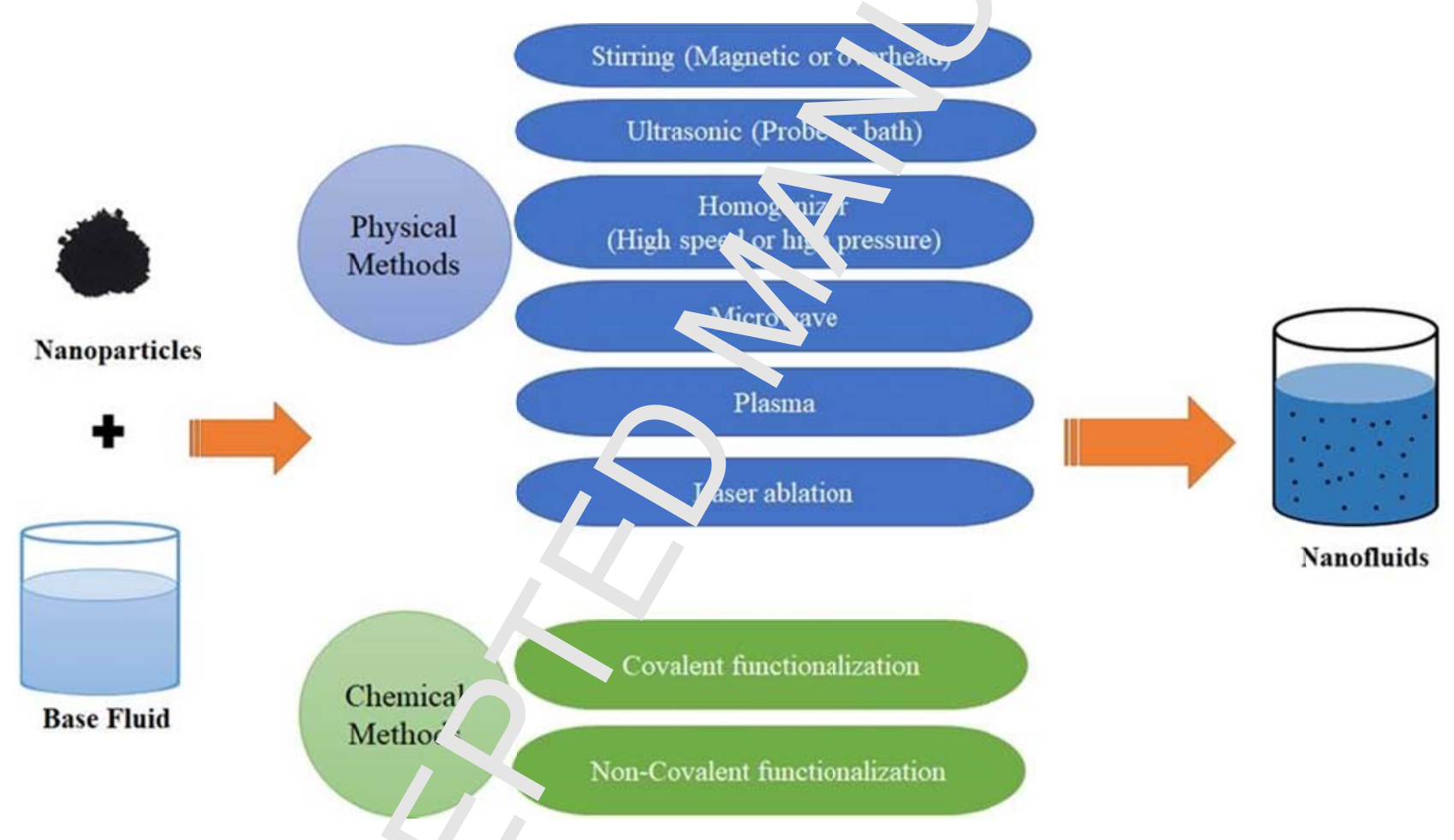

Figure 3. Nanofluid preps uion is ,.ot just mixing nanoparticles and a liquid but special physical and chemical te, hniques are needed to have a stable nanofluid.

\subsection{How has the $\mathrm{I}$ 'searcl on nanofluids evolved?}

After the initial ir croduction of nanofluids, many researchers assessed the potential of various nanofluids for heat transfer enhancement. Figure 4 indicates how the research on nanofluids evolved 
from its introduction in 1995 up to the present time, and which subject areas hr ve been of most interest during this time period. The results were extracted from the Scopus $d a{ }^{\prime} b_{a_{n}}>$ by searching "nanofluid" or "nanofluids" in the article title, abstract, and keywords (date of e tra t: 16 April 2018). As seen in Fig. 4(a), after 2005 the number of articles per year increased remark n ly year by year, so that by 2017 it reached more than 2000 papers. Regression analysis of data _. - the , zars between 1995 and 2017 shows that a polynomial of degree 4 can be fit to the data wi. hi h accuracy. If this trend were to continue, by polynomial expression it is predicted that the numbor of articles per year on nanofluids will exceed 3800 in 2020 . Figure 4 (b) shows a word clou ${ }^{\top}$ of $t^{\prime}$,e most prevalent subject areas to which nanofluids have been applied. As indicate , F..1. neering, Physics, Chemical Engineering and Materials Science have been the subject areas . whi...i nanofluids were most widely engaged.

\subsection{What applications are suitable for nanofluids?}

Indeed, in most applications in which conventional fluids re used for cooling or heating purposes, nanofluids can be used to replace single-phase fluids. Nanofluids u n be used in solar collectors and photovoltaic systems, car radiators, refrigerators, boilers, medicine-r ${ }^{-}$c delivery, cooling of electronic equipment, lubrication of components, heating and cooling of buildi.._c, desa ination, $\mathrm{CO}_{2}$ absorption, porous media, aerospace, oil recovery, and any type of liquid-based hea exchangur [4-18]. Figure 5 gives an overview of primary nanofluid applications.
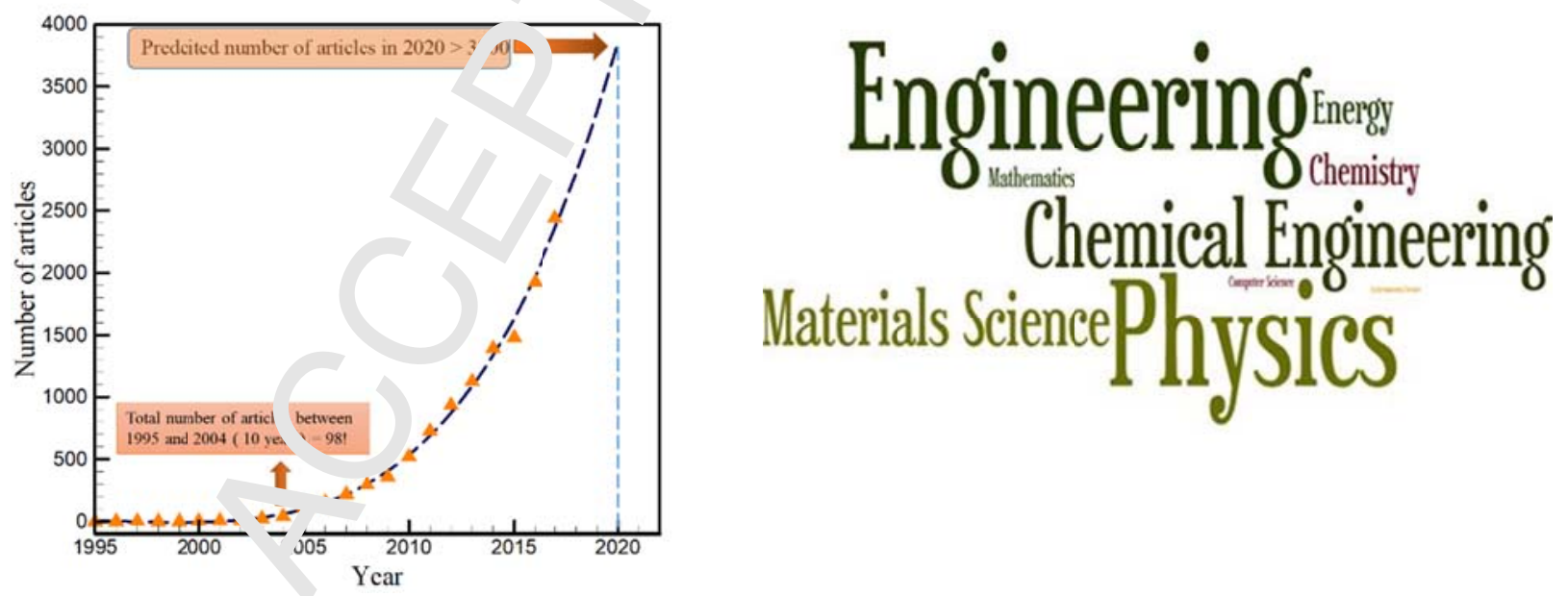
a)

Figure 4. Research in field of nanofluids, (a) number of articles per year (b) word cloud of most pupular subject areas (done with wordle.net); information extracted from Scop s

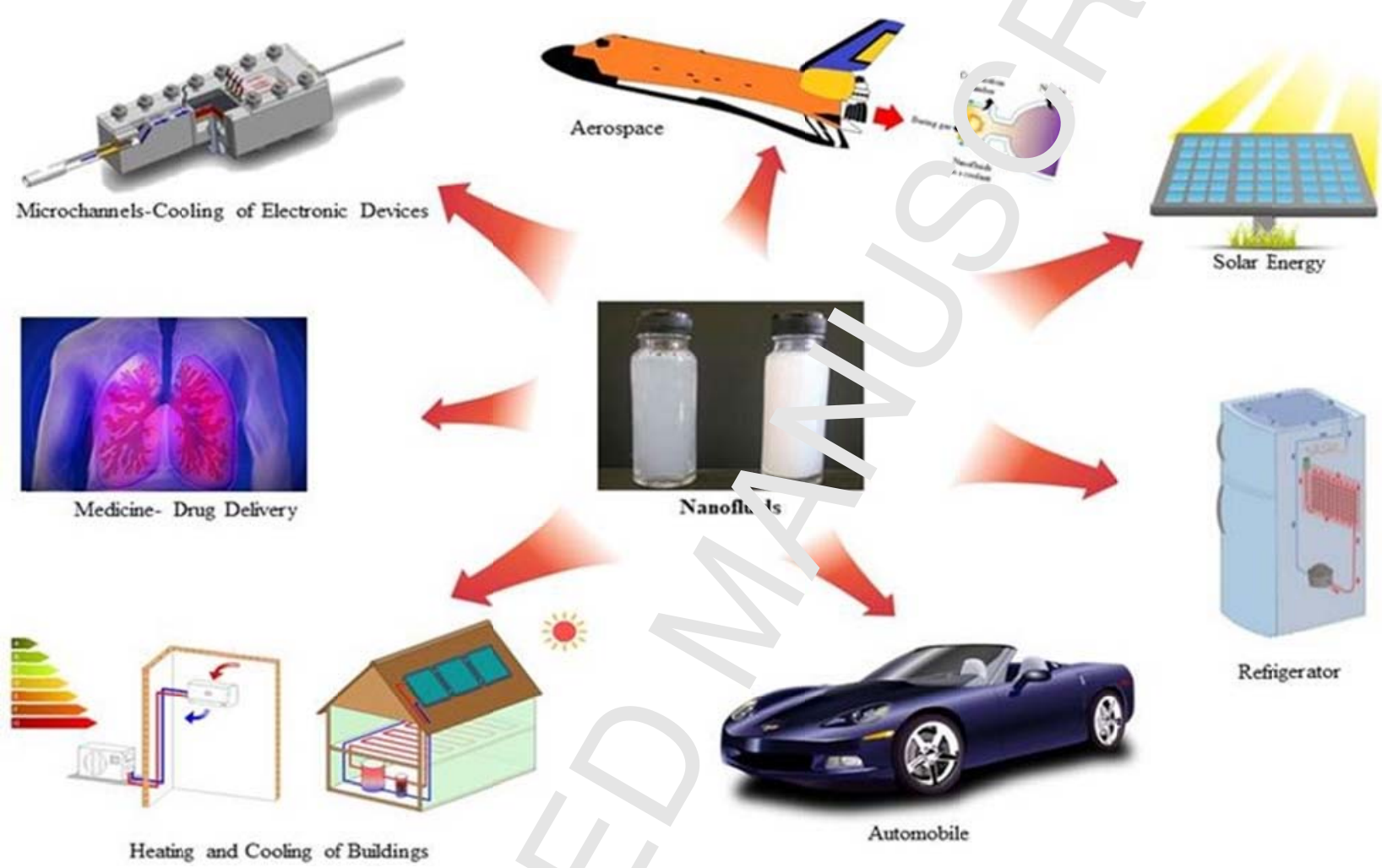

Figure 5 . me applications of nanofluids in a glance

\subsection{What are the advantages and disadvantages of nanofluids?}

Generally, by using a nanof' id ne $r$.te of heat exchange in thermal systems is enhanced because of higher thermal conductivity of $\mathrm{n}$ a culluids ompared to the base fluid. Therefore, to transfer a specified value of heat, the size of a thermal syst $\mathrm{m}$ can $1 \mathrm{e}$ reduced by using nanofluids to enhance heat transfer rate, implying a more compact system and aving in material weight and expense. In comparison with microfluids, nanofluids have a higher stability and bette ability to enhance heat conduction. On the other hand, nanofluids have some disadvantages $\mathrm{w}_{1}^{\prime}$. vi. $-\mathrm{n}$ he listed as follows [19]:

- $\quad$ Nanofluids ha e a relatively high cost of production. 
- $\quad$ Preservation of nanofluids for long-term use without aggregation and sedimentation $\mathrm{f}$ nanoparticles is a challenge.

- The higher viscosity of nanofluids compared to base fluids leads to increases in ey ired pumping power and increases the rate of frictional heating.

- Use of nanofluids can increase rates of corrosion and erosion of components tha 'nme into contact with the nanofluids.

\subsection{What is the aim of present review article?}

As mentioned in the section 1.4, one of the challenges of using $1 a_{n} s^{s} u_{1}$ ts is high cost of production. Therefore, it is reasonable that before applying nanofluids in a al s: ation, the effects of nanofluids on the system performance are physically modeled. Up to i ' $w$, sor e interesting review articles and books have been published on physical modeling of nanofluia, including Refs. [20-27].

The present article aims to comprehensively investigate 1 . latest developments in modeling of nanofluid flow, focusing on physical phenomena affecir $\mathrm{g}$ the heat and fluid flow of nanofluids. The review is presented in two parts. In the present part ( $\left.1 \mathrm{~A}^{2} \mathrm{~T}\right)$, various mathematical models and the main physical phenomena that affect the heat transfe, "ate in nanofluid flows are reviewed. In part II, an overview of common computational fluid dvnamics (CFD) approaches and software used for solving nanofluid flows is presented. Finally, aree-dil rensional studies on modeling of nanofluids are reviewed, focusing on differences be ${ }^{+}$Neen $2 \mathrm{~L}$ and $3 \mathrm{D}$ simulations, physical models and solution method effects. Figure 6 summarize; th ma $₫$ questions that the review aims to answer in parts I and II. 


\section{ACCEPTED MANUSCRIPT}

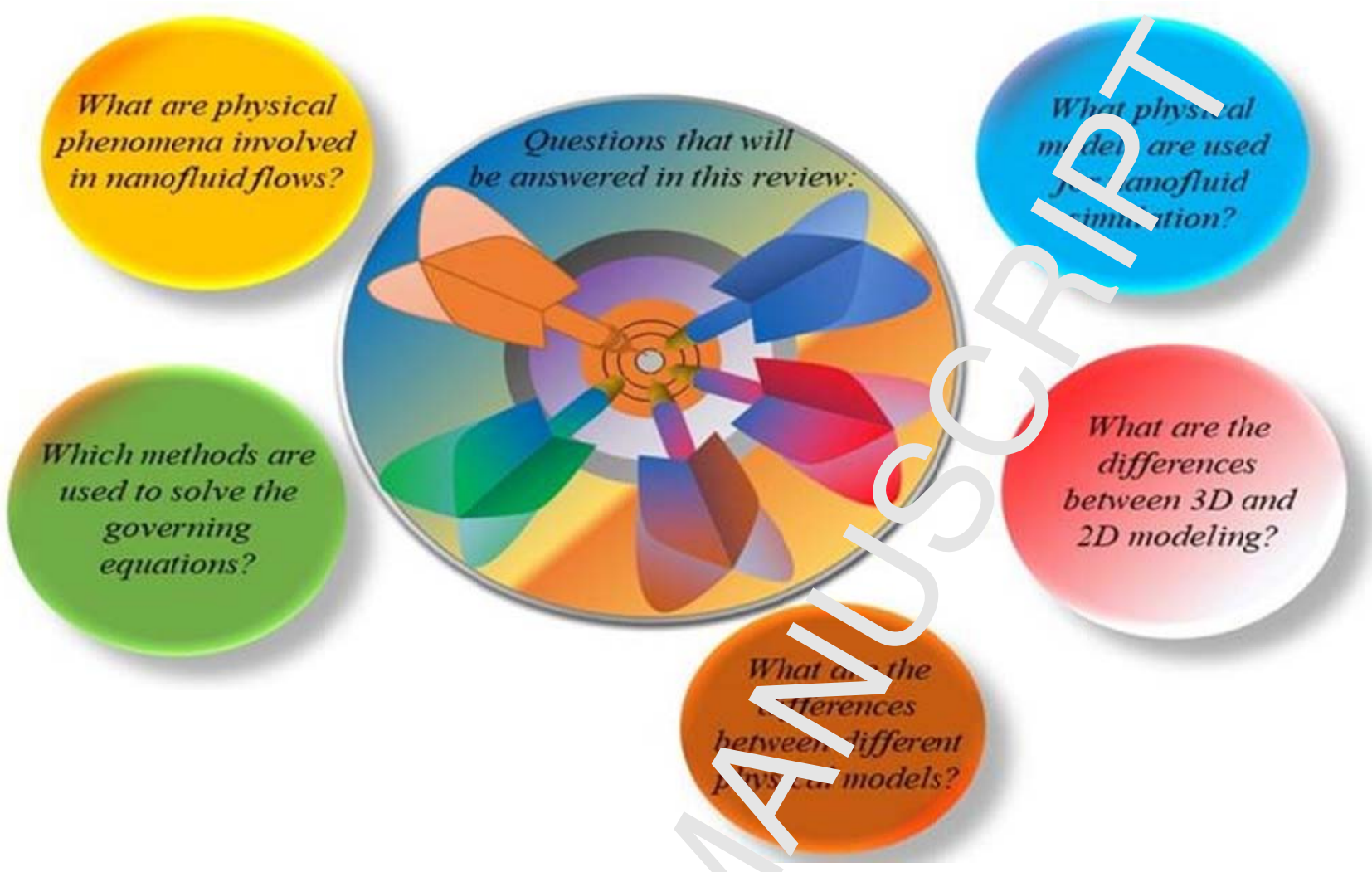

Figure 6. The main questions that, ill be answered in the present work 


\section{Dynamics of nanoparticle motion in a liquid}

Knowledge of the dynamics of nanoparticles in the base liquid is a pl - aqui ${ }^{+}{ }^{+}$for accurately describing the processes of heat transfer in nanofluid flows. There are a $\mathrm{v}$ idt range of forces that act on particles suspended in a fluid, but only a fraction of these forces are s1y. ficant for nanofluids due to the small particle size. In general, forces acting on particles sus sendec in a fluid include those induced by:

1- The base liquid

2- Surrounding walls and solid surfaces

3- Other nanoparticles

4- External magnetic or electric fields (if any)

5- An acoustic field (if any)

Figure 7 summarizes the main acting forces on a $g$, ral suspended particle in a fluid flow. In following sections, we present definitions of forces $\left.s_{u}\right\urcorner$ marized in Fig. 7 and discuss which ones are most important and which ones can be neglecteu "r.m. fluid flows. 


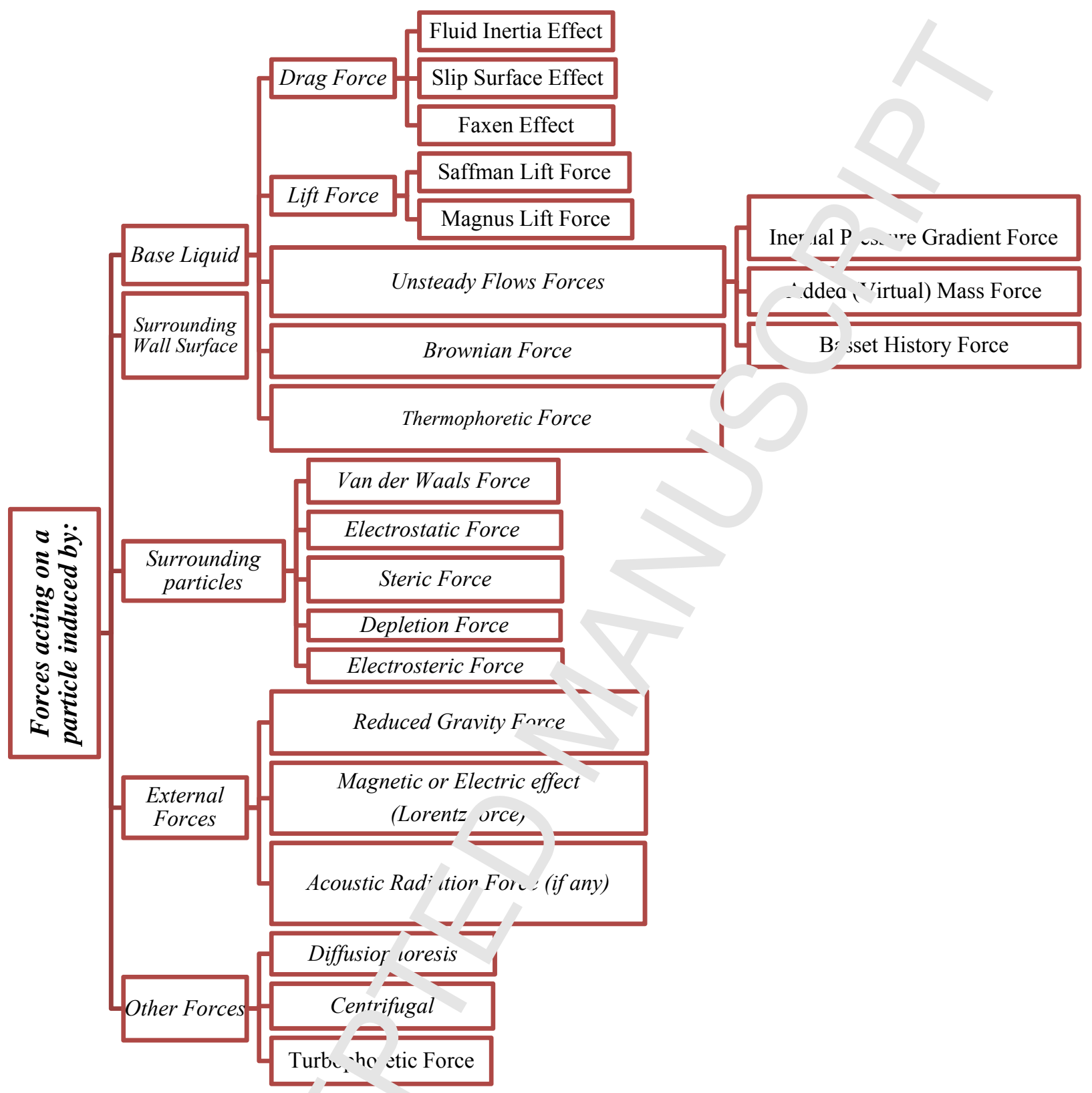

Figure 7. Forces acı. ' on a general particle suspended in a fluid flow by different sources 


\subsection{Forces acting on a nanoparticle by the base liquid}

\subsubsection{Drag force}

When a spherical nanoparticle with a vector velocity of $\boldsymbol{V}_{p}$ and a diameter $v_{-} \boldsymbol{l}_{n}$ moves through a viscous liquid with a velocity of $\boldsymbol{V}_{f}$ and a viscosity of $\mu_{f}$, a force oppo ${ }^{+{ }^{+}}{ }^{+} \mathrm{s}$ the motion direction of the particle due to relative velocity between the particle and the liquir is cre ted which is called "drag force". The drag force based on Stokes law, which is modified by a frici in ${ }^{f}$ Actor $(f)$, is given by [28]:

$$
\boldsymbol{F}_{D}=-3 \pi d_{p} \mu_{f} \boldsymbol{V}_{s} f
$$

where $\boldsymbol{V}_{s}=\boldsymbol{V}_{p}-\boldsymbol{V}_{f}$ is the particle slip velocity, defined as the r.. tive velocity of the particle with respect to the fluid. The friction factor, defined as $f=C_{I} C_{C} r_{5}$, mines into account the effects of fluid inertia $\left(C_{I}\right)$, slip flow $\left(C_{C}\right)$ and crowding by fluid part. es $\left(C_{F}\right)$. It should be noted that the Faxen effect, which takes into account the non-uniformity $\epsilon \ldots$ of $\mathrm{n}$ the incident fluid velocity profile $\left(\boldsymbol{V}_{f}\right)$, is not included in Eq.(1) because it is generally $n,{ }^{1}$ igib a due to the ultra-fine size of nanoparticles [29]. The above equation can be rewritten as:

$$
C_{D}=\frac{F_{D}}{\frac{1}{2} \rho V_{s}^{2} A}=\frac{\angle-}{\operatorname{Re}_{p}} f
$$

where $F_{D}$ is the drag force magnitude $C_{\Gamma}$ is the drag coefficient, $V_{\mathrm{s}}$ is the slip velocity magnitude, $A$ is the cross-sectional area of the anopa : le $\left(\pi d_{p}^{2} / 4\right)$ and $\operatorname{Re}_{\mathrm{p}}$ is the particle Reynolds number, defined as:

$$
\operatorname{Re}_{p}=\frac{\rho_{f} V_{s} d_{p}}{\mu_{f}} .
$$

It should be noted that setting $\because$, riction factor at $f=1$ recovers the original Stokes relation. Also, the inertial coefficient $\left(C_{I}\right.$, depen 's on the particle Reynolds number, so for a small particle Reynolds number $\left(R e_{p}<1\right), \mathrm{w}, \mathrm{can}$ leı $c_{I}=1$. However, for higher particle Reynolds numbers, in the range of 1800 (transition regi ^e), it hould be corrected by the Schiller-Naumann relation [30]:

$$
C_{I}=1+0.15 \operatorname{Re}_{p}^{0.687}
$$

The comparison butween experimental data and Eq.(4) shows good agreement [28]. Other experimental correlations are also suggested for higher Reynolds numbers, but for nanofluid flows the 
mentioned range for particle Reynolds number is sufficient and higher values ar not expected to occur. Concerning typical range of particle Reynolds number in nanofluids, sen. 'ni et al. [31] performed a series of numerical simulations for alumina nanoparticles with a si ce i f $47 \mathrm{~nm}$ dispersed in water with concentrations up to $1.8 \%$ under laminar flow $(100 \leq \operatorname{Re} \leq 160 n) 1 \mathrm{~h} \cdot 2 \mathrm{D}$ channel. They indicated that for the range of their simulations, $R e_{p}$ changes between $3.5{ }^{-n^{-5}}$ anc $6 \times 10^{-4}$ (i.e., much smaller than 1). The slip velocity magnitude for the experiments of $\left[31, a^{r}\right.$ then be estimated using Eq. (3) using the values of water properties.

As a particle gets very small, the no-slip assumption on the particle su face jan begin to break down, necessitating a slip correction to the drag force expression. The Kn $\mathbf{n} \mathrm{sc} \mathrm{n}$ number is a dimensionless parameter that determines the significance of slip between partic: $\checkmark$ ar. 1 . ne base fluid, and it is defined as the ratio of the mean-free-path of fluid molecules to $\therefore$ part cle diameter $\left(K n=\lambda / d_{p}\right)$. The Cunningham relation [32] approximates the slip correction coe, cient for small Knudsen numbers as the following:

$$
C_{C}=\frac{1}{1+3.26}-
$$

Slip correction becomes important if $K n$ excee $^{\prime} \cap n 1$. For nanoparticle suspensions in a gas, particle slip relative to the fluid can be very important. Howt ver, for liquid nanofluid flows the slip effect on drag is generally not very important due to she sn. 11 values of mean-free-path in a liquid. The effect of crowding by fluid particles is importan ${ }^{+}$in $t_{1}$ : ${ }^{\prime}$ zed beds and flow through packed beds. This effect should not be relevant in dilute fluid : nw, as is the case with many nanofluids, for which we can set $C_{F}=1$.

\subsubsection{Wall effect on drag coef ici nt}

Here, we consider two cases s. wn in Figure 8. In the first case, a particle migrates with a low Reynolds number (creepin' flo v) trwards a wall, for which case the drag coefficient is given by [33]:

$$
C_{D}=\frac{24}{\operatorname{Re}_{p}}\left(1+\frac{d_{p}}{2 h_{p}}\right)
$$

where $h_{p}$ stands for the dis ance between the center of the particle and the wall surface.

In the case that a parıviu moves parallel to wall surface, Faxen suggested the following expression to calculate the drag - efficient [28]: 
$C_{D}=\frac{24}{\operatorname{Re}_{p}}\left[1-\frac{9}{16}\left(\frac{d_{p}}{2 h_{p}}\right)+\frac{1}{8}\left(\frac{d_{p}}{2 h_{p}}\right)^{3}-\frac{45}{256}\left(\frac{d_{p}}{2 h_{p}}\right)^{4}-\frac{1}{16}\left(\frac{d_{p}}{2 h_{p}}\right)^{5}\right]^{-1}$

$$
C_{D}=\frac{24}{\operatorname{Re}_{p}}\left(1+\frac{d_{p}}{2 h_{p}}\right)
$$

$$
C_{D}=\frac{24}{\operatorname{Re}_{p}}\left[1-\frac{9}{16}\left(\frac{d_{p}}{2 h_{p}}\right)+1\left(\frac{d_{p}}{2 h}\right)^{3} \frac{45}{256}\left(\frac{d_{p}}{2 h_{p}}\right)^{4}-\frac{1}{16}\left(\frac{d_{p}}{2 h_{p}}\right)^{5}\right]^{-1}
$$

a)

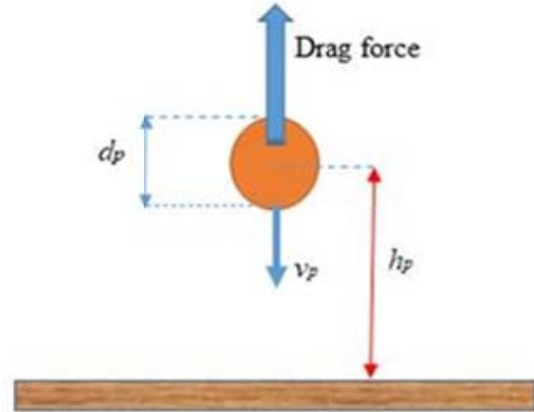

Figure 8. Drag coefficient when (a) particle moves toward

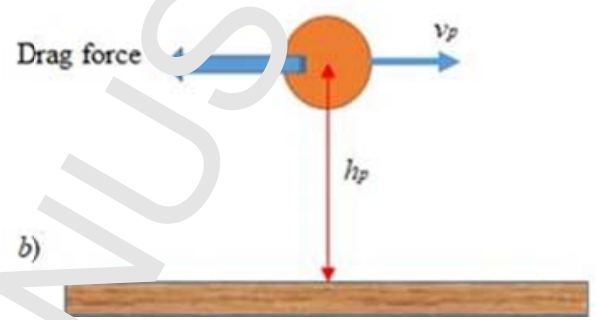

11 (h) particle moves parallel to wall.

\subsubsection{Lift force}

Lift force (also called lateral force) acting on a nanoparticle moving in a liquid is composed of two independent forces, typically referred to as he Sa ' fman and Magnus lift forces.

\subsubsection{Saffman force}

Consider a nanoparticle moving in a $u_{1}: f_{c} . m s$ sear flow where the movement directions of particle and fluid are the same (say, the $x$-d ation). The shear-induced force that acts on a particle moving with the fluid elements is called ${ }^{+1}$ - Saffman force. Saffman [34,35] presented the following equation for the lift force (in the $y$-direci $` n$ ' due to shear flow:

$$
F_{L S}-6+6 \mu_{f}\left(d_{p} / 2\right)^{2} V_{s}\left(\rho_{f} G / \mu_{f}\right)^{1 / 2},
$$

Where $G$ is the flui 1 sheaı rate. 


\subsubsection{Magnus force}

A rotating particle in a flowing fluid experiences an aerodynamic lift force that vas cirst studied by Rubinow and Keller [36], and which is referred to as the Magnus lift force $\mathrm{L} \mathrm{L}$ : rotation may be induced by collision between particles with each other or collision between a sarticle and a wall surface. If we again consider a flow in the $x$-direction, such that the rotation: velo ty of the particle is given by $\Omega \mathbf{k}$, where $\mathbf{k}$ is the basis unit vector in the $z$-direction, the $\mathrm{M}_{\boldsymbol{u}_{c}}{ }^{-\eta_{\mathrm{v}}}$, force will be a force in the $y$-direction given by:

$$
F_{L M}=\pi \rho_{f}\left(d_{p} / 2\right)^{3} V_{s}\left(\Omega-\frac{11}{8 \pi} G\right)
$$

Saffman employed an asymptotic analysis to write the total lift : ree acting on a particle in a shear flow is the sum of the Saffman and Magnus forces, or:

$$
F_{L}=6.46 \mu_{f}\left(d_{p} / 2\right)^{2} V_{s}\left(\rho_{f} G / \mu_{f}\right)^{1 / 2}+\pi \rho_{f}\left(a_{p}^{\prime} 2\right)^{3} V_{s}\left(\Omega-\frac{11}{8 \pi} G\right) .
$$

\subsubsection{Scale of lift force compared to drag force}

As pointed out in the scaling analysis by ' rarsha. and $\mathrm{Li}$ [29], the ratio of the Saffman lift to the fluid drag varies in proportion to $\operatorname{Re}_{G}^{1 / 2}$ and the ra:- of the Magnus lift to the fluid drag force varies in proportion to $\operatorname{Re}_{G}$, where $\operatorname{Re}_{G}=\rho_{f} a_{p}^{\prime} ₹ / \rho_{f}$ is the shear Reynolds number. Since $\operatorname{Re}_{G}<<1$ for a nanofluid flow, the lift force on t'ue pa : much smaller than the Saffman iorc : for nanofluid flows.

\subsubsection{Unsteady Flows For es}

Unsteady flow forces on narı. ${ }^{1}$ er can be divided into three groups including inertial pressure gradient force, added (virtual) $\mathrm{n}$ ass for 2 , and Basset history force, which are defined as follows.

\subsubsection{Inertial pre sure oradient force}

Consider a spherica,$\ldots$.... cle with a diameter of $d_{p}$ and volume of $V=\frac{\pi}{6} d_{p}^{3}$ immersed in a liquid with density of $\rho_{f}$. Th force acting on the particle due to pressure gradient is obtained by integration over the volume [29]: 


$$
\boldsymbol{F}_{p}=-\int_{V} \nabla p d v=-V \nabla p=-\frac{\pi}{6} d_{p}^{3} \nabla p
$$

On the other hand, the momentum equation in simple form is written as:

$$
\rho_{f} \frac{D \boldsymbol{V}_{f}}{D t}=-\nabla p+\nabla \cdot\left[\mu_{f}\left(\nabla \boldsymbol{V}_{f}+\left(\nabla \boldsymbol{V}_{f}\right)^{T}\right)\right]
$$

In the above equation, $D \boldsymbol{V}_{f} / D t$ is the material derivative and the visr us .ernı can be neglected for high fluid Reynolds numbers, outside the boundary layer, therefore wf nave:

$$
\nabla p=-\rho_{f} \frac{D \boldsymbol{V}_{f}}{D t}
$$

The final form for the inertial pressure gradient force becomes:

$$
\boldsymbol{F}_{p}=\rho_{f} \frac{D \boldsymbol{V}_{f}}{D t}\left(\frac{\pi}{6} d_{p}^{3}\right)
$$

One of the important applications in which inertial pres. 're gradient force appears is in vortex flow fields, where it is responsible for drawing particles $t_{1}$ th a . 1ighter than the surrounding fluid (such as gas bubbles) into the vortex core.

\subsubsection{Added (Virtual) Mass Force}

The force acting on an accelerating particle in a in uid is higher than the force acting on the same particle in vacuum because of the need to $\mathrm{AlsO}$ a celerate the surrounding fluid elements that are set in motion by the particle. Added (virtual ma fr ce is the additional force that is needed to act on a particle inside a fluid to change its ve $\mathrm{nci}^{1} \mathrm{y}$ in comparison with the case in which the particle moves in vacuum in an inviscid flow. It is or ained as [29]:

$$
I_{A}=-c_{M} \rho_{f}\left(\frac{\pi}{6} d_{p}^{3}\right)\left(\frac{d \boldsymbol{V}_{p}}{d t}-\frac{D \boldsymbol{V}_{f}}{D t}\right)
$$

where $c_{M}$ is the added mas cof ificient and for a sphere is equal to 0.5 . The first derivative on the righthand side of (15) is the +..e dt. ative with respect to the particle, whereas the second derivative is the material derivative witi resper, to the fluid. Although the above equation has been derived for inviscid flows, it has been $\mathrm{s}^{1}$ own ${ }^{\dagger} \mathrm{o}$ remain accurate also for viscous flows over a wide range of Re numbers.

\subsubsection{Basset Histc. ", Fr ce}

Boussinesq-Bass $t \mathrm{t}$ s stury force, or simply Basset force (sometimes simply called the 'unsteady drag force'), is an unsteac. force due to velocity change of a suspended particle in a viscous flow. This force 
can affect the drift rate of particles significantly in vortex flows. It is calculated by th 2 following equation derived by Boussinesq (1885) and Basset (1888) [29]:

$$
\boldsymbol{F}_{B H}=\mu_{f} d_{d} \int_{-\infty}^{t}\left(\frac{3}{2}\right)\left(\frac{\pi \rho_{f} d_{p}^{2}}{\mu_{f}\left(t-t^{\prime}\right)}\right)^{1 / 2}\left(\frac{d \boldsymbol{V}_{f}}{d t^{\prime}}-\frac{d \boldsymbol{V}_{p}}{d t^{\prime}}\right) d t^{\prime}
$$

where $\left(t-t^{\prime}\right)$ is the time delay of the acceleration term.

\subsubsection{Scales of Unsteady Flows Forces}

The order of magnitude of the pressure gradient force with respect tc the par icle inertia is proportional to the density ratio $\left(\rho_{f} / \rho_{p}\right)$. As the added mass force given $\mathrm{r}_{\mathrm{y}}(1$, , also follows a similar scaling relationship. Therefore, the importance of pressure gradient $a_{1}{ }^{1}$ aciud (virtual) mass forces become more important for nanoparticles with lower density. We w:11 inver igate the importance of these two forces for different nanofluids. Consider five common nanopu ticles including $\mathrm{Cu}, \mathrm{Al}_{2} \mathrm{O}_{3}, \mathrm{TiO}_{2}, \mathrm{SiO}_{2}$, and CNTs with densities of 8933, 3970, 4250, 2220, and $.^{2} 50 \mathrm{~kg} / \mathrm{m}^{3}$ [37] and three conventional base fluids including ethylene glycol (EG), water, and oil vith sprroximate densities of 1100, 1000 and 900 $\mathrm{kg} / \mathrm{m}^{3}$. The lowest value of $\rho_{f} / \rho_{p}=0.1$ belongs $、 C_{2} /$ Oil nanofluid, and the highest value of 0.81 corresponds to CNTs/EG; therefore, for na. rum. . $_{\text {. }}$ such as $\mathrm{CNTs} / \mathrm{EG}$ the inertial pressure gradient and added (virtual) mass forces are not negligible compared to particle inertia. Figure 9 shows the order of magnitude of pressure gradient and ad ced (vi ual) mass forces with respect to particle inertia for a wide range of nanoparticle densities.

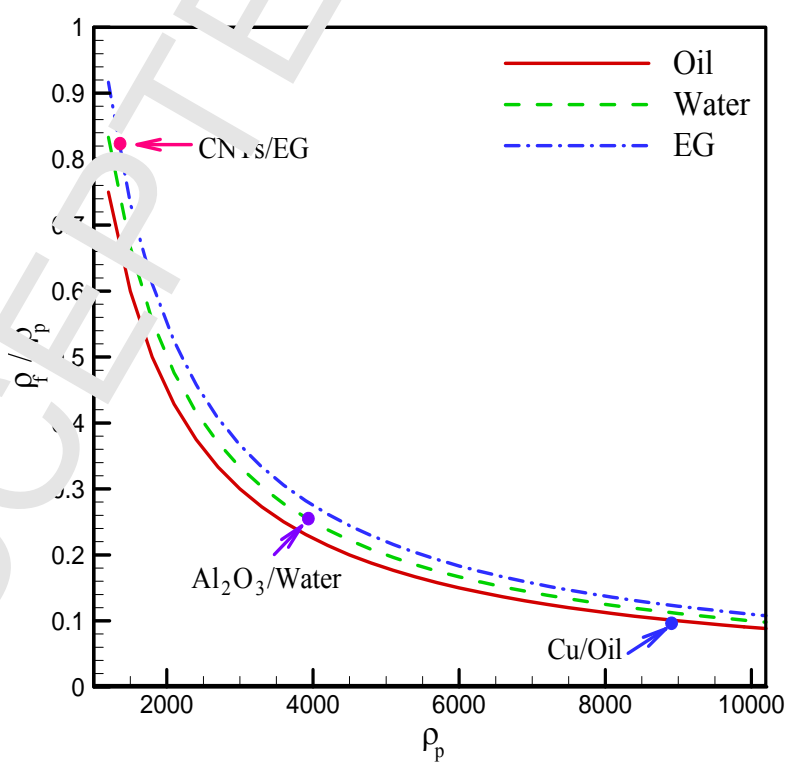


Figure 9. The order of magnitude of inertial pressure gradient and added (virtual) mass forces with respect to particle inertia (proportional with $\rho_{f} / \rho_{p}$ ) for common nanofluids

The ratio of the Basset history force to the fluid drag force is given by [29] as:

$$
\frac{F_{B H}}{F_{D}}=O\left(\frac{\rho_{f} d_{p} V_{s}}{\mu_{f}}\right)^{1 / 2}=O\left(\operatorname{Re}_{p}\right)^{1 / 2}
$$

where $V_{s}$ is the particle slip velocity. As seen, the Basset history for :e is $\mathrm{n}$ y gligible in nanofluid flows because of the ultrafine size of nanoparticles.

\subsubsection{Brownian force}

In 1827, Brown, a botanist, was probably the first one wh nerved by microscope the collisions between grains of pollen of a plant with water molecules win 2 h leads to random motion of grains in water [38]. In general, Brownian motion (called also pe. ${ }^{\prime}{ }^{\prime}$ sis) is defined as the random motion of solid particles inside a fluid due to collisions between solı ${ }^{\prime} p_{n}$ ticles and fluid molecules. In nanofluids, heat and mass transfer might be enhanced significan $\imath_{\text {, a }}$ au co micro-convection and mechanical agitation which are induced mainly by Brownian motion of nanoparticles in the base fluid [39].

Figure 10 shows schematically the Browniaı mo on of a solid particle in a vessel filled with a liquid, and the position of the particle versus im .. A seen, the position of the particle changes rapidly with time, therefore Brownian force ir a timu dependent force. In this regard, Li and Ahmadi [40] suggested to simulate the Brownian forc as a white noise process with zero mean and finite variance. They proposed the following e uat' on to obtain the components of Brownian force [40]:

$$
\frac{F_{B i}}{m_{p}}=\varsigma_{i} \sqrt{\frac{\pi S_{o}}{\Delta t}}
$$

where at every time $\backsim p, \zeta_{i}$ is selected from a population of zero mean unit variance Gaussian random variable, $\Delta t$ is the $i$ me-s $\mathrm{s}^{\dagger} \mathrm{p}$ used for integration of particle equation of motion, and $S_{o}$ is a spectral intensity functic , $w$ ind is related to the diffusion coefficient and is given as: 


$$
S_{0}=\frac{216 v_{f} \kappa_{B} T}{\pi^{2} \rho_{f} d_{p}^{5}\left(\frac{\rho_{p}}{\rho_{f}}\right)^{2} C_{c}}
$$

where $\kappa_{B}$ is Boltzmann constant equal to $1.38064852 \times 10^{-23} \mathrm{~m}^{2} \mathrm{~kg} / \mathrm{s}^{2} \mathrm{~K}, v$ is kı. -matic viscosity of fluid and $C_{c}$ is the Cunningham coefficient.
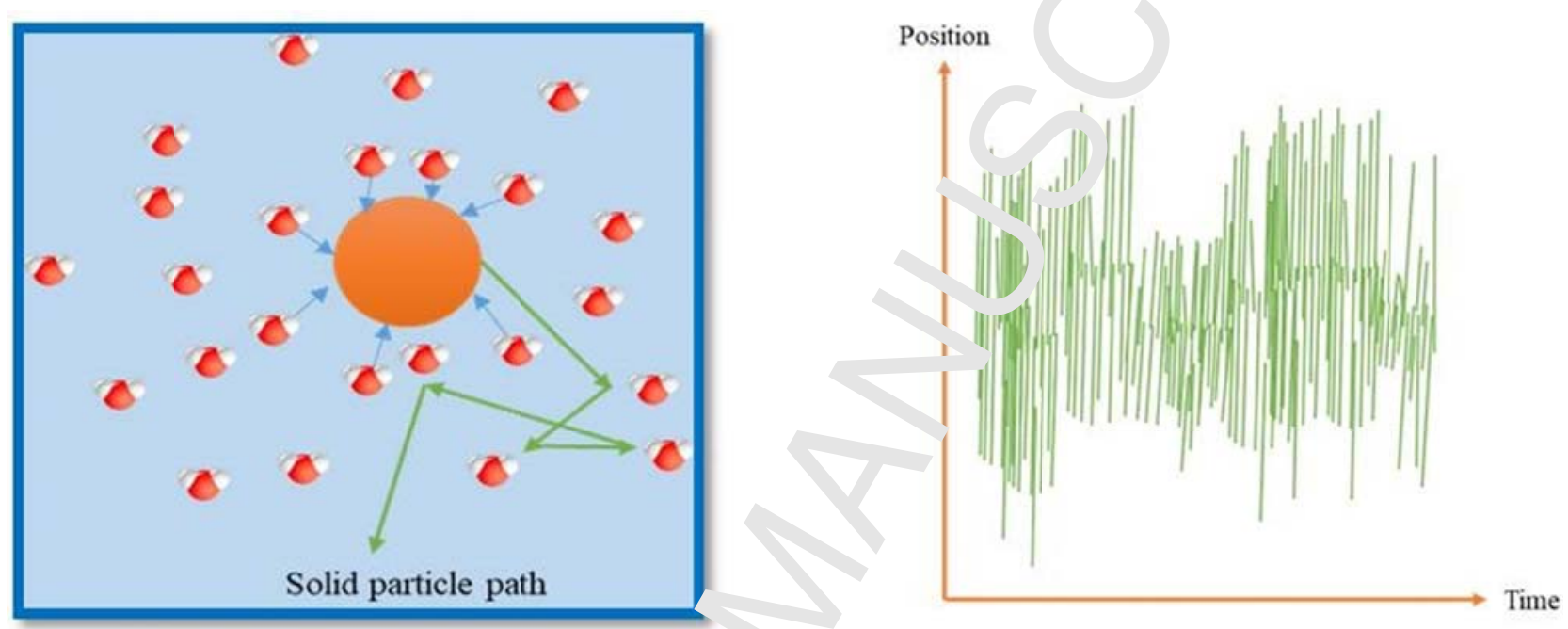

Figure 10. Schematic of the Brow .lan.. tion of a solid particle immersed in a liquid

In separate studies, Einstein and Smoly showsn $[29,41,42]$ proved that after passing a specified time (t) where $t>>\frac{m_{p}}{3 \pi d_{p} \mu_{f}}$ (in the case Jf $n_{a_{2}}$ or articles the time may be just a hundredth of a second), particles diffuse from a region ${ }^{2} \ldots$ ing high concentration of particles towards a region with a lower concentration via Brownian m৬ ${ }^{*} \boldsymbol{r}$. In this regard, if concentration $\phi$ is assumed to be a function of time and space, the diffusic .1 ec tation for particles can be written as:

$$
\frac{\partial \phi}{\partial t}=D_{B} \nabla^{2} \phi
$$

where the Brownian *..ifusıun coefficient $\mathrm{D}_{\mathrm{B}}\left(\mathrm{m}^{2} / \mathrm{s}\right)$ is defined as [43]:

$$
D_{B}=\frac{\kappa_{B} T C_{c}}{3 \pi \mu_{f} d_{p}}
$$


The above equation is called the Stokes-Einstein relation. It is worth mentioning that the StokesEinstein relation is used to identify the size of particles where $D_{B}$ can be measurer e $x_{1}$ srimentally via dynamic light scattering.

The equation for Brownian force presented by Li and Ahmadi [40] can be rewrittc. in terms of $\mathrm{D}_{\mathrm{B}}$ as:

$$
\frac{F_{B i}}{m_{p}}=\varsigma_{i} \frac{\mu_{f}}{\rho_{p} d_{p}^{2} C_{c}} \sqrt{\frac{648 D_{B}}{\Delta t}}
$$

The magnitude of the Brownian force per unit mass affects the her. trans ar rate. The value of the Brownian force per unit mass, as well as the diffusion coefficient, incre ${ }^{\cdots}{ }_{\text {vith }}$ decreasing size of the nanoparticles and increasing temperature.

\subsubsection{Thermophoretic Force}

Thermophoresis (also known as thermomigration, thermou ${ }^{-f u s i o n}$, the Soret effect, or the LudwigSoret effect) can be viewed as a consequence of the . sy nmietry imposed on Brownian motion by a temperature gradient. In nanofluids, the thermophc to ${ }^{\circ}$ p. enomenon acts to migrate particles from a region with higher temperature (hot zone) to a . sicn , ith lower temperature (cold zone) [44]. Figure 11 shows the thermophoresis phenomenon schematicaily.

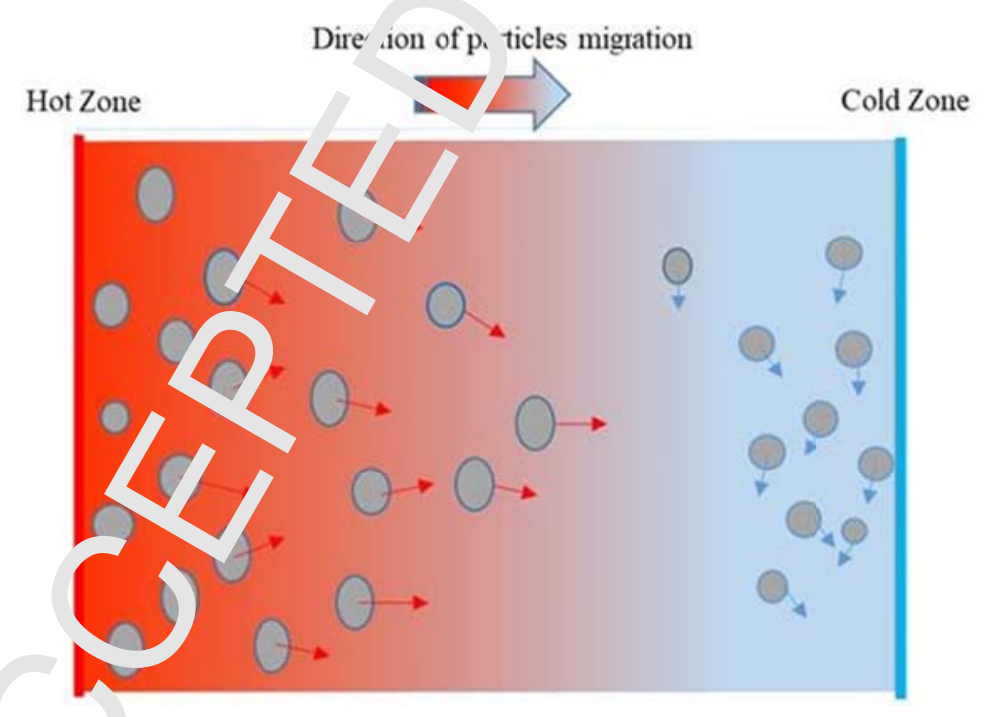

Figure 11. Schematic of thermophoresis phenomenon

Most of studies ava ${ }^{1}$ able in the literature deal with thermophoretic force in gas-solid suspensions, and relatively few studies has been done on solid-liquid suspensions (nanofluids). In this section, we first 
review three models that have been derived for solid-gas mixtures, but which are sor ietimes also used for solid-liquid mixtures. Epstein [45] was probably the first study that deve' $\mathrm{pt}_{\mathrm{i}}$ a relation for particle velocity and force induced by thermophoresis in solid-gas mixtures by ' on: dering continuum conditions. Epstein [45] obtained the following relationship for the theromophore force:

$$
\boldsymbol{F}_{T}=-\frac{9}{2} \pi d_{p}\left(\frac{k_{f}}{2 k_{f}+k_{p}}\right) \frac{\mu_{f}^{2}}{\rho_{f}} \frac{\nabla T}{T_{f}}
$$

where $T_{f}$ is the mean temperature of the fluid and $\nabla T$ is the fluid te nperat re gradient, $k_{f}$ and $k_{p}$ are respectively the fluid and particle thermal conductivity. Accordj ${ }_{\circ}$ to in Stokes' law, Epstein [45] suggested that the steady thermophoretic velocity can be obtained

$$
\boldsymbol{V}_{T}=-\frac{3}{2}\left(\frac{k_{f}}{2 k_{f}+k_{p}}\right) \frac{\mu_{f}}{\rho_{f}} \frac{\nabla T}{T_{f}}
$$

In writing this expression, Epstein [45] has assumed th- thermophoretic force is the sole resistance force that balances the drag force.

Later, Brock [46] suggested the following expressi ns fo, obtaining thermophoretic force and velocity, respectively as:

$$
\begin{aligned}
& \boldsymbol{F}_{T}=-3 \pi \frac{\mu_{f}^{2} d_{p}}{\rho_{f}}\left(\frac{\left.2 C_{s}\left(k_{f}\right\urcorner{ }_{p} K n\right)}{\left(1+3 C_{m} \wedge n k_{f}+k_{p}+2 k_{p} C_{t} K n\right)}\right) \frac{\nabla T}{T_{f}} \\
& V_{T}=-\left(\frac{-\tau\left(k_{f}+k_{p} K n\right)}{\left(1+3 C_{n}\right.} \frac{K n)\left(2 k_{f}+k_{p}+2 k_{p} C_{t} K n\right)}{\rho_{f}}\right) \frac{\mu_{f}}{\rho_{f}} \frac{\nabla T}{T_{f}}
\end{aligned}
$$

where $\mathrm{C}_{\mathrm{s}}=0.75, \mathrm{C}_{\mathrm{m}}=1.14$, and $\mathrm{C}_{\mathrm{t}}-2.18$. The above equations were obtained by including thermal slip at the interface of gas and partic.

Talbot et al. [47] presented nor $\dot{a}$ acrurate equations for thermophoretic force and velocity in solid-gas mixtures as:

$$
\begin{aligned}
& \boldsymbol{F}_{T}=-3 \pi \frac{\mu_{f}^{2} d_{p}}{\rho_{f}}\left(2 C_{s}\left(\frac{\left.i_{f}+k_{p} K n\right)[1+K n[1.2+0.41 \exp (-0.88 / K n)]]}{\left(1+3 C_{m} K n\right)\left(2 k_{f}+k_{p}+2 k_{p} C_{t} K n\right)}\right) \frac{\nabla T}{T_{f}}\right. \\
& \left.\boldsymbol{V}_{T} \cdot \frac{\left(\angle \iota_{s} \cdot{ }^{\prime}+k_{p} K n\right)[1+K n[1.2+0.41 \exp (-0.88 / K n)]]}{\left(1+3 C_{m} K n\right)\left(2 k_{f}+k_{p}+2 k_{p} C_{t} K n\right)}\right) \frac{\mu_{f}}{\rho_{f}} \frac{\nabla T}{T_{f}}
\end{aligned}
$$


where $C_{\mathrm{s}}=1.17, C_{\mathrm{m}}=1.14$, and $C_{\mathrm{t}}=2.18$. It is noted that the above equations reduce $\mathrm{t}^{\prime}$ that of Epstein [45] in the limit of vanishing Knudsen number.

He and Ahmadi [48] proposed a semi-empirical model to account the thermophs es, force (even for the non-continuum regimes) with large Knudsen numbers $(\mathrm{Kn}>1)$. They modifieu re equation of ChaMcCoy-Wood (CMW), calling it the MCMW model, and presented the foll . . ing 1 . ' ation for the thermophoresis force:

$$
\boldsymbol{F}_{T}=1.15 \frac{K n}{4 \sqrt{2} \alpha\left(1+\frac{\pi_{1}}{2} K n\right)}\left[1-\exp \left(-\frac{\alpha}{K n}\right)\right]\left(\frac{4}{3 \pi} \phi \pi_{1} K n\right)^{1 / 2} \cdot{ }_{B}\left(\frac{d_{p}^{2}}{d_{p}^{2}}\right) \nabla T
$$

where $d_{m}$ is the molecular diameter, and $\alpha$ and $\pi_{1}$ are given by:

$$
\begin{gathered}
\alpha=0.22\left[\frac{\frac{\pi}{6} \phi}{1+\frac{\pi_{1}}{2} K n}\right]^{1 / 2} \\
\pi_{1}=0.18 \frac{36 / \pi}{\left(2-S_{n}+21 \frac{1}{-}+S_{n}\right.}
\end{gathered}
$$

As mentioned, the above equations for thu no horetic force were derived for solid-gas mixtures; however, Michaelides [49] argued tha $\mathrm{sp}_{\mathrm{f}}$ ial elations should be obtained for thermophoretic force in solid-liquid mixtures for the follow; ig reasu. s:

- The Knudsen number (the ratio of mean free path, $\lambda$, to particle diameter) should be small enough in a solid-liqui $\mathrm{mi}$, ture so that the continuum assumption is valid. Consequently, the size of particles that an be cispersed in liquids via Brownian motion are much smaller than in gases because the mu, fr e path for liquid molecules is much less than that of gas molecules (e.g. $\frac{\lambda_{\text {air }}}{\lambda_{\text {water }}}>>10$ !.

- The trend ( $\mathrm{f}$ variai ons of viscosity with temperature for liquids is the inverse of the trend in gases. With ilıu dsing temperature, liquid viscosity reduces while in gases the viscosity increases $v$ ch temperature. 
In this regard, Michaelides [49] suggested the following correlations to obtain therms phoretic force and velocity:

Thermophoretic force:

$$
\boldsymbol{F}_{T}=-6 \pi d_{p} A\left(\frac{d_{p}}{d_{p 0}}\right)^{-B} \frac{\mu_{f}^{2}}{\rho_{f}} \frac{\nabla T}{T_{f}}
$$

Thermophoretic velocity:

$$
\boldsymbol{V}_{T}=-A\left(\frac{d_{p}}{d_{p 0}}\right)^{-B} \frac{\mu_{f}}{\rho_{f}} \frac{\nabla T}{T_{f}}
$$

where $d_{p_{0}}=2 \mathrm{~nm}$. Also, $A$ and $B$ are constants that have been ot ained fr. 20 different nanofluids [49]. Table 1 provides the coefficients of $A$ and $B$.

Table 1. Constant coefficients of (A, B) to obtain thermo.' nretic force for common nanofluids [49].

\begin{tabular}{|c|c|c|c|c|}
\hline Base fluid & Water & Engin Oil & Ethylen Glycol & R-134 \\
\hline Nanoparticle & & & & \\
\hline Aluminum & $(1264,1.417)$ & $(3.09-1.24-1$ & $(14.615,1.869)$ & $(4401,1.774)$ \\
\hline Aluminum Oxide & $(1227,1434)$ & $(7.1026,1.5 \% 9)$ & $(5.1095,1.621)$ & $(6270,1.819)$ \\
\hline CNTs & $(945.5,1.263)$ & $(5.804 .1 .445)$ & $(3.6765,1.406)$ & $(8580,1.894)$ \\
\hline Copper & $(2039,1.870)$ & $(1.39,1.724)$ & $(2.3558,1.587)$ & $(4191,1.659)$ \\
\hline Gold & $(3155,1.799)$ & $(6 . f 783,1.917)$ & $(4.2431,1.672)$ & $(2721,1.603)$ \\
\hline
\end{tabular}

\subsubsection{Scaling Analysis}

A scaling analysis for $\mathrm{r}$. crom ater-scale particulate flows is given by Marshall and $\mathrm{Li}$ [29], and scaling analyses for nanofluids . re gi en by Buongiorno [21] and Savithiri et al.[50]. It is generally the case for micrometer-scc e part. 'ulate flows that the particle motion in the fluid, in the absence of collision or external electric, 1.....netic or gravitational fields, is controlled primarily by a balance between particle inertia $a_{1} f$ fluid drag. Other forces, such as added mass force or inertial pressure gradient force, can often have the same magnitude as the particle inertia for liquid flows, and for purposes of a 
scaling analysis these forces are typically lumped in with inertia. In addition to Jrag and inertia, secondary forces such as Saffman and Magnus lift forces, Bassett history force, Piow ian force, etc., can influence particle motion in a non-negligible way, but are usually smaller $\mathrm{t}^{\prime}$ an the dominant drag and inertia forces.

For nanometer-scale particulate flows (nanofluids), the fluid drag remains _ nrin. ry importance, but the inertia decreases sufficiently rapidly with particle size that other for a lay become of a similar, or greater, order of magnitude as the inertia. In examining the relativ, scale of the fluid forces on the nanoparticles, we recall our previous argument that the lift force $a_{1} 1$ the Basset history force are negligible for nanofluids due to the very small particle sizes. Th:pr $\mathbb{w}$ : Reynolds number is small, so that the inertial correction to the drag force can be omitted. : $7 \mathrm{r} l_{i_{-}}$ald nanoparticle flows, usually the Knudsen number is also small, so that the slip corre ion on the drag force can be omitted. Furthermore, we will assume that the nanoparticle density in of a similar magnitude to that of the surrounding fluid, so that the inertial pressure gradient for ${ }^{-}$and the added mass force are of the same order of magnitude as the particle inertia (and these torr s are therefore lumped in with inertia for simplicity). The two forces of particular interest in .. nop r ticle flows, with the potential of displacing particle inertia in balancing the drag force, $\mathrm{a}^{m}$ the ?rownian force and the thermophoretic force, which are examined in more detail below.

The significance of Brownian force comr dred , particle inertia is determined by the value of the particle Peclet number, $P e_{p}$, which is de

$$
r_{\epsilon_{p}}-V_{s} c_{p} / D_{B}
$$

In this equation, $V_{s}=\left|\boldsymbol{V}_{p}-\boldsymbol{V}_{f}\right|$ is ne $\mu$ - rticle slip velocity, $d_{p}$ is the particle diameter, and $D_{B}$ is the Brownian diffusion coefficient givf a by Eq. (21). The ratio of Brownian force to particle inertia scales like [29]:

$$
\frac{F_{B}}{F_{i}}=O\left(\mathrm{Pe}_{p}^{-1 / 2}\right)
$$

so that the Browni: n force is significant for $P e_{p} \leq O(1)$. The slip velocity $V_{s}$ associated with particle inertia scales as $\ldots$ nrnduct of the fluid free stream velocity $U$ and the Stokes number St. The Stokes number is defined. $\mathrm{s}$ the ratio of the particle time scale $\tau_{p}$ to the fluid time scale $\tau_{f}=L / U$, so that 


$$
\mathrm{St} \equiv \frac{\tau_{p}}{\tau_{f}}=\frac{\rho_{p} U d_{p}^{2}}{18 \mu_{f} L}
$$

where $L$ is a characteristic fluid length scale. Using the estimate $V_{s}=O(\operatorname{St} U) \mathrm{fu}_{\mathrm{c}} \mathrm{s}^{1} \mathrm{p}$ velocity, the particle Peclet number can be written in terms of constant quantities as

$$
P e_{p}=O\left(\text { St } U d_{p} / D_{B}\right)
$$

The significance of the thermophoretic force compared to the part $1_{e}$ ir stia can be assessed by equating the force ratio to the ratio of the thermophoretic drift ve $x^{i}$ y $m$ ignitude $V_{T}$ to the inertial slip velocity magnitude $V_{s}=O(S t U)$, giving:

$$
\frac{F_{T}}{F_{i}}=\frac{V_{T}}{V_{s}}=O\left(\frac{V_{T}}{S t U}\right)=O\left(\overline{\operatorname{Re}}_{f} \frac{A}{\nu_{\iota}}-\frac{\Delta t}{T_{f}}\right)
$$

where $\operatorname{Re}_{f}=\rho_{f} U L / \mu_{f}$ is the Reynolds number of we an hient fluid flow. In writing Eq. (38), we made use of the data in Table 1 for the two cons ... $A$ nd $B$ in Eq. (32), which indicates that $B=$ $\mathrm{O}(1)$ but that $A$ varies in magnitude from $\mathrm{O}(1)$ to $\mathrm{O}\left(\mathrm{l}^{4}\right)$ for different nanofluids.

A typical example illustrating the signific s se of 3rownian and thermophoretic forces in nanofluids is given by the problem of $10 \mathrm{~nm}$ dia tete aluminum particles in water, for which Table 1 gives $A=1264$. We assume a temperatu e d1. ${ }^{2}$ r , nce $\Delta T_{f}=10 \mathrm{~K}$, an ambient temperature $T_{f}=300 \mathrm{~K}$, a fluid length scale $L=1 \mathrm{~cm}$, and a fluia elocity scale $U=1 \mathrm{~m} / \mathrm{s}$. The Brownian diffusion coefficient for this problem is $D_{B} \cong 4 \times 1^{r}{ }^{-11} \mathrm{r} \% \mathrm{~s}$ and the fluid kinematic viscosity is $v_{f} \cong 10^{-6} \mathrm{~m}^{2} / \mathrm{s}$. The fluid Reynolds number is $\operatorname{Re}_{f}=10^{4}$ and the Stokes number is $S t=5 \times 10^{-10}$. Our estimates Eqs. (35) and

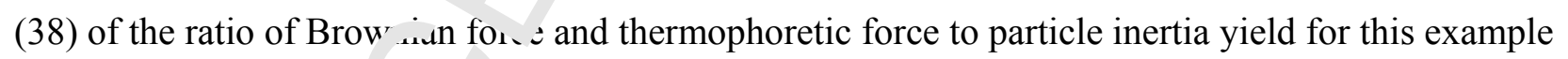

$$
\begin{gathered}
\frac{F_{b}}{F_{i}}=O\left(\mathrm{Pe}_{p}^{-1 / 2}\right) \cong O\left(2.7 \times 10^{3}\right) \\
\frac{F_{T}}{F_{i}}=O\left(\frac{A}{\operatorname{Re}_{f} S t} \frac{\Delta T_{f}}{T_{f}}\right) \cong O\left(8.4 \times 10^{6}\right)
\end{gathered}
$$


Both the Brownian force and the thermophoretic force are observed to be significan ${ }^{4}$ ly larger than the particle inertia. For this particular example the thermophoretic force dominates, na rould therefore balance the drag force to determine the particle motion, but the balance $b^{\prime} w_{1}$ en Brownian and thermophoretic force in general depends on the problem details and the materials a ed.

The readers may refer to Refs. [21] and [50] to see more examples of scal $;$ an : ris.

\subsection{Inter-particle forces}

Interparticle forces become important especially when the numb $f_{i}$ of $\ldots$ ticles in a specific volume of mixture increases, however, if the concentration of particles $i$. the ${ }^{\prime} r$ em is small, the interparticle forces acting between non-adhesive particles - ignoring ag ${ }^{\top}$ lomera on or aggregation of particles may be safely neglected. Of course in systems of adhesive ${ }_{p}$ 'rticies, collisions will eventually occur even in dilute suspensions, giving rise to formation of $p_{n}$ ticle agglomerates. In these suspensions of adhesive particles, interparticle forces are therefor ".n - mary at all values of the bulk particle concentration. In this section, we first study $t^{\prime}-c^{\prime}$, rion that determines the range in which interparticle forces are negligible in systems of non-a 'hesive particles, or for short-time computations of systems of adhesive particles, and in the next seci $\sim \eta$ various interparticle forces are discussed.

\subsubsection{Dilute and dense nanofluids}

Based on the solid volume fractio' of $n_{\omega^{-}}$, particles dispersed in the base fluid, nanofluids (solidliquid mixtures) can be classified ınto ı, ' general groups including: diluted and dense [51,52]. Solid volume fraction (or nanofluid vol me concentration) is defined as the ratio of solid nanoparticles volume to the total volume $\mathrm{c}$ mixı $\cdot$. Mathematically it can be written as:

$$
\phi(\%)=\frac{1 \mathrm{n}, \mathrm{par}^{+} \text {cle volume }}{\text { Toul volume }}=\frac{\left(m_{p} / \rho_{p}\right)}{\left(m_{p} / \rho_{p}\right)+\left(m_{f} / \rho_{f}\right)} \times 100
$$

A nanofluid can be con: 'terer' to be a dilute mixture when its volume concentration is less than $0.1 \%$ [51,52]. Interpartir e forc 's can be safely neglected for a dilute nanofluid provided that adhesive forces are not presen. ${ }^{\sim}$ or concentrations higher than $0.1 \%$ the nanofluid is dense. The dense flow is also divided into w $J$ groups. When $0.1 \leq \phi(\%) \leq 10$ collision between particles is dominated and when $\phi \geq 10 \%$ contact is dominated in the flow [52]. Due to the heterogeneous distribution of nanoparticles 
that may be created by aggregation and sedimentation of nanoparticles, in nanoflv $\mathrm{d}$ flows we may have both dilute and dense flows in different regions of the flow field at the sa ne : me. It may be interesting to estimate the minimum distance between two spherical nanopartir es $\mathrm{n}$ ideal conditions so that the suspension is considered dilute (i.e., with almost no collision between ${ }_{\text {r }}$ rticles). For a case with two spherical particles with the same diameter $\left(d_{p}\right)$ and where the di . . nce $\iota$ tween the particle centers is $l_{p}$, the relation between particle diameter, distance between $i_{2}+t_{\text {No }}$ particles and volume fraction of the nanoparticles is [52]:

$$
\frac{l_{p}}{d_{p}}=\left(\frac{\pi}{6 \phi}\right)^{\frac{1}{3}}
$$

Based on the definition of dilute flow in which the volume concentr c tion should be less than $0.1 \%$ and using the above equation we find that the ratio of particle dista. - e to particle diameter $\left(\frac{l_{p}}{d_{p}}\right)$ should be more than almost 8 to have a dilute nanofluid. Fig . 1 1) ilıustrates schematically the concepts of dilute and dense flows and the associated range of nlum fraction [52]. 


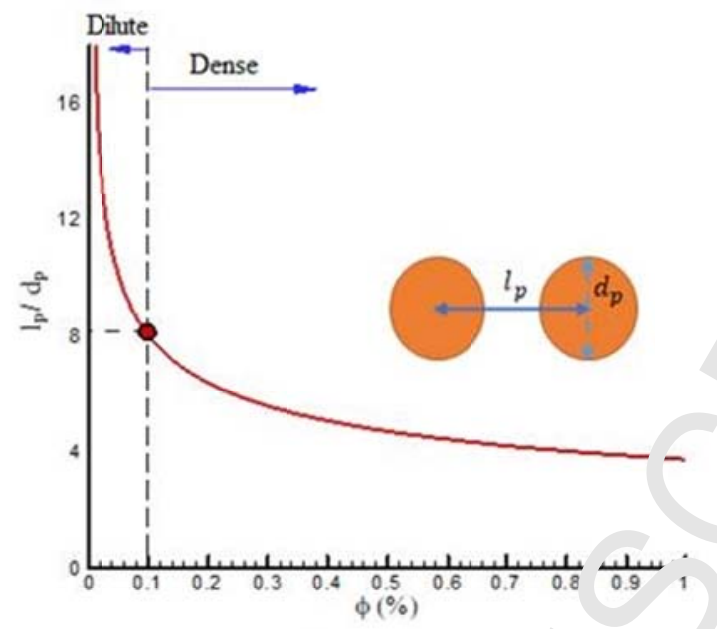

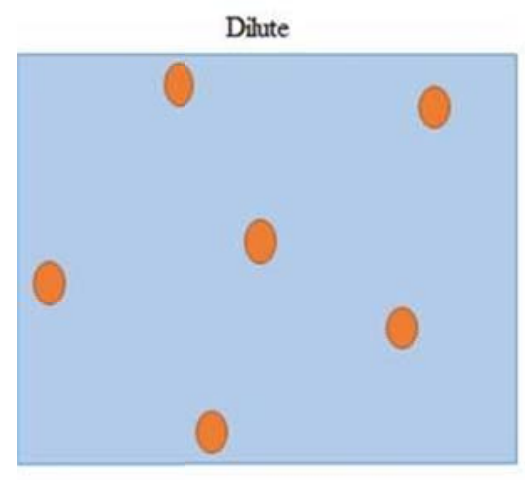

$\phi(\%) \leq 0.1$

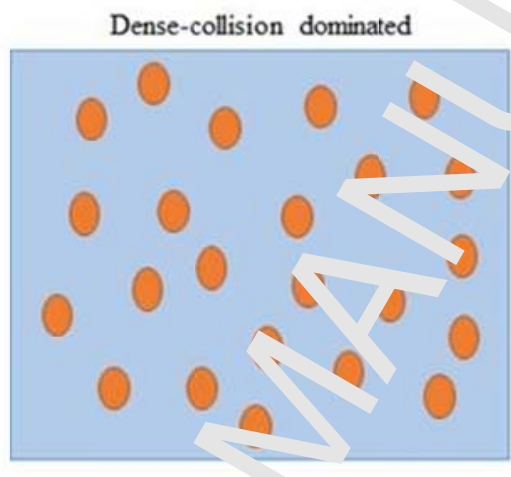

$0.1 \leq \phi(\%) \leq 10$
Dense-contact dominated

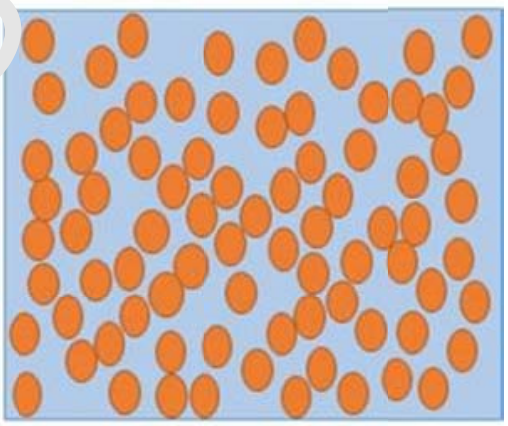

$\phi(\%) \geq 10$

Figure 12. Concepts of dilute and lense ft. ws based on solid volume fraction of particles.

\subsubsection{Van der Waals Force}

Van der Waals force appears retw ien molecules or tiny particles and acts generally as an attractive force. Van de Waals force iself is composed of three forces: dispersion interaction (London force), dipole-dipole interaction ( $\mathbf{n}$ sor 1 force) and dipole-induced dipole interaction (Debye force)[53]. The van der Waals for :e may be significant in a wide range of distances ranging from atomic scale $(0.2 \mathrm{~nm})$ to greater than $\left.1 \mathrm{C}^{-} . .454,55\right]$. The Hamaker theory [56] is used to estimate the van der Waals force between diffe "ent me erials. The van der Waals force between two rigid (non-deforming) spheres formed of the s mo material is given by [36]: 


$$
F_{V a n}=-\frac{A_{H}}{6 z_{p}^{2}} \frac{r_{p_{1}} r_{p_{2}}}{r_{p_{1}}+r_{p_{2}}}
$$

where $z_{p}$ is the distance between surfaces of two spheres(the shortest distance), $\omega^{-\lambda} r_{p_{1}}$ and $r_{p_{2}}$ are radii of spheres. Also, $A_{H}$ is Hamaker constant that depends on the materials of $\mathrm{t}^{\mathrm{t}}$ - sphe . If the spheres are made from different materials (we face with this in hybrid nanofluids), $\therefore$, oefficient $A_{H}$ is replaced by $A_{H 12}$ so that it is estimated as[28]:

$$
A_{H 12}=\sqrt{A_{H 11} A_{H 22}}
$$

where $A_{H 11}$ is Hamaker constant for the first sphere and $A_{H} 22$ \& Hamaker constant for the second sphere. If the two spheres are dispersed in a medium (like . flu; 1 ) the Hamaker constant can be estimated as:

$$
A_{H 132}=\left(\sqrt{A_{H 11}}-\sqrt{A_{H 33}}\right)\left(\sqrt{\Lambda_{1} \cdot 22} \times \sqrt{A_{H 33}}\right)
$$

where $A_{H} 33$ is the Hamaker constant for the medium, (tluid). Hamaker constant for some materials is given in Table 2. 
Table 2. Hamaker constant for some materials[52].

\begin{tabular}{|c|c|}
\hline & $\begin{array}{c}\text { Hamaker constant } \\
\text { Material }\end{array}$ \\
& $\left(\mathbf{A}_{H}\right)$ \\
& $\left(\mathrm{J} \times 10^{20}\right)$ \\
\hline Water & 4.38 \\
\hline $\mathbf{A l}_{2} \mathbf{O}_{3}$ & 15.5 \\
\hline $\mathbf{C u}$ & $2 \mathrm{C}^{20}$ \\
\hline Au & 456 \\
\hline
\end{tabular}

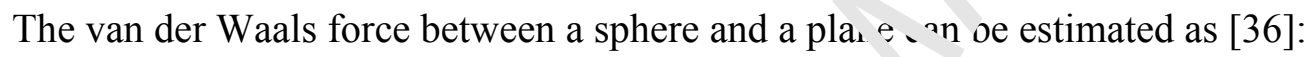

$$
F_{V a n}=-\frac{A_{H} r_{p}}{i^{2}}
$$

The above equations for van der Waal, fo'se assume that the particles are perfect spheres. Since the van der Waals force acts only ove vt.' st ort distances, even tiny deformation of a sphere upon collision can have a significant $\mathrm{e}_{1}$ - $\mathrm{c}$ on the van der Waals force. The influence of particle deformation is quite importar. I r micrometer-scale and larger particles, but of only moderate importance for nanoscale partı'ss. A more extensive review of van der Waals force between deforming spheres is giv $a b /[19]$. The van der Waals force is one of the reasons behind the aggregation of particle since ney act mainly as an attractive force); therefore, the stability of nanofluids is critically ( spendf at on accurate modeling of this force [53].

\subsubsection{Electrostati doubl layer force}

The presence of inns in tne base fluid (e.g., electrolytes, such as salt water) can result in the formation of an electrical do , le layer around charged particles. This electrostatic double layer will induce a 
force of very small range which can be modeled using the Hogg-Healy-Fuerstenau ('IHF) formula [57]:

$$
\begin{aligned}
E_{E d l} & =\frac{\varepsilon r_{p_{1}} r_{p_{2}}\left(\psi_{01}^{2}+\psi_{02}^{2}\right)}{4\left(r_{p_{1}}+r_{p_{2}}\right)}\left[\frac{2 \psi_{01} \psi_{02}}{\left(\psi_{01}^{2}+\psi_{02}^{2}\right)} \ln \left[\frac{1+\exp \left(-\kappa z_{p}\right)}{1-\exp \left(-\kappa z_{p}\right)}\right]+\ln (1-\exp (-2 \kappa-))\right. \\
F_{E d l} & =-\frac{d \vec{E}}{d z_{p}}
\end{aligned}
$$

Here $E_{E d l}$ is the particle-particle electrostatic interaction potential ene ${ }_{0}:{ }_{01}$ and $\psi_{02}$ are the particle surface potentials, $\varepsilon$ is the dielectric constant of the solution, and $\cdot^{-1}$ is th 2 Debye length (double layer thickness). The above relation is a good approximation when pari ${ }^{-1}$ e surface potentials are less than 50-60 mV. The above relation can also be modified to estimate. ' $\mathrm{i}$.teraction force between a particle and a wall by assuming one of the particle radii tends to infinits. Contrary to the van der Waals force, electrostatic double layer forces are repulsive in nature; ther ' 're, they decrease the agglomeration of nanoparticles, and, hence, enhance the stability of a nan $f^{\prime}$ did [53].

\subsubsection{Other interparticle forces}

Other interparticle forces such as steric electrc steric, depletion, capillary, solvation, structural or hydration forces can affect the stabili y of $1 \mathrm{~h}$. Iofluids. For example, steric force can prevent the aggregation of nanoparticles. Steric tu. - les $\mathrm{ds}$ to absorption of a layer of organic molecules at the surface of particles. Depending is the thickness and density of the layer, attractive forces and consequently the aggregation $\mathrm{ra}^{+} \ldots$ duce [53]. Interested readers may refer to Refs. $[53,55,58]$.

\subsubsection{DLVO theory and ne lofluı' stability}

Based on independent itudies sf Derjaguin and Landau (1941) and Verwey and Overbeek (1948), a quantitative theory nown as DLVO was established to demonstrate the stability of colloidal dispersions [53,55, The t 1eory of DLVO combines the effects of two opposite forces i.e. van der Waals attraction an a e e ectrostatic double layer repulsion to describe the dispersion stability. Indeed in DLVO theory o . er forces are ignored. Figure 13 (replotted based on a figure given in [53]) shows schematically the DLVO theory concept. At the primary minimum point, the amount of attraction 
between particles is maximized; therefore, the suspension is unstable (strong ${ }^{1} f$ flocculated or irreversible aggregation). At the energy barrier point, the repulsive force is maxir $1 \mathrm{zu}{ }^{1 \cdot}$ therefore, the suspension attains a stable condition. At the secondary minimum point, the amo $\mathrm{nt}$ if attractive forces is less than at the primary minimum point, giving rise to a weakly flocu. ated or reversible aggregation.

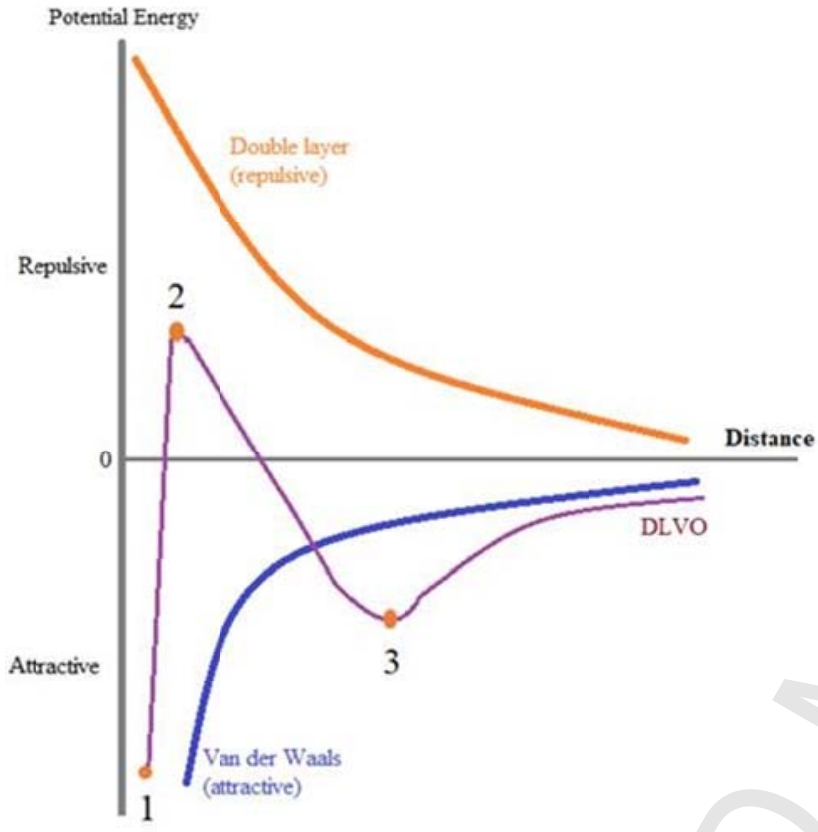

1 : Primary minimum

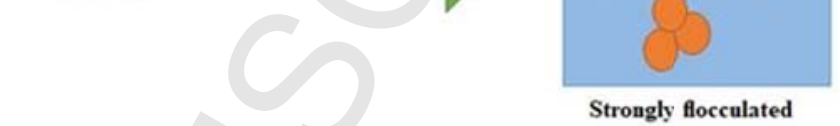

2 : Energv ham.
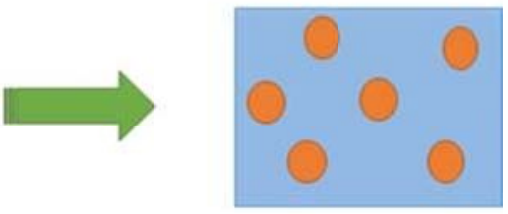

Dispersed (Stable)

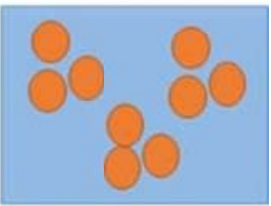

Weakly flocculated

Figure 13. DLVO theory , be ised to describe the stability of suspensions.

\subsection{External forces}

Sources such as gravity, mag. atir eler ric fields, and acoustic oscillations can create forces which affect the flow and heat transfer fiel $s$ in a nauıfluid-based thermal system. Here, an overview of these forces is presented.

\subsubsection{Reduced gri vity fo ce}

The reduced gr - ritv force is the outcome of gravitational and buoyancy (obtained from Archimedes' law) forces. It can ' e obtained by the following relation [29]: 


$$
\mathbf{F}_{G}=\left(\pi \frac{d_{p}^{3}}{6}\right)\left(\rho_{f}-\rho_{p}\right) g
$$

The reduced gravity force can be neglected usually in nanofluid flows due to ultı ${ }^{\mathrm{f}}$ ne size of nanoparticles.

\subsubsection{Lorentz force}

If a fluid with an electrical conductivity of $\sigma$ (with dimension of $1 / \Omega .1$ ) flor s in a duct under an external electrical field of $\mathbf{E}$ and magnetic field of $\mathbf{B}$, a force is appliea $\sim$ el ments of the fluid called Lorentz force. Lorentz force affects the velocity magnitude and te $n p$ at re field in the thermal equipment. Lorentz force is defined as [59]:

$$
\mathbf{F}_{L z}=\mathbf{J} \times \mathbf{B}=\sigma(\mathbf{E}+\mathbf{V} \times \mathbf{B}) \times \mathbf{L}
$$

In the above, $\mathbf{V}$ is fluid velocity vector, and $\mathbf{J}$ is current dens $y_{\text {. }}$ ( with dimension of $\mathrm{A} / \mathrm{m}^{2}$ ). In the case of magnetohydrodynamic (MHD) flows, by neglecting.$h$ electrical field and assuming that the external magnetic field has a constant strength of $\mathrm{B}_{0}, \mathrm{t}_{\mathbf{1}} \cdot$ Lurentz force simplifies to:

$$
\mathbf{F}_{L z}=\sigma \mathbf{B}_{0}^{2} \mathbf{V}
$$

For MHD flows, a dimensionless number alled " Iartmann number" comes into play, which can be defined as:

$$
H a=\lrcorner_{0} L_{c} \sqrt{\frac{\sigma}{\mu}}
$$

where $L_{c}$ is the characteristic le gth (for example, the diameter of a tube) and $\mu$ is the viscosity of the working fluid.

For nanofluids, the correspu. ${ }^{\prime}$ ng lectrical conductivity can be calculated based on the Maxwell model that is used to ca culatc the thermal conductivity of nanofluids (See section 3.1.1.1).

\subsubsection{Acoustic rad dition torce}

The energy of sour 1 wave (acoustic waves) can also be used to enhance the performance of thermal systems. The fc …'time averaged) acting on particles by acoustic waves (e.g., an ultrasound field) is called acoustic raa tion force [60]. For a particle dispersed in a fluid, the acoustic radiation force is a nonlinear function of acoustic pressure, velocity of particle, sound velocity and fluid density $[60,61]$. 
Many studies have been done to determine the radiation force on particles (either elas ic or rigid) in a

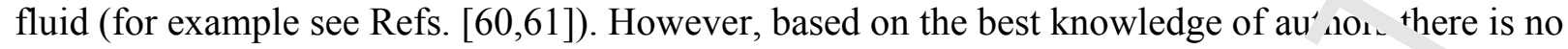
CFD study on nanofluid-based systems in which the interaction of radiation forc $-\mathrm{w}$ th other forces acting on nanoparticles in nanofluid flows has been assessed. However, since the "nustic radiation force is proportional to the particle volume, it would be expected to be $\mathrm{sma}^{1}$. . mmpa ed to forces such

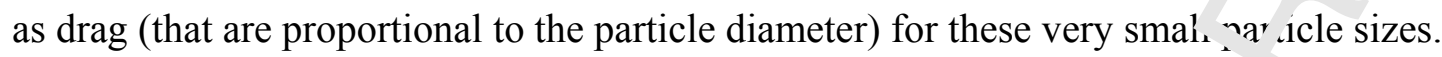

\subsection{Other forces}

There are some other forces such as diffusiophoresis, centrifugal, ind .ur. ophoresis that may be found in the literature. Here, an overview of these forces is given.

Diffusiophoresis phenomenon happens due to concentratio orac ${ }^{2}$ s of solution. In this phenomenon, due to diffusiophoresis force, nanoparticles migrate from . . ........ ith high concentration to a zone with lower concentration. Since diffusiophoresis requires two ^ ase fluids, it is not common in nanofluid systems (which historically have just one bast ${ }^{f}$.uid component [21]).

Another force included in some studies is the crntrifus al force. One should note that centrifugal force is related not to the rotation of the particle abou - fixed point, but rather to the rotation of the

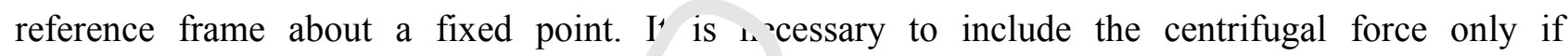
computations are needed to be done in r rola ${ }^{n g}$ reference frame (for example, consider nanofluid on a rotating circular disk). If instead, $s$, ir $\mathrm{rti}^{2}$ reference frame is used, the centrifugal force on the particle is contained within the pr ticle inurtia. The centrifugal force for a coordinate system that rotates with an angular velocity of $\Omega_{S}$ caı be expressed as [62]:

$$
\mathbf{F}_{C l}=\left(\frac{\rho_{f}}{\rho_{p}}-1\right) m_{p} \Omega_{S}^{2} r
$$

where $r$ stands for the $\mathrm{p}$ ssition ff nanoparticle times the unit vector in the radial direction.

Turbophoresis is a ,henor enon in which the particles tend to migrate towards a region with less turbulent fluctuation. Sir e turbulent fluctuations decrease very close to a wall, the possibility of particle sedimen ، tir $n$ on the wall increases through this phenomenon [63]. For turbulent flow in a pipe, turbophoretic 1 rce can be evaluated as[64]: 


$$
\left\{\begin{array}{l}
\mathbf{F}_{T u}=-\rho_{p} \frac{\pi d_{p}^{3}}{6}\left(\frac{d\left\langle v_{p}^{\prime 2}\right\rangle}{d y}\right) \\
V_{T u}=-\tau_{p}\left(\frac{d\left\langle v_{p}^{\prime 2}\right\rangle}{d y}\right)
\end{array}\right.
$$

in the above, $\left\langle v_{p}^{2}\right\rangle$ is the particle mean square fluctuation velocity in th . . . orman direction and $\tau_{p}=\frac{\rho_{p} d_{p}^{2}}{18 \mu_{f}}$ is the particle relaxation time as defined earlier.

\section{An overview of nanofluids thermophysical pe nerties}

In this section, the main models available for therm . hysi al properties of nanofluids are first presented, and then the importance of using pro, ar mo' els in flow and heat transfer simulations is highlighted.

\subsection{Thermophysical properties}

\subsubsection{Thermal conductivity $\left(k_{n f}\right)$}

Thermal conductivity characterize ᄂ. ability of a material to conduct heat, and it is measured in units of $\mathrm{W} / \mathrm{mK}$. The thermal conducti . is, of nanofluids is generally higher than that of conventional liquids. Here, the most used theoretı. 1 models and experimental correlations for thermal conductivity presented in the literature a e re jiev'ed.

\subsubsection{Theoretical mod is}

The Maxwell mod $1[65,6]$ is probably the first model presented for the thermal conductivity $k_{n f}$ of solid-liquid dis ${ }_{1}^{1}$ _. inns. where we set

$$
k_{n f}=\frac{k_{p}+2 k_{f}+2 \phi\left(k_{p}-k_{f}\right)}{k_{p}+2 k_{f}-\phi\left(k_{p}-k_{f}\right)} k_{f}
$$


and $k_{f}$ and $k_{p}$ are the thermal conductivities of the base fluid and the nanoparti les, respectively. This model is valid for spherical particles with small concentration $(\phi<<1)$.

Bruggeman $[65,67]$ presented the following model by considering interact; sns setween spherical particles:

$$
\begin{aligned}
& \frac{k_{n f}}{k_{f}}=\frac{(3 \phi-1) \frac{k_{p}}{k_{f}}+\{3(1-\phi)-1\}+\sqrt{\Delta}}{4} \\
& \text { where }: \Delta=\left[(3 \phi-1) \frac{k_{p}}{k_{f}}+\{3(1-\phi)-1\}\right]^{2}+8 \frac{k_{p}}{k_{f}}
\end{aligned}
$$

Hamilton and Crosser [68] extended the Maxwell model by inclu ' ir 6 a shape factor as follows:

$$
k_{n f}=\frac{k_{p}+(n-1) k_{f}+(n-1) \phi\left(k_{p}\right.}{k_{p}+(n-1) k_{f}-\phi\left(k_{l}-k_{f}\right)} \because k_{f}
$$

where $n$ is the empirical shape factor, determined $b_{0} \ldots=-\frac{2}{2}$ in which $\psi$ is the particle sphericity. The sphericity parameter is 1 for spherical particles anc ${ }^{+}+$reduces to 0.5 for cylindrical particles.

It is important to mention that the previ us models, valid for large particle sizes and generally underestimate the thermal conductivity $n_{\text {. }}$ rnitur e compared to real (experimental) data. However, they are still widely used in numerica sir ulations of nanofluid flows. To avoid these discrepancies, several attempts have been made to exten $?$ : renovate the previous models and take in consideration phenomena involved in heat condu ion of nanoparticles and nanofluids such as nanolayer, nanoparticle interaction, aggres stio and Brownian motion.

The following models are rainı, developed for metallic and oxide nanoparticles which are also spherical in shape.

When nanoparticles ar, disporsed in a liquid, a thin layer of liquid is formed on the surface of nanoparticles called the "liqu; $\downarrow$ nanolayer". Yu and Choi [69] considered this factor to derive a new thermal conductivi y moa. 1 as follows:

$$
{ }_{I_{\text {.f }}}=\frac{k_{p}+2 k_{f}+2\left(k_{p}-k_{f}\right)(1+\gamma)^{3} \phi}{k_{p}+2 k_{f}-2\left(k_{p}-k_{f}\right)(1+\gamma)^{3} \phi} k_{p}
$$


where $\gamma$ is the ratio of liquid nanolayer thickness to radius of nanoparticles and it is $u$ ually assumed to be 0.1 .

Xuan et al. [70] presented a model for nanofluid thermal conductivity by consi ter ig the aggregation and Brownian motion of nanoparticles, giving

$$
\frac{k_{n f}}{k_{f}}=\frac{k_{p}+2 k_{f}-2 \phi\left(k_{f}-k_{p}\right)}{k_{p}+2 k_{f}+\phi\left(k_{f}-k_{p}\right)}+\frac{\rho_{p} \phi c_{p, f}}{2 k_{f}} \sqrt{\frac{2 \kappa_{B} T_{a v e}}{3 \pi d_{p} \mu_{f}}}
$$

where $\kappa_{B}$ is the Boltzmann constant and $d_{p}$ is nanoparticle diameter. There 1 re, based on this model,

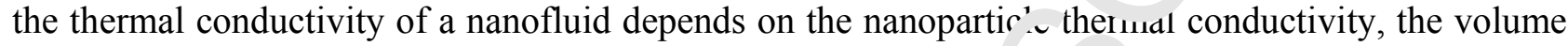
fraction of nanoparticles, the temperature of the mixture, the $\angle \mathrm{e} c$ the nanoparticles, and the properties of the base fluid, including thermal conductivity, viscosit, and specific heat capacity.

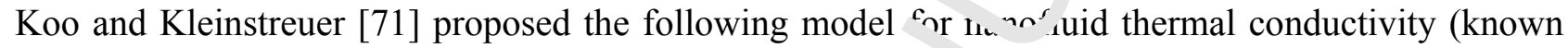
as the $\mathrm{K}-\mathrm{K}$ model):

$$
k_{n f}=k_{\text {static }}+k_{\text {Brownian }}
$$

This model is composed of two parts, referred to as rtatic rnd dynamic. The static part $\left(k_{\text {static }}\right)$ has the form

$$
k_{\text {static }}=\left(1+\frac{3\left(k_{p} / k_{f}-1\right) \phi}{\left(k_{p} / k_{f}+2-\left(k_{p}^{\prime} k_{f}-1\right) \phi\right.}\right) k_{f}
$$

The dynamic part accounts for the effec . of Bro nian motion on nanoparticles $\left(k_{\text {Brownian }}\right)$ and is calculated by:

$$
k_{\text {Brownian }}=5 \times 10^{4} \sigma \phi\left(, c_{p}\right)_{f} \sqrt{\frac{\kappa_{B} T}{\rho_{p} d_{p}}} f(T, \phi)
$$

where $\sigma$ and $f$ are two empiri al tu. ^tions and $\kappa_{B}$ is the Boltzmann constant.

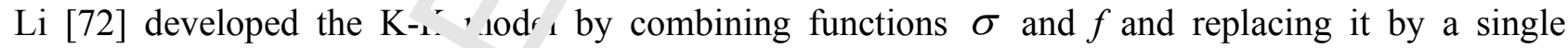
function $\mathrm{g}$, which resul' $\mathrm{s}$ in th expression

$$
k_{\text {ownian }}=5 \times 10^{4} \phi\left(\rho c_{p}\right)_{f} \sqrt{\frac{\kappa_{B} T}{\rho_{p} d_{p}}} g\left(T, \phi, d_{p}\right)
$$

where: 


$$
\begin{aligned}
g\left(T, \phi, d_{p}\right)= & \left(a_{1}+a_{2} \ln \left(d_{p}\right)+a_{3} \ln (\phi)+a_{4} \ln (\phi) \ln \left(d_{p}\right)+a_{5} \ln \left(d_{p}\right)^{2}\right) \ln (T)+ \\
& \left(a_{6}+a_{7} \ln \left(d_{p}\right)+a_{8} \ln (\phi)+a_{9} \ln (\phi) \ln \left(d_{p}\right)+a_{10} \ln \left(d_{p}\right)^{2}\right)
\end{aligned}
$$

The constants $a_{1}-a_{10}$, which may be either positive or negative, are determ. ad bu ad on the type of nanoparticle and base liquid.

Feng and Kleinstreuer [73] presented a more advanced model in which here is no need for any empirical function (called the F-K model). This model takes into ar count $\imath$ le Brownian motion and turbulent fluctuation effects. This model is valid for water-based nanoruuds containing metal oxide nanoparticles with diameter in the interval $30<d_{p}<50 \mathrm{~nm}$, ${ }_{\lrcorner}$me iractions less than $5 \%$, and absolute suspension temperatures lower than $350 \mathrm{~K}$. The F-K mode ${ }_{1}$ : $s$ written as:

$$
k_{n f}=k_{\text {static }}+k_{m m}
$$

in which $k_{\text {static }}$ is the same as defined earlier in the $\mathrm{K}-1$, model and $k_{m m}$ indicates the micro-mixing contribution caused by the Brownian motion. The para net $\wedge_{i m}$ is given by

$$
\begin{aligned}
& k_{m m}=49500 \frac{\kappa_{B} \tau_{P}}{2 m_{p}} \cdot C_{c} \cdot\left(\rho c_{p}\right)_{n f} \cdot \phi^{2} \cdot\left(T \iota^{\prime} \iota \quad T\right) .
\end{aligned}
$$

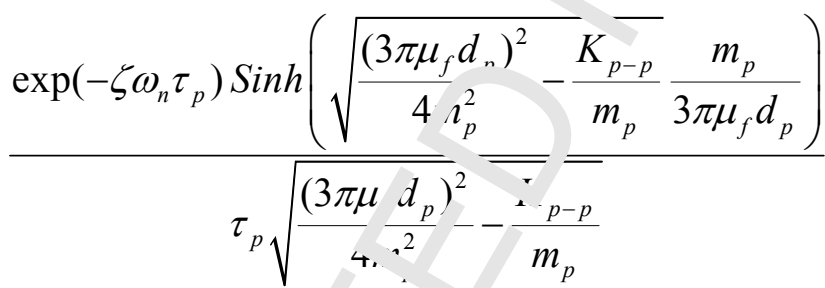

Here, $m_{p}$ is the particle mass. $\mathrm{Tr}: \mu_{2}$-ameter $C_{c}$ is constant and equal to 38 for metal-oxide based nanofluids. Also, the damping oef icient $\zeta$, natural frequency $\omega_{n}$, and characteristic time interval $\tau_{p}$ are defined as

$$
\zeta=\frac{3 \pi d_{p} \mu_{\nu}}{2 m_{p} \omega_{1}}, \omega_{n}=\sqrt{\frac{K_{P-P}}{m_{p}}}, \tau_{p}=\frac{m_{p}}{3 \pi \mu_{f} d_{p}}
$$

where $K_{P-P}$ shows he mas aitude of particle- particle interaction intensity and is estimated by

$$
F_{P-P}=\rho_{p} \cdot \sqrt{d_{p}} \cdot\left(\frac{32.1724 \times 273 K}{T}-19.4849\right)
$$

In 2014, $\mathrm{Xu}$ and Kleinstreuer [74] proposed a new model that is more accurate than the F-K model 
and considers the effect of aggregates, it reads as:

$$
k_{n f}=k_{\text {static }}+k_{m m}
$$

where $k_{\text {static }}$ reads as

$$
k_{\text {static }}=k_{f}\left(1+\frac{3\left(k_{a} / k_{f}-1\right) \phi}{\left(k_{a} / k_{f}+2\right)-\left(k_{a} / k_{f}-1\right) \phi}\right)
$$

In this equation, $k_{a}$ is the effective thermal conductivity of the aggreg tes, ar proposed by Nan et al. [75]:

$$
k_{a}=k_{d e} \cdot \frac{3+\phi_{b}\left[2 \beta_{11}\left(1-L_{11}\right)+\beta_{33}\left(1-L_{33}\right]\right.}{3-\phi_{b}\left(2 \beta_{11} L_{11}+\beta_{33} L_{33}\right)}
$$

The thermal conductivity of the aggregate due to dead-end artic es, $k_{d e}$, is defined based on the Bruggeman model[67].

The geometrical factors $L_{11}$ and $L_{33}$ are expressed in [75] as

$$
L_{11}=p^{2} / 2\left(p^{2}-1\right)-p^{2} \cosh ^{-1} / 2\left(p^{2}-1\right)^{1.5} \text { ar: }: I_{33} \cdot 1-L_{11}
$$

The aspect ratio is $p=R_{g} / d_{p}$, and

$$
\beta_{i i}=\left(k_{i i}^{c}-k_{d e}\right) /\left[k_{d}\left\ulcorner L_{l u}\left(k_{i i}^{c}-k_{d e}\right)\right], i=1,3\right.
$$

$k_{i i}^{c}$ are equivalent thermal conductiv ies $\mathrm{a}_{\curvearrowleft} \cdot \mathrm{g}$ corresponding symmetric axis of an ellipsoidal composite unit cell, with $k_{i i}^{c}=k_{r}^{\prime}\left(1+, I_{j ;} i_{p} / k_{b f}\right), \gamma=(2+1 / p) \alpha, \alpha=A_{k} / d_{p}$ with $A_{k}$ is the Kapitza length. Also,

$$
\begin{aligned}
k_{d e}= & \left(3 \phi_{d e}-1\right) \cdot k_{p e f f}+\left(2-3 \phi_{d c} \cdot k_{b f}\right. \\
& +\sqrt{\left.\left(3 \phi_{d e}-1\right)^{2} \cdot k_{p e f f}^{2}+(-3 ;)_{d e}\right)} \overline{k_{b f}^{2}+2\left[2+9 \phi_{d e}\left(1-\phi_{d e}\right)\right] k_{p e f f} k_{b f}}
\end{aligned}
$$

and the improved param $\ldots r k_{m m} \cdot s:$

$$
\text { 19631. } C_{c} \phi \frac{\kappa_{B} \tau_{a}}{m_{a}}\left(\rho c_{p}\right)_{n f}(\bar{T} \cdot \ln \bar{T}-\bar{T})
$$

In the above, $\mathrm{C}_{\mathrm{c}}$ is a arre tion factor having a value about 1 for water-based nanofluids.

Prasher et al. [7t] d $\mathrm{d}_{\text {ilved }}$ a correlation as follows: 


$$
\frac{k_{n f}}{k_{f}}=\left(1+\Gamma \operatorname{Re}_{b}^{m} \operatorname{Pr}^{0.333} \phi\right) \times\left(\frac{\left[k_{p}(1+2 \alpha)+2 k_{f}\right]+2 \phi\left[k_{p}(1-2 \alpha)-k_{f}\right]}{\left[k_{p}(1+2 \alpha)+2 k_{f}\right]-\phi\left[k_{p}(1-2 \alpha)-k_{f}\right]}\right)
$$

in which the random motion-induced convection is included. In the above rel ion Reynolds number due to Brownian motion is $\operatorname{Re}_{b}=\frac{\sqrt{18 \kappa_{b} T / \pi \rho_{p} d_{p}}}{v_{f}}$, and $\alpha$ is the nanoparti ${ }^{-1}$ Bic number defined as $\alpha=2 R_{b} k_{f} / d_{p}$. Also, $R_{b}$ is the thermal interface resistance equal to $9.7 \%,{ }^{1} 0^{-8} \mathrm{Km}^{2} / \mathrm{W}$ for waterbased nanofluids, while $\Gamma$ and $m$ are empirical constants depending $n$ nan sparticle type. $\mathrm{For} \mathrm{Al}_{2} \mathrm{O}_{3}$ nanoparticles, $m=2.5$ and $\Gamma=40000$.

Another model that considers Brownian motion of nanopartic ss is esented by Patel et al.[77] as follows:

$$
\frac{k_{n f}}{k_{f}}=1+\frac{k_{p} A_{p}}{k_{f} A_{f}}+C_{e} k_{p} P e \frac{A_{p}}{k_{f} A_{f}}
$$

where $C_{e}$ should be determined by experiments. In adc ' ${ }^{1} 10^{\prime} \cdot,{ }^{\prime}{ }_{p} / A_{f}$ and $P e$ are obtained by:

$$
\frac{A_{p}}{A_{f}}=\frac{d_{f}}{d_{p}} \frac{\phi}{(1-\phi)} \text { and } P e=\frac{u_{p}{ }^{p}}{\sim}
$$

in which $u_{p}$ is the Brownian motion velocity of nanoparticles:

$$
u_{p}=\frac{\kappa_{B} T}{\pi \mu_{f}} \frac{a_{p}^{2}}{2}
$$

In another model, Amiri and Vafai crnsı 'ser' the contribution of thermal dispersion to thermal conductivity model, this model rer $1 \mathrm{~s}$. $\neg 778,79]$ :

$$
\prime_{f}=k_{\text {static }}+k_{d}
$$

Maxwell's model is used $\mathrm{t} \mathrm{es}^{\dagger} \cdot \mathrm{ma}^{\dagger} \mathrm{j} k_{\text {static }}$, and the thermal conductivity induced by thermal dispersion $\left(k_{d}\right)$ is estimated by:

$$
\therefore d=C_{e}\left(\rho C_{p}\right)_{n f} \sqrt{v_{x}^{2}+v_{y}^{2}} \phi d_{p}
$$

where $C_{e}$ is the con ‘ 'ant $\mathrm{o}^{1}$ tained from experiments, $v$ is the fluid velocity.

Several models hav, ...'so been developed for the prediction of thermal conductivity of nanofluids containing carbon- $\iota$ 'sed nanotubes. 
Xue et al. [80] offered a model to obtain the thermal conductivity nanosuspensions r ontaining carbon nano tubes (CNTs). The model originates from the classic model given by Ma .Wu." Moreover, it takes into account the influence of physical characteristics of CNTs, includins ax al ratio and space distribution, to obtain

$$
k_{n f}=\frac{1-\phi+2 \phi \frac{k_{p}}{k_{p}-k_{b f}} \ln \frac{k_{p}+k_{b f}}{2 k_{b f}}}{1-\phi+2 \phi \frac{k_{b f}}{k_{p}-k_{b f}} \ln \frac{k_{p}+k_{b f}}{2 k_{b f}}} k_{b f}
$$

Patel et al. [81] presented a model in which the thermal conduc ivity of CNT nanofluids was a function of nanofluid volume concentration, and both the ban - fluıd molecular and nanoparticle radii, $r_{b f}$ and $r_{p}$ respectively, which reads as

$$
k_{n f}=k_{b f}\left[1+\frac{k_{p} \phi r_{b f}}{k_{b f}(1-\phi)} \mid\right.
$$

Nan et al. [82] proposed the following model fo- -NTs based nanofluids:

$$
k_{n f}=\frac{3+\phi\left(\beta+\beta_{33}\right)}{3-\psi_{r}} k_{b f}
$$

where

$$
\beta_{11}=\frac{2\left(k^{c},-k_{b f}\right)}{k_{11}^{c}+k_{b f}} ; \beta_{33}=\frac{k_{33}^{c}}{k_{b f}}-1
$$

and

$$
k_{11}^{c}=-\frac{k_{p}}{2} \frac{k_{k} k_{p}}{d k_{b f}} \quad ; k_{33}^{c}=\frac{k_{p}}{1+\frac{2 a_{k} k_{p}}{l k_{b f}}}
$$

In the previous eq ations. $\mathrm{k}^{\mathrm{c}}{ }_{11}$ is thermal conductivity along transverse axis and $\mathrm{k}_{33}^{\mathrm{c}}$ is the thermal conductivity alrno longitudinal axis of a thin interfacial thermal layer and depend on dimensions of CNT. Also, Kapit . radius $a_{\mathrm{k}}=\mathrm{R}_{\mathrm{k}} \mathrm{k}_{\mathrm{bf}}$, with $\mathrm{R}_{\mathrm{k}}=8 \times 10^{-8} \mathrm{~m}^{2} \mathrm{~K} / \mathrm{W}$ [83]. 
Murshed et al.[84] developed a model for CNTs nanofluids by considering the siz of nanoparticle, nanosuspension volume concentration, and interfacial layer. It writes as

$$
k_{n f}=\frac{\left(k_{p}-k_{l r}\right) \phi k_{l r}\left(\gamma_{1}^{2}-\gamma^{2}+1\right)+\left(k_{p}+k_{l r}\right) \gamma_{1}^{2}\left[\phi \gamma^{2}\left(k_{l r}-k_{b f}\right)+k_{b f}\right]}{\gamma_{1}^{2}\left(k_{p}+k_{l r}\right)-\left(k_{p}-k_{l r}\right) \phi\left(\gamma_{1}^{2}+\gamma^{2}-1\right)}
$$

with

$$
\gamma_{1}=1+t / r_{p} ; \gamma=1+t / d_{p}
$$

$k_{l r}$ represents the thermal conductivity of interfacial layer and $\mathrm{t}$ is te thic ness of interfacial layer between nanoparticle and base fluid.

A comprehensive overview about thermal conductivity models $c^{c}-\mathrm{NT}$ oased nanofluids is given in Ref. [85]. In addition, Estellé et al. [86] measured the thermal conc ctivity of CNTs/water nanofluids and compared the results with available models.

\subsubsection{Experimental based correlations}

With regards on experimental based correlations, $t_{2}$ we a mainly obtained for spherical metallic and oxide nanoparticles. Maiga et al. [87] presente ${ }^{-1}$ two - orrelations based on experimental data for the thermal conductivity of $\mathrm{Al}_{2} \mathrm{O}_{3}$ - water and $\mathrm{Al}_{2} \mathrm{O}_{3}-\mathrm{EG}$. anofluids as follows:

$\mathrm{Al}_{2} \mathrm{O}_{3}$ /water:

$$
k_{n f}=\left(4.97 \phi^{2}+2.12 \lambda+1\right) k_{f}
$$

$\mathrm{Al}_{2} \mathrm{O}_{3}$ / ethylene glycol:

$$
k_{n f}=\left(28 r^{\ulcorner} u_{\sim} h^{2}+2.8273 \phi+1\right) k_{f}
$$

The above correlations were de elo led for nanoparticles with a size of $28 \mathrm{~nm}$.

Based on various experimental $a_{n}$ ? for thermal conductivity of nanofluids, Corcione [88] developed the following correlation:

$$
\frac{k_{n f}}{\vdots}=1-4.4 \operatorname{Re}_{p}^{0.4} \operatorname{Pr}_{f}^{0.66}\left(\frac{T}{T_{\text {freez }}}\right)^{10}\left(\frac{k_{p}}{k_{f}}\right)^{0.03} \phi^{0.66}
$$

where:

$$
\operatorname{Re}_{p}=\frac{2 \rho_{f} \kappa_{B} T}{\pi \mu_{f}^{2} d_{p}}
$$


The above relation is valid for nanoparticle sizes between $10-150 \mathrm{~nm}$, volume fractio is of $0.2-9 \%$, and temperatures between 294 and $324 \mathrm{~K}$. It should be noted that $T_{\text {freez }}$ is the freezins, te. nerature of the base fluid.

Khanafer and Vafai [65] proposed a general correlation for the thermal conduc: ity of $\mathrm{Al}_{2} \mathrm{O}_{3} / \mathrm{water}^{2}$ and $\mathrm{CuO} /$ water nanofluids as follows:

$$
\frac{k_{n f}}{k_{f}}=1+1.0112 \phi+2.4375 \phi\left(\frac{47}{d_{p}(n m)}\right)-0.0248 \phi_{p}\left(\frac{k_{p}}{0.613}\right)
$$

The above correlation is valid for nanoparticle size between $13 \mathrm{~nm}$ anc $\mathrm{e} n \mathrm{nr}$. and volume fractions up to $15 \%$.

Chon et al.[89] derived the following correlation for alumina/wa's ranofluids which is valid for the temperature range between 21 and $71{ }^{\circ} \mathrm{C}$, and nanoparticle sic - betw sen 11 and $150 \mathrm{~nm}$ as follows:

$$
\frac{k_{n f}}{k_{f}}=1+64.7 \phi^{0.7460}\left(\frac{d_{f}}{d_{p}}\right)^{0.3690}\left(\frac{k_{p}}{k_{f}}\right)^{0.7476}, \cdots \operatorname{Re}_{p}^{1.2321}
$$

As seen, $\mathrm{Re}_{\mathrm{p}}$ is included in the equation which imnlies ? 'ownian motion has been taken into account in this correlation.

Ho et al. [90] derived the following empirical c relauon for thermal conductivity of alumina/water nanofluids where the size of nanoparticles is $22 \mathrm{~nm}$ :

$$
k_{n f}=k_{b f}\left(1+: 944 \phi \cdot 19.672 \phi^{2}\right)
$$

The above relation is valid for concent atis as un to $4 \%$.

A correlation developed by Sharr a et a' [91,92] can be applied to all water-based nanofluids containing either metal or metal oxide no 'oparticles where the particle diameter is between 20 and 150 $\mathrm{nm}$, nanofluid temperature is $\mathrm{b}^{\prime}$ iwe $\mathrm{n} 20$ and $70{ }^{\circ} \mathrm{C}$, and maximum volume fraction of $4 \%$. It reads as:

$$
\frac{k_{n f}}{k_{f}}=0.8938\left(1+\frac{\phi p}{10 \Gamma}\right)^{37}\left(1+\frac{T_{n f}}{70}\right)^{0.2777}\left(1+\frac{d_{p}}{150}\right)^{-0.0336}\left(\frac{\alpha_{p}}{\alpha_{f}}\right)^{0.01737}
$$

In conclusion, it shoulc be not 1 that most of articles on nanofluids indicate that the thermal conductivity increas so witn increases in volume concentration and temperature, and it decreases with increase in the part le sizf. It should also be mentioned that many other empirical correlations have been developed is - rin in the literature, but they are specific to the kind of nanofluids tested, including the natur. of the base fluid and the nanoparticles, the size and shape of the nanoparticles, the range of nanoparticle content, and the temperature. 
To date, there is no universal model for the prediction of nanofluid thermal condur tivity, which is a significant challenge in nanofluid research. The readers can refer to several paper su ${ }^{h}$ as Refs. [93104] on the thermal conductivity of EG-based nanofluids and Refs. [105-11.] on the thermal conductivity of water based nanofluids, as well as comprehensive reviews such as 'efs. [114-123].

\subsubsection{Viscosity $\left(\mu_{n f}\right)$}

Viscosity is defined as the resistance of a liquid to flow and it is me sured in terms of Pa.s (pascal*second) or N.S $/ \mathrm{m}^{2}$. When we say water flows faster th $\mathrm{n} \mathrm{o}^{\mathrm{i}^{1}} \mathrm{n}$ an inclined glass it means viscosity (resistance) of water to flow is less than oil. Fluid can he divided into two groups, i.e. Newtonian and non-Newtonian fluids. A fluid is called a Newtonian fluid if (i) shear stress (the force per unit area applied to fluid) has a linear relationship witı sheiı rate (called also deformation rate$G=\partial V_{f} / \partial y$ ) and (ii) when shear stress is zero, the she $a_{2}$ ate being also zero (see Fig. 14 (a)) at fixed temperature and pressure. For a Newtonian fluid, visc slty . . zs not change with increase in shear rate (Fig. 14 (b)). Fluids such as water and air are simp - inst، nces of Newtonian fluids. However, in nonNewtonian fluids the viscosity follows the variation. of shear rate. Non-Newtonian fluids can be categorized as (i) time-dependent, if shear rate varı with magnitude and amplitude of shear stress, and possibly time between two consecutiv app ${ }^{\prime}$ 'd shear stress. Fluids with time-dependent viscosity can be classified as thixotropic (viscosity re 'ce, with time) and rheopectic (viscosity increases with time) fluids. However, if shear rate $\mathrm{c} \cdot \mathrm{ly}$.epe ds on current shear stress the fluid is classified as (ii) time-independent, and generally re ${ }^{f} \mathrm{r}$ to pur ly viscous fluids. Non-Newtonian fluids can also present (iii) viscoelastic properties. Among nor Newtonian fluids, one can distinguish shear-thinning (also called pseudoplastic) fluids ar 1 sh sar-thickening (also called dilatant) fluids, as shown in Fig.14. In addition, they can possess a yield sı ess, i.e. a minimum stress that should be applied for starting the flow. Toothpaste is a familla. on Newtonian fluid which is classified as Bingham plastic (see Fig. 14 (a)). 
Shear Stress $(\mathrm{Pa})$

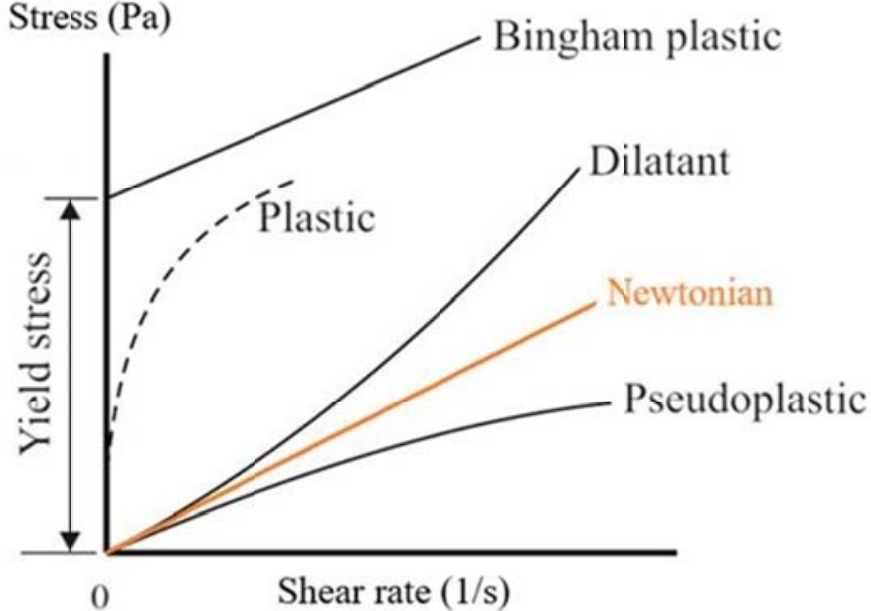

(a)

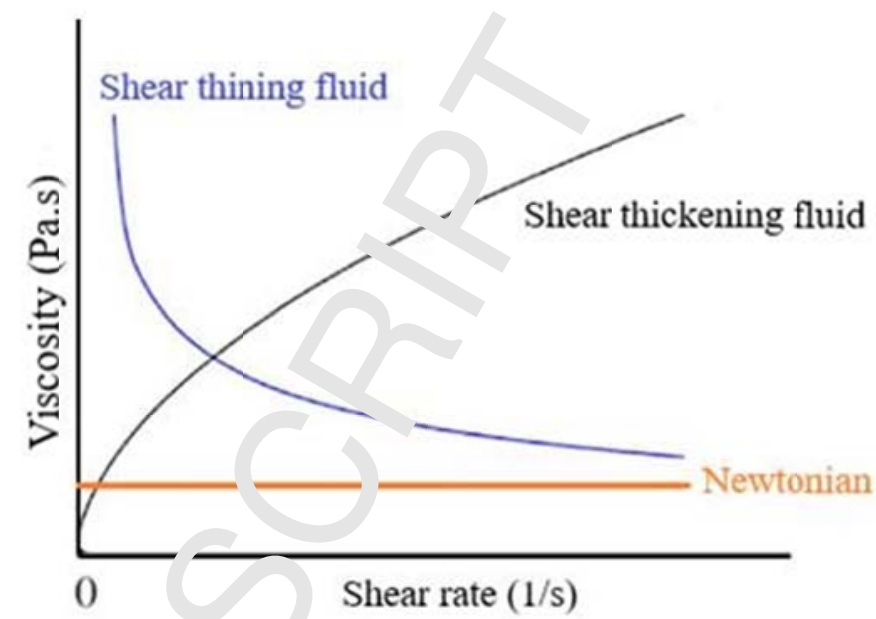

(b)

Figure 14. Newtonian versus non-Newtonian fluid (a) shear st. 'ss $v_{\mathrm{u}}$ : $\mathrm{i}$. ons with shear rate determines the fluid is Newtonian or non-Newtonian (b) Varistinn ? iscosity with shear rate

The viscosity of nanofluids is generally higher tha that , $f$ conventional liquids. With increases in the concentration of nanofluids, they may become non-N w wtonian liquid. Here, a brief review is done on models presented for viscosity of nanofluids basea $n$ a Newtonian behavior or at a fixed shear rate. As for thermal conductivity, first model con idered are issued from suspension theory of large spherical particles. However, they are als un sle to predict viscosity enhancement of nanofluid viscosity with volume fraction.

\subsubsection{Theoretical models}

Einstein presented a model $\mathrm{Jas}^{\prime} \mathrm{d}$ or kinetic theory for mixtures of solids and liquids which is valid for volume fractions less the $1 \%$. . gives the mixture effective viscosity as [65]

$$
\mu_{n f}=\mu_{f}(1+2.5 \phi)
$$

Brinkman propose $\mathrm{t}$ the i llowing model for particles(spherical)- useable up to $4 \%$ particle volume loadings [124]:

$$
\mu_{n f}=\frac{\mu_{f}}{(1-\phi)^{2.5}}
$$


For wider range in nanoparticle content, the model proposed by Krieger and Dr ugherty[125] for monodisperse spherical particles is more suitable. It reads as

$$
\mu_{n f}=\mu_{f}\left(1-\frac{\phi}{\phi_{m}}\right)^{-[\mu] \phi_{m}}
$$

where the intrinsic viscosity $[\mu]=2.5$ for hard spheres and the maximum $\rho$ ac $\because$ o fraction $\phi_{m}$ is about 0.605. This equation reduces to the Maron-Pierce equation with exponent $\left[\mu \mu_{\psi_{1}}=2[126]\right.$.

The equations given in $[125,126]$ were successfully used with nano luids $\mathrm{c}$ different natures in the presence of aggregates[127-129], with the nanoparticle volur \&e fraction being replaced by the aggregate volume fraction.

Masoumi et al. [130] presented a theoretical model for nano rid viscosity as a function of nanoparticle size, nanofluid temperature, volume fraction - f na._particles, nanoparticle density and viscosity of the base fluid as

$$
\mu_{n f}=\mu_{f}+\frac{\rho_{p}}{72 C}\left(\sqrt{\frac{18 \kappa_{B} T}{\pi \rho_{p} d}}\right)\left(\begin{array}{l}
\bar{v} \\
\downarrow-1
\end{array}\right)
$$

where

$$
C=\frac{1}{\mu_{f}}\left[\left(-0.000001133 d_{p}-0.000002771\right) \phi+\left(0.00000009 d_{p}-0.000000393\right)\right]
$$

\subsubsection{Experimental based correlations}

By using experimental data for $\mathrm{A}^{1} \mathrm{O}_{3^{-}}$, ater nanofluids, Singh et al. [131] modified the Einstein model as

$$
\mu_{n f}=\mu_{f}(1+10 \phi)
$$

Corcione [88]presented a. mp; ical correlation for viscosity of nanofluids as a function of nanoparticles diameter $\left.d_{p}\right)$ a $d$ the molecular diameter of base fluid $\left(d_{f}\right)$ as

$$
\frac{\mu_{n f}}{l_{f}}=\frac{1}{1-34.87\left(d_{p} / d_{f}\right)^{-0.3} \phi^{1.03}}
$$

where the mole ${ }^{1} \Delta$ diameter of base fluid can be calculated by knowing the molecular weight of base fluid $(M)$ as 


$$
d_{f}=\left[\frac{6 M}{N \pi \rho_{f, 0}}\right]^{1 / 3}
$$

Here, $N$ is the Avogadro number $\left(6.022140857 \times 10^{23}\right)$ and $\rho_{f, 0}$ is the density f $b$ se fluid calculated at the temperature of $293 \mathrm{~K}$. The above correlation is valid for nanoparticle s. as bu. ween 25 and 200 $\mathrm{nm}$, concentrations between 0.01 and $7.1 \%$, and temperatures between $29 ?$ anc $223 \mathrm{~K}$.

Maiga et al. [87] presented two experimental-based correlations for the v1s - sity of $\mathrm{Al}_{2} \mathrm{O}_{3}$-water and $\mathrm{Al}_{2} \mathrm{O}_{3}$-EG nanofluids, respectively, as

$$
\begin{gathered}
\mu_{n f}=\left(123 \phi^{2}+7.3 \phi+1\right) \mu_{f} \\
\mu_{n f}=\left(306 \phi^{2}-0.19 \phi+1\right) \mu_{f}
\end{gathered}
$$

Rea et al. [132], using regression analysis of experimental $\mathrm{a}_{\mathrm{a}} \sim$ of $\mathrm{V}$ illiams et al.[133], presented the following correlation for $\mathrm{Al}_{2} \mathrm{O}_{3} /$ water nanofluids that is valia $:>\mathrm{r}$ volume fractions less than $6 \%$ and temperatures in the interval $20-80{ }^{\circ} \mathrm{C}$ :

$$
\mu_{n f}(\phi, T)=\mu_{f}(T) \exp \left[4.91 \phi\left(0.20 S^{\prime}-\rho\right)\right]
$$

The water viscosity $\left(\mu_{f}\right)$ can be obtained by the folı ' $:$ - equation:

$$
\mu_{f}=\mu_{r e f}\left(\frac{T}{T_{r e f}}\right)^{n} \operatorname{exn}\left[B\left(\frac{1}{T}-\frac{1}{T_{r e f}}\right)\right]
$$

where $\mathrm{B}=4700, \mathrm{n}=8.9, \mathrm{~T}_{\text {ref }}=295 \mathrm{~K}$.nd $\iota_{\text {ref }}=959 \times 10^{-6} \frac{N . S}{m^{2}}$.

In a combined experimental and numerıal study, Jang et al. [134]noted that the viscosity of nanofluids when the nanofluid flows $1 \mathrm{~h}$ micro and mini tubes depends on the size of the tube. Therefore, they developed the in cein model by including the effect of slip velocity of nanoparticles for nanofluid flow in micro .nd ninı cubes as follows:

$$
\frac{\mu}{\ddots_{f}}=(1+\alpha .5 \phi)\left[1+\eta\left(\frac{d_{p}}{D_{m}}\right)^{-2 \varepsilon} \phi^{2 / 3(\varepsilon+1)}\right]
$$

in which $D_{m}$ is the nner 'iameter of microchannel (or minitube), and $\varepsilon$ and $\eta$ are empirically obtained constants which for $1 . \cap$, nanoparticles are equal to- $1 / 4$ and 280 , respectively.

Ho et al. [90] $p_{1}$ 's ${ }^{r}$ nted the following correlation based on their experimental data for viscosity of alumina/water nanol.uids, where the size of nanoparticles is $33 \mathrm{~nm}$ (valid for $\phi \leq 4 \%$ ): 


$$
\mu_{n f}=\mu_{f}\left(1+4.93 \phi+222.4 \phi^{2}\right)
$$

Sharma et al. [91,92] presented the following correlation for viscosity of rate -based nanofluids containing either metal or metal oxide nanoparticles:

$$
\frac{\mu_{n f}}{\mu_{f}}=\left(1+\frac{\phi}{100}\right)^{11.3}\left(1+\frac{T_{n f}}{70}\right)^{-0.038}\left(1+\frac{d_{p}}{170}\right)^{-0.061}
$$

The above correlation is valid for particle diameters between 20 anc $150 \mathrm{n}$, , nanofluid temperature between 20 and $70{ }^{\circ} \mathrm{C}$, and maximum volume fraction of $4 \%$.

It should be noted that most articles on nanofluids indicate that thu viscr sity increases with $\phi$ and the increase in the particle size and temperature lessens the viscosity.

Here, only a few models are presented as the literature $\urcorner$ n ims topic is abundant. For a more comprehensive overview, the reader can refer to recent " "Iew papers on this specific topic [135-138] and other research papers [139-144].

Contrary to thermal conductivity and viscosity, $r$ nly a few equations are available and useful for density, specific heat capacity and thermal coefficie $t \epsilon_{\iota}$ pansion. They are mainly based on mixing rules.

\subsubsection{Density $\left(\rho_{n f}\right)$}

Density is defined as the ratio of $\mathrm{m} r \mathrm{~s}$ to $\mathrm{vu}$. me of a substance and it is measured in terms of $\mathrm{kg} / \mathrm{m}^{3}$. For a nanofluid with a volume concentrai in of $\phi$, the nanofluid density can be calculated as[145]

$$
\rho_{n f}=\rho_{f}(1-\phi)+\rho_{p} \phi
$$

\subsubsection{Specific heat cay dcity ( $c_{p, n f}$ )}

Specific heat capacitr is a mount of heat that should be given to one kilogram of a substance to increase its temper ture b! 1 degree Kelvin, and it is measured in units of $\mathrm{J} / \mathrm{kg} . \mathrm{K}$. The specific heat capacity of nan flıids can be calculated by [65]

$$
c_{p, n f}=\frac{\rho_{f} c_{p, f}(1-\phi)+\rho_{p} c_{p, p} \phi}{\rho_{n f}}
$$


where $c_{p, f}$ and $c_{p, p}$ are, respectively, the specific heat capacities of base fluid and nan particles.

A common simplified model that is valid when the nanoparticle density is similar wo that $f$ the base

fluid is given by

$$
c_{p, n f}=(1-\phi) c_{p, f}+\phi c_{p, p}
$$

Specific heat capacity significance is highlighted in solar collector appl ati ns where the demand is higher outlet temperature of collector.

\subsubsection{Thermal expansion coefficient $\left(\beta_{n f}\right)$}

The volumetric thermal expansion coefficient for a nanofluid is tne $\mathrm{a}^{r}$ tount of change in nanofluid volume per one degree Kelvin increase in the temperature of the mix are, and it is measured in units of $1 / \mathrm{K}$. The following relation is used to estimate the thermal $\epsilon_{. .2}$ ansivil coefficient[65]:

$$
\beta_{n f}=\frac{(1-\phi)(\rho \beta)_{f}+\phi(\rho \beta)_{p}}{\rho_{n f}}
$$

Again, if the particle and fluid densities are similar, . - mı .

$$
\beta_{n f}=(1-\phi) \beta_{f}+\phi \beta_{p}
$$

Significance of the thermal expansion c efficie $t$ is highlighted in natural and mixed convection problems.

\subsubsection{Surface tension $\left(\gamma_{n f}\right)$}

Surface tension is the amount of force pe $\mathrm{e}_{\mathrm{t}}$ unit length that is consumed for extending the surface of a liquid by overcoming the inter tole ular forces (measured in units of $\mathrm{N} / \mathrm{m}$ ). Surface tension is a crucial parameter in the analysis of teat tran fer phenomena such as pool boiling since it affects surface wettability and bubble grow: $144^{\prime} \mathrm{J}$. On the measurement of surface tension of nanofluids, Ahammed et al. [147] measured th $\_$surfa e tension of graphene/water nanofluids and showed that with increasing the temperatun $\ldots$ nanofluid concentration the surface tension decreases. They developed a correlation as:

$$
\frac{\gamma_{n f}}{\gamma_{f}}=0.493\left(\frac{T_{\infty}}{T_{n f}}\right)^{0.163}\left(\frac{1}{\phi}\right)^{0.0884}
$$


where $\gamma_{n f}$ is the surface tension of nanofluid, $\gamma_{f}$ is the surface tension of base fluid, $z$. $T_{\infty}$ is the ambient temperature. The above relation is valid for temperatures ranging from 10 to $9 v^{\wedge} \mathrm{r}$, and graphene volume fractions between $0.05 \%$ and $0.15 \%$.

Similar trends of nanoparticle effect were also reported in [148] with graphenı nanu. '1ids while opposite effect of nanoparticle content was observed in [98] with different jas : fluias and nanoparticles. In another study, Chinnam et al. [149] presented a nanopartı: size dependent correlation for surface tension with four different nanoparticles, inclur ing $\mathrm{Al}_{2} \mathrm{O}_{3}, \mathrm{ZnO}, \mathrm{TiO}_{2}$ and $\mathrm{SiO}_{2}$, suspended in a mixture of propylene glycol and water $\left(60^{\circ} \cdot 10,{ }^{\prime}\right.$, vater $)$ as follows:

$$
\frac{\gamma_{n f}}{\gamma_{f}}=A_{1} \phi+A_{2}\left(\frac{T_{0}}{T_{n f}}\right)+A_{3}\left(\frac{d_{p}}{d_{f}}\right) \neg A_{1}
$$

where $\mathrm{T}_{0}=299 \mathrm{~K}, \mathrm{~A}_{1}=-1.02219, \mathrm{~A}_{2}=-0.27706, \mathrm{~A}_{3}=0.06$ ¿ $35 \mathrm{~s}$ and $\mathrm{A}_{4}=1.17344$. Also, $d_{f}$ is the molecular diameter of the base fluid. The above relation . u ve used for $303<T_{n f}<343 \mathrm{~K}, 0.5<\phi$ $(\%)<6$ and $15<d_{p}(\mathrm{~nm})<50$.

In a recent review, Estellé et al. [146] highlighter the 1. le of surface tension in thermal engineering applications and investigated the effects of variou parameters such as temperature, surfactant, morphology and concentration of particles, and ba $~$ fluid type on the surface tension of nanofluids. There are some other correlations on the su rau tension of nanofluids which are gathered by Estellé et al. [146].

\subsection{On the importance of thermophys: al r codels in modeling}

A challenge in modeling of nar $\sim$ fluid tıws is the choice and use of suitable models for property determination, specifically for the nal conductivity and viscosity. Figure 15 gives a summary of the effects of nanoparticle cor en ${ }^{+}$ation, nanoparticle size, and nanofluid temperature on the thermal

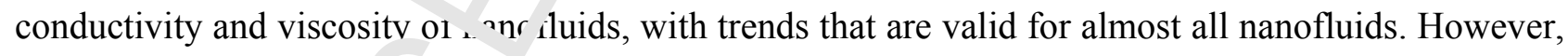
it should be noted that. Ist the rediction of trends by models (or correlations) is not sufficient, but it is vital to have the mi - num uncertainty in the estimation of thermal conductivity and viscosity when the data are compa ad witl experimental (real) data. 

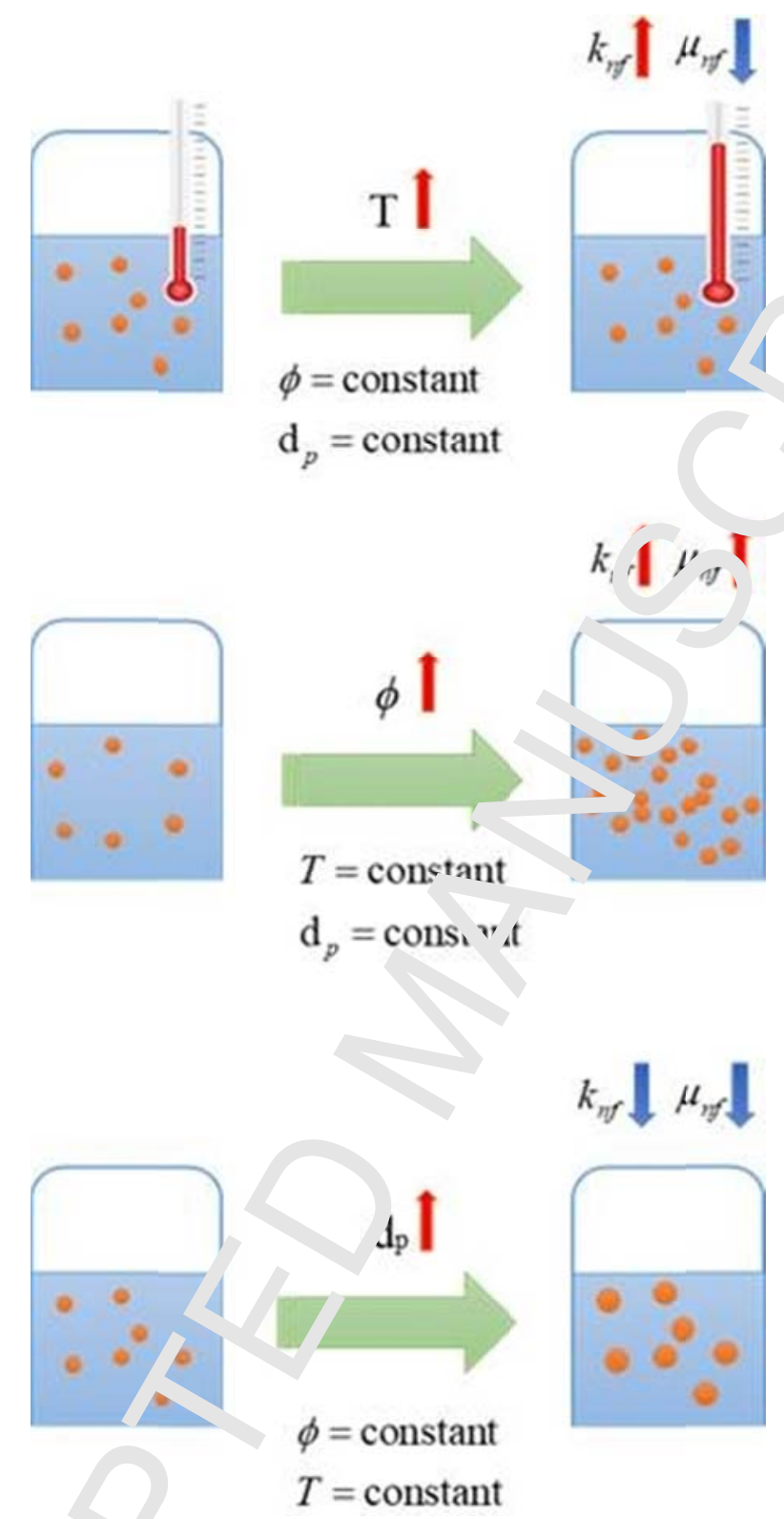

Figure 15. Variations of therm i conan tivity and viscosity with temperature, volume fraction, and nanoparticle size. Note thu' al lost ill of studies on nanofluids have verified the above trend.

In this section, some $\mathrm{wc}^{-\mathrm{k}}$ for ${ }_{A}$ sing on the impact of uncertainties in thermophysical properties on the results of nanofluic mode. $i n g$ are reviewed.

Mahian et al. [150] - d: ated that although using different thermophysical models has a significant effect on the valu s s of heat transfer coefficient in solar collector tubes, there is no significant effect on the outlet temperatur $\_$of solar collectors. Mahian et al. [151] found that using different thermophysical 
models may lead to opposite predictions of entropy generation between two rotati ig cylinders. For natural convection in square and triangular cavities, Mahian et al. [152] noter th. + using classic models for thermophysical properties instead of experimental based correlatir as lay give opposite predictions of heat transfer coefficient. Abu-Nada and Chamkha [153] also s. 'wed that different thermophysical models can give different trends for prediction of $N^{\top}$. selt - umber in natural convection of cavities. In other work, Abu-Nada [154] analyzed the $\mathrm{r}^{\prime} \sim r \dot{i}$ ditferent viscosity and thermal conductivity models on flow and heat transfer characteristics, $\mathrm{f}_{2} \mathrm{O}_{3}$ /water nanofluid natural convection flow in cavities.

Figure 16 highlights this note that using different thermophysical mo may provide opposite trends for heat transfer coefficient variations.

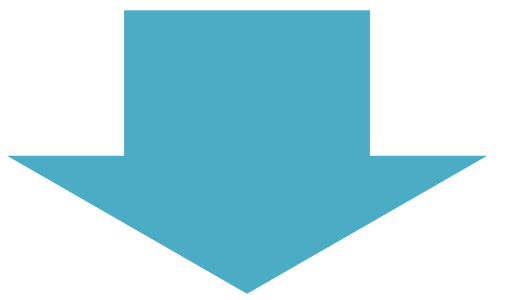

Classic Thermophysical Models

(just consider effect of concentration)

Advanced Thermophysica' Models

(consider effects of nanonartli: size, nanofluid tempera are nd concentration, and $\mathrm{ro}^{+}$)

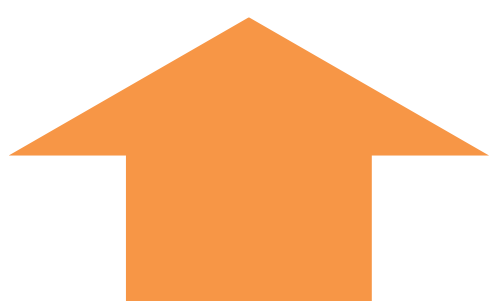

Figure 16. Using different thermo ${ }_{Y}$ hysı.' models may provide opposite trends for heat transfer coefficient variations

\section{Physical moc els fou nanofluid flow and heat transfer}

In analysis of a ther.nal system, one seeks to solve for the velocity and temperature fields and to use these fields to determine integral measures such as heat transfer coefficient, Nusselt number, thermal 
efficiency, and entropy generation rate of the system. In this section, we present the main physical models used to describe the nanofluid flow and heat transfer characteristics. We sey- $\sim$ by reviewing the transport equations for conventional fluids, including continuity, the Navier stc ies equations, and the energy equation, which are used for evaluating the velocity, pressure, and ten ${ }_{r_{r}}$ 'rature fields due to motion of a conventional fluid in an arbitrary geometry. This is followed ', the r tension of for the conservation laws to nanofluid flows.

\subsection{Transport equations for conventional fluids}

In the following equations, $\mathbf{V}$ is the velocity vector, $p$ is th a presst e, $T$ is the temperature, $\mathbf{I}$ is the identity matrix and $\boldsymbol{F}$ is the summation of external body $i$ "ces (due to gravity or magnetic field) discussed in section 2. The transport equations as written below for steady, Newtonian, incompressible flow of a conventional fluid with a d ' los - $\rho_{f}$, a thermal conductivity of $k_{f}$, and a viscosity of $\mu_{f}$. The continuity equation states the : virt nent of mass conservation for the fluid, and is given by:

$$
\nabla \cdot\left(r_{f} \mathbf{v}\right)=0
$$

The momentum equation is obtained by spply'ng ahe Newton's second law applied to an element of a viscous fluid and is given by

$$
\rho_{f}(\mathbf{V} \cdot \nabla) \mathbf{V}=-\nabla r \cdot \nabla \cdot\left[\mu_{f}\left(\nabla \mathbf{V}+\nabla \mathbf{V}^{T}\right)\right]+\nabla \cdot[\lambda(\nabla \cdot \mathbf{V}) \mathbf{I}]+\mathbf{F}
$$

In the above equation $\lambda$ is the se $v_{1} 1$ coefficient of viscosity due to viscous effects of volume changes, and usually can be considered to ' negligible. However, $\lambda \approx-2 \mu_{f} / 3$ is a common approximation for this parameter, when it', nc igr srable. In addition, $\rho_{f}(\nabla \cdot \mathbf{V}) \mathbf{V}$ is the convective term, $-\nabla p$ is the pressure gradient, $\nabla \cdot\left[/_{f}\left(\nabla \mathbf{V}+V \mathbf{V}^{T}\right)\right]$ is the viscous diffusion term where the viscosity is a function of temperature and nonopu.t. ${ }_{-1}$ concentration.

Considering the ( $\mathrm{v}$ ry com non) case of incompressible flow with constant viscosity and density and ignoring the ser a viscosity coefficient $(\lambda)$, the momentum equation can be simplified as follows:

$$
\rho_{f}(\boldsymbol{V} \cdot \nabla \boldsymbol{V})=-\nabla p+\mu_{f} \nabla^{2} \boldsymbol{V}+\boldsymbol{F}
$$

The energy equation that indicates the temperature field $(T)$ can be written as 


$$
\nabla \cdot\left(\rho_{f} c_{p, f} \mathbf{V} T\right)=\nabla \cdot\left(k_{f} \nabla T\right)+\Phi
$$

In the above equation, the left side represents the thermal convection, $\nabla \cdot\left(k_{f} \nabla T\right) \nabla \cdot\left(k_{f} v^{\top}\right)$ is the heat conduction and $\Phi$ is the viscous dissipation function, which arises from the wc $k d$, ne against viscous forces and for a Newtonian incompressible viscous fluid and is given by:

$$
\begin{gathered}
\Phi=\mu_{f}\left\{2\left[\left(\frac{\partial u}{\partial x}\right)^{2}+\left(\frac{\partial v}{\partial y}\right)^{2}+\left(\frac{\partial w}{\partial z}\right)^{2}\right]+\left(\frac{\partial v}{\partial x}+\frac{\partial u}{\partial y}\right)^{2}+\left(\frac{\partial w}{\partial y}+\frac{\partial v}{\partial z}\right)^{2}+\left(\frac{\partial u}{o_{\iota}}+\frac{\iota^{2} \cdot{ }^{2}}{\partial x}\right)^{2}\right\} \\
+\lambda(\nabla \cdot \boldsymbol{V})^{2}
\end{gathered}
$$

It is also worth mentioning that the viscous dissipation energy is usually lgnored with respect to the other energy transfer terms. In the remainder of this section, we ha.. nes ected the viscous dissipation source term on the right side of the energy equation.

The component forms of the above equations are presented :-Appendix A for different coordinate systems.

\subsection{Transport equations for nanofluids}

Considering the transport equations mentionea : ‘ c..ventional liquids, we will develop governing equations associated with different approaches for nanofluid flow modeling in the next sections. In this regard, Fig. 17 presents the main appr saches or nanofluid flow modeling, which can be classified as either single-phase or two-phase app Jaches.

\subsection{Single-phase approaches}

A nanofluid is inherently a tw ,-ph ise fluid (solid-liquid); however, for numerical simulations under certain conditions some apr opria. assumptions can be made to model nanofluids as single-phase fluids.

In single-phase models the go erning equations are solved only for an effective liquid phase. Singlephase based mode', an ue divided into three main approaches including homogenous, thermal dispersion, and Buc ngiorn, models. In the following each model is described in detail. 


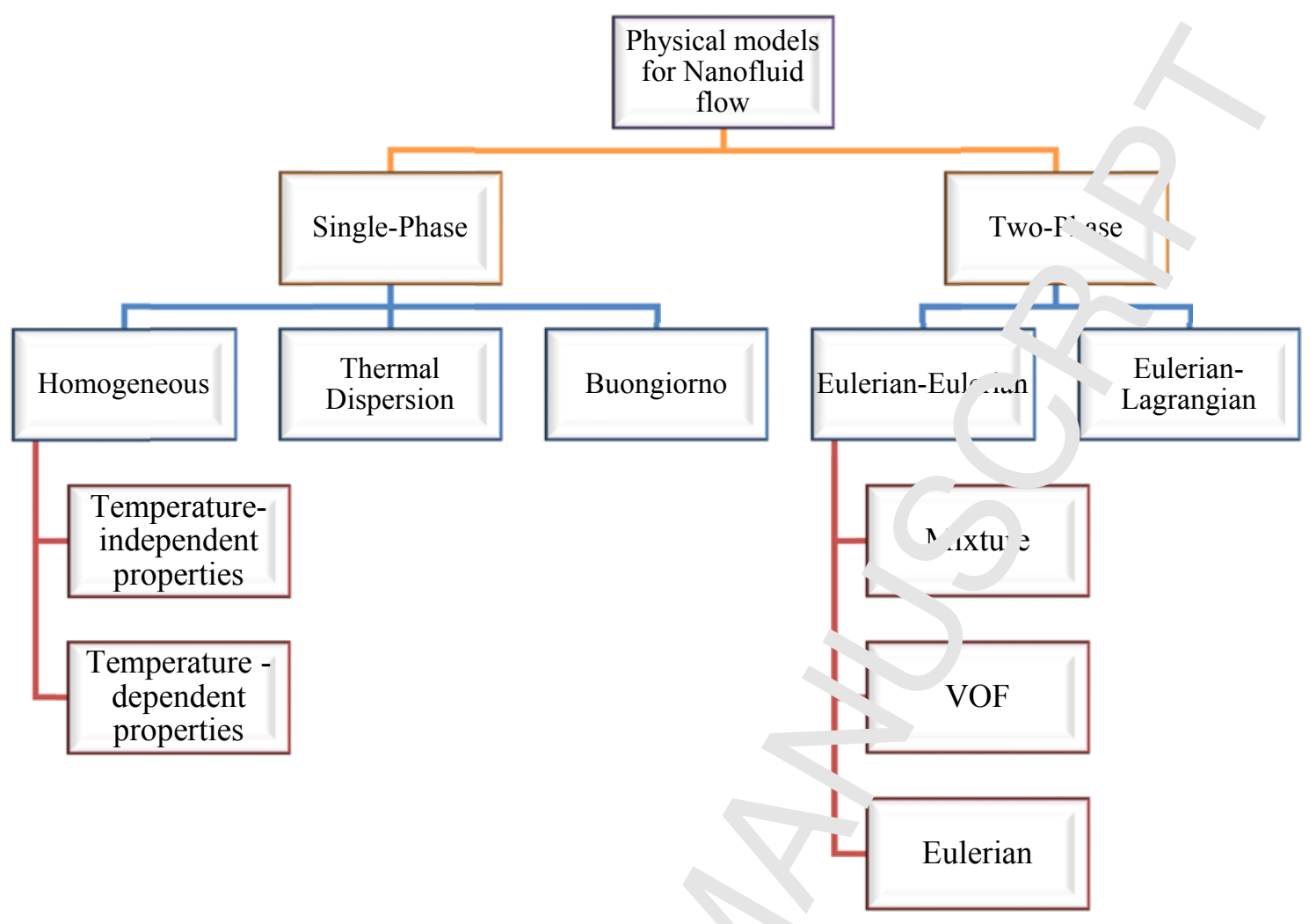

Figure 17. Main approaches ju. nanofluid flow modeling

\subsubsection{Homogenous model}

The simplest approach for mode ing or anofluid flow is the homogenous model. The main assumptions in this model are:

- The slip between the base liqu. ${ }^{1}$ and the nanoparticles is negligible.

- The size of solid particles . - ultr „fine and dispersed uniformly throughout the base fluid.

- Solid and fluid phases are in ydrodynamic and thermal equilibrium.

The above assump ions in ply that any interphase forces and thermal exchange between the fluid and the solid particles can un neglected. Therefore, the mixture of nanoparticles and the base fluid can be considered as a ' ngle-phase continuum with certain effective material properties. Figure 18 schematically describes the single-phase flow approximation for nanofluid flow in a tube. 
Homogenous model
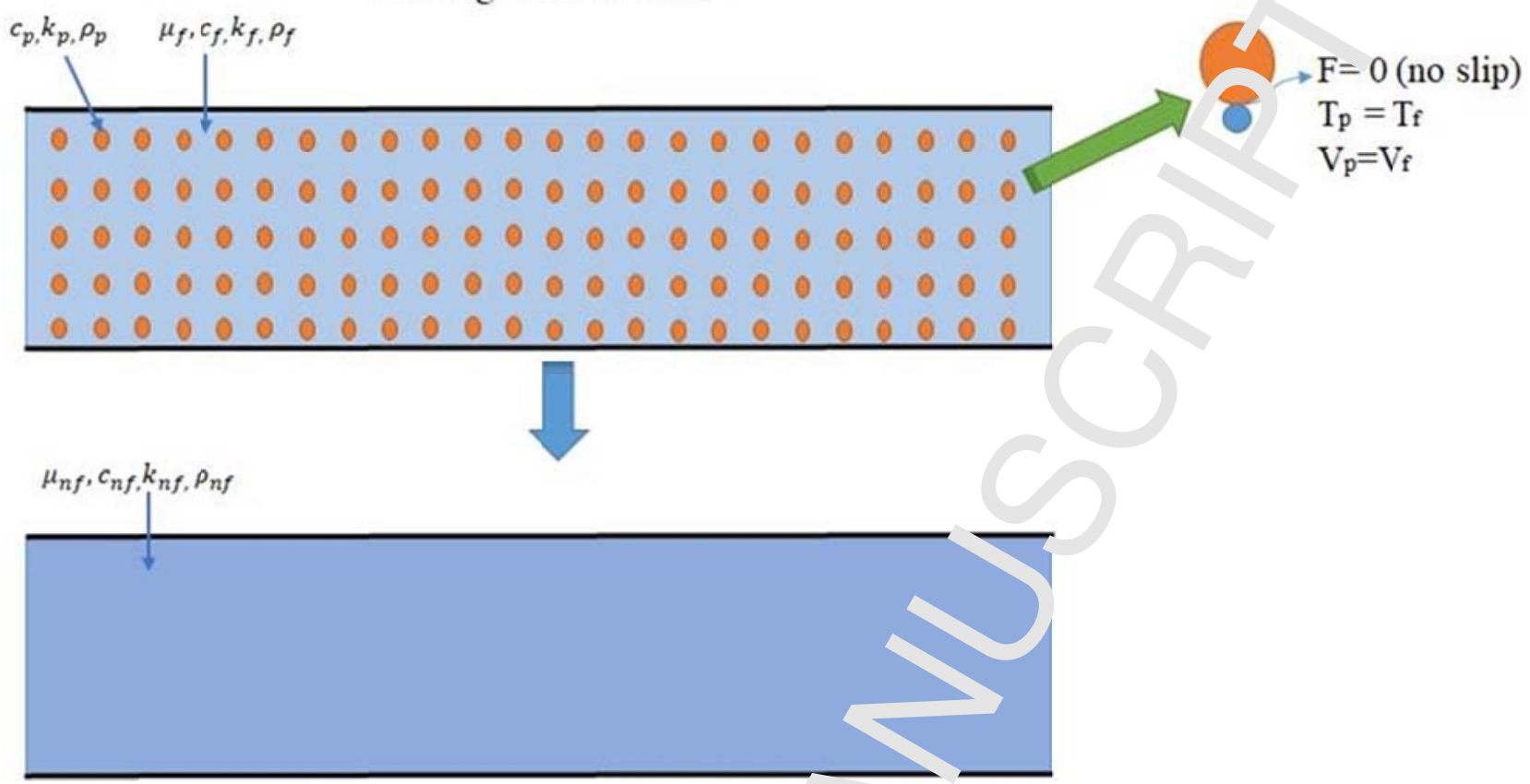

Figure 18. A schematic of the single-phase homogenor 'moa' in which effective properties of the mixture are used to capture the nan nar.icle influence

The transport equations given in part 4.1, can be t.lodified for nanofluids, considering negligible viscous dissipation and $\lambda=0$, and applyin, the $h$ mogenous model as follows:

Continuity equation:

$$
\checkmark\left(,_{n f} \mathbf{V}\right)=0
$$

Momentum equation for a nan flui , with variable viscosity:

$$
\rho_{n f}(\mathbf{V} \cdot 7) \mathbf{V}=-\nabla p+\nabla \cdot\left[\mu_{n f}\left(\nabla \mathbf{V}+\nabla \mathbf{V}^{T}\right)\right]+\mathbf{F}
$$

Regarding the momentum zqua: $\wedge$ presented above, it should be noted that in many studies on nanofluids the viscosity is cons dered to be a function of temperature and concentration. In such a case, it is necessary 0 include $(\nabla \boldsymbol{V})^{T}$ in the viscous shear term.

Energy equation:

$$
\nabla \cdot\left(\rho_{n f} c_{p, n f} \mathbf{V} T\right)=\nabla \cdot\left(k_{n f} \nabla T\right)+\Phi
$$


Selecting suitable models for thermophysical properties of nanofluids (mainly the mal conductivity and viscosity) is the main challenge of this approach. The properties can be cor sia -ed as constant (temperature-independent) or temperature-dependent, depending on th $\mathrm{f}$ oblem and the characteristics of the mixture. A large number of studies have been conducted $\mathrm{re}_{5}$ rding the modeling of the nanofluids by employing the homogenous single-phase model. Herf, sme . tudies that utilized homogenous model are reviewed briefly.

Saha and Paul [155] simulated the turbulent flow of water-based $\mathrm{Al}_{2} \mathrm{O}_{3}$ a nd $\mathrm{TiO}_{2}$ nanofluids in a horizontal tube under constant heat flux boundary condition usir ${ }_{\sigma}$ homıgenous single-phase model and temperature-dependent properties. Demir et al. [156] simula a for ed convection of $\mathrm{Al}_{2} \mathrm{O}_{3}$ and $\mathrm{TiO}_{2}$ based nanofluids in a heat exchanger with double tube strucı 'e. The homogenous single-phase model was used to solve the problem.

Namburu et al. [157] studied the turbulent flow of EG/wa ${ }^{-r}$ nanofluids having $\mathrm{SiO}_{2}, \mathrm{Al}_{2} \mathrm{O}_{3}$, and $\mathrm{CuO}$ nanoparticles in a tube using homogenous single-phas III $^{\prime} \therefore$ ? with temperature-dependent properties. Moraveji et al. [158] investigated the convective : at । ansfer of $\mathrm{Al}_{2} \mathrm{O}_{3} /$ water nanofluid flow as a single-phase liquid in the developing region $c^{f}$ a tu $a$ with constant heat flux. Manca et al. [159] analyzed the forced convection of alumina/water anofluid in a two-dimensional channel under uniform heat flux using homogenous s.ngle-, hase approach and the properties were assumed temperature-independent. Ahmed et al. [16u, st died the laminar convective heat transfer from tube bank under constant wall temperatur co diti ns in cross flow using $\mathrm{Al}_{2} \mathrm{O}_{3}$ nanofluid. Vajjha et al. [161] carried out a numerical ana' ssis of iuid dynamic and heat transfer performance of ethylene glycol/water-based $\mathrm{Al}_{2} \mathrm{O}_{3}$ and $\mathrm{Cu}()$ nano: sids $_{1}$ in the flat tubes of a radiator.

For obtaining Nusselt number $a_{1}$ heat transfer coefficient as indicators of heat transfer enhancement in some simple problems su $\mathrm{n}$ a natural convection in enclosures where the walls have either constant temperature or . . to solve transport equai ins wl ere the nanofluid is assumed as single-phase and homogenous. In such cases the heat trans er enªncement can be estimated simply just by calculating the ratio of nanofluid thermophysical prop ritie co base fluid properties [162]: 


$$
\begin{aligned}
& \frac{N u_{n f}}{N u_{f}}=\left(\frac{k_{n f}}{k_{f}}\right)^{-m}\left(\frac{\mu_{n f}}{\mu_{f}}\right)^{-m}\left(\frac{c_{p, n f}}{c_{p, f}}\right)^{m}\left(\frac{\beta_{n f}}{\beta_{f}}\right)^{m}\left(\frac{\rho_{n f}}{\rho_{f}}\right)^{2 m} \\
& \frac{h_{n f}}{h_{f}}=\left(\frac{k_{n f}}{k_{f}}\right)^{1-m}\left(\frac{\mu_{n f}}{\mu_{f}}\right)^{-m}\left(\frac{c_{p, n f}}{c_{p, f}}\right)^{m}\left(\frac{\beta_{n f}}{\beta_{f}}\right)^{m}\left(\frac{\rho_{n f}}{\rho_{f}}\right)^{2 m}
\end{aligned}
$$

where the value of $m$ depends on the geometry and boundary condition of the ${ }_{r}$ roblem. Standard correlations are then used to determine the Nusselt number and heat tr. nsfer $r$ sefficient of the base fluid. In this way, the computational time reduces significantly.

Figure 19 shows the schematic of different enclosures in which ht. ${ }^{+}$transfer enhancement due to natural convection of a homogenous nanofluid was estimated $\iota_{\jmath}$ ' usir \& Eqs. (126) and (127), and the results were in good agreement with $C F D$ simulation results $\left\lceil 10 \iota^{`\urcorner}\right.$
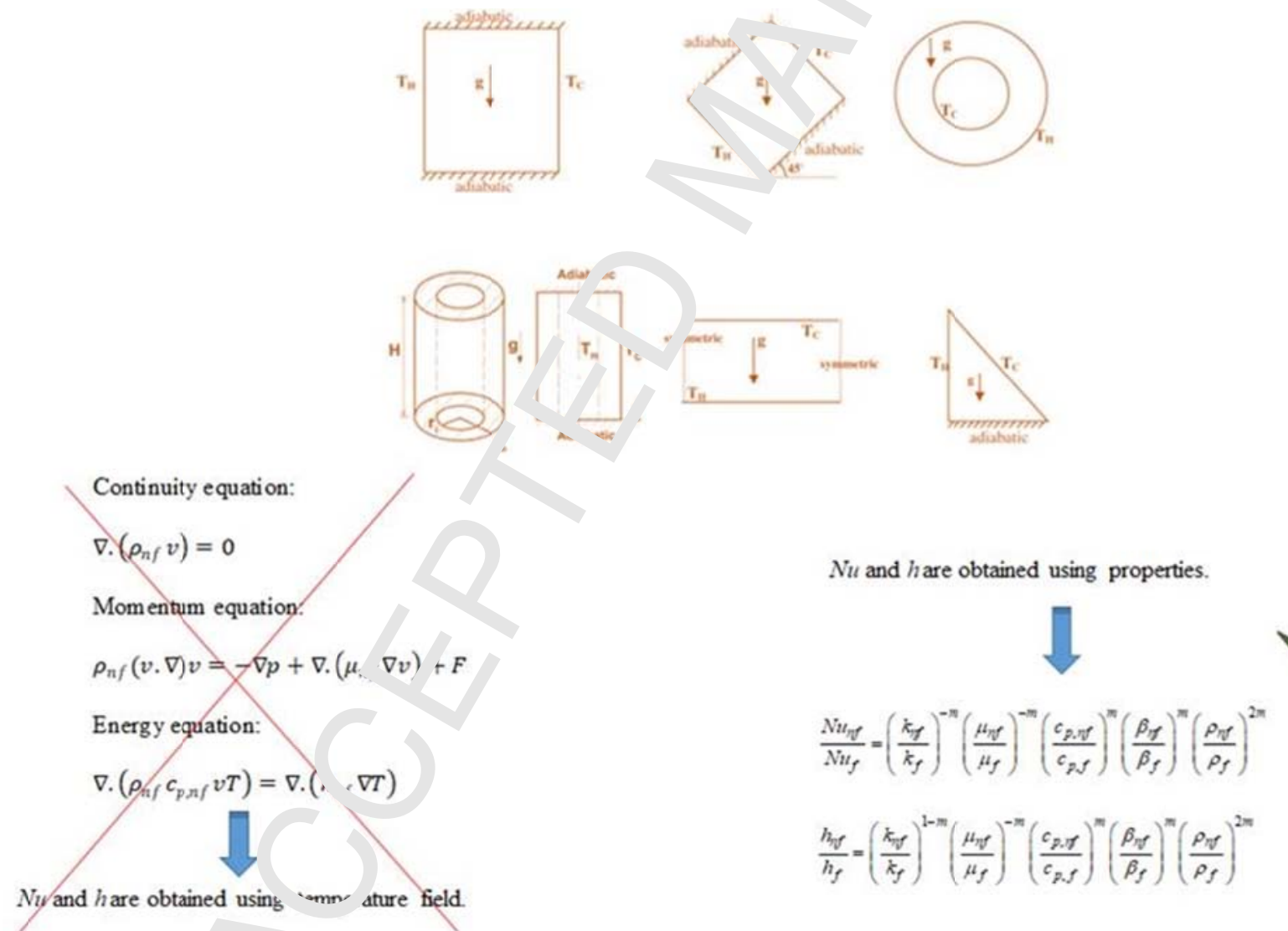

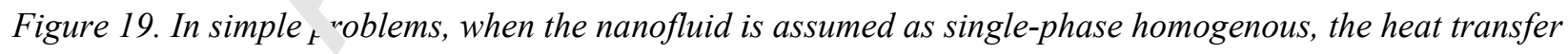
enhancement can be estimated simply by calculating the properties [162] . 


\subsubsection{Thermal dispersion model}

The thermal dispersion model was studied by Xuan and Roetzel [163] by mor fyir $g$ the homogenous single-phase model. Random and irregular motion of nanoparticles raises the - nergy exchange rate in the nanofluid and induces small perturbations in both velocity and tem $r$ eral $\cdots$ The intrinsic phase averages are defined in analogy with turbulence, and are given as:

$$
\begin{aligned}
& \boldsymbol{V}=\overline{\boldsymbol{V}}+\boldsymbol{V}^{\prime} \\
& T=\bar{T}+T^{\prime}
\end{aligned}
$$

where $V^{\prime}$ and $T^{\prime}$ stand for fluctuations in velocity and tempera. tre due to nanoparticle chaotic

movement and mean values are given by $\overline{\boldsymbol{V}}=\frac{1}{\forall_{f}} \int_{\forall_{f}} \boldsymbol{V} d \forall \cdot \cdot d=\frac{1}{\forall_{f}} \int_{\forall_{f}} T d \forall$ where $\forall$ is volume of the working fluid. By neglecting the boundary surface bu veen the fluid and the nanoparticles, the energy equation is written as:

$$
\nabla \cdot\left(\rho_{n f} c_{p, n f} \overline{\mathbf{V}} \bar{T}\right)=\nabla \cdot\left(k_{n f} \nabla \bar{T},-\nabla \cdot 1, \rho_{n f} c_{p, n f} \overline{\mathbf{V}^{\prime} T^{\prime}}\right)
$$

The second term on the right side of the ahove equation demonstrates the perturbation effect of temperature and velocity in enhancing the neat flı $\mathrm{s}$ in the energy equation. The heat flux generated by the thermal dispersion in the nanofluid tow is cumputed as follows:

$$
q_{d}=\rho n f^{\iota_{r}} n f^{\bar{\top}} \cdot \overline{T^{\prime}}=-k_{d} \nabla \bar{T}
$$

where $k_{d}$ is the dispersion therma' con $^{1}{ }^{1}$ Ictivity. The energy equation can be rewritten as:

$$
\nabla \cdot\left(\rho_{n f^{\prime}, n f} \overline{\mathbf{V}} \bar{T}\right)=\nabla \cdot\left[\left(k_{n f}+k_{d}\right) \nabla \bar{T}\right]
$$

In fact, $k_{d}$ reveals the therm $d$ dispe $e_{\star}$ ion contribution to thermal conductivity enhancement.

Xuan and Roetzel [163] $\mathrm{p}_{\boldsymbol{1}}$ ose $\downarrow$ the following model based on a porous media formulation for estimation of dispersion thern. 1 conductivity in nanofluids:

$$
k_{d}=C^{*}\left(\rho c_{p}\right)_{n f} V R
$$

where $R$ is the mins or a tube in which the nanofluid flows and $C^{*}$ is a constant that can be obtained by matching the e, erimental results. 
Khanafer et al. [79] suggested the following relation for estimating the di persion thermal conductivity:

$$
k_{d}=C\left(\rho c_{p}\right)_{n f}|V| d_{p} \phi
$$

In the above equation, the effects of particle size and nanoparticle volume $f_{\ldots} \ldots$ ion $\ldots$ ive been included. Mojarrad et al. [164] proposed a new correlation for determination of di $_{\Delta_{1}}{ }^{-a r}$ ion thermal conductivity by investigating the heat transfer performance of $\mathrm{Al}_{2} \mathrm{O}_{3} /$ water nanoflu' $\lrcorner$ in a ircular tube as follows:

$$
k_{d}=c\left(\rho c_{p}\right)_{n f} \frac{R \phi}{d_{p}}\left(\frac{\partial T}{\partial r}\right)
$$

Although in the above equation, there is no velocity term " $V$ ", in effent alas been considered indirectly by involving a temperature gradient in the relation. It shoul ${ }^{\top}$ be not $d$ that sides in Eq. (135) are not compatible dimensionally.

A more accurate correlation for the dispersion thermal co. ${ }^{\top}{ }^{1} l$ ctivity in radial direction was presented by Bahiraei and Hosseinalipour [165] as:

$$
k_{d}=c\left(\rho c_{p}\right)_{n f}\left(\frac{\partial v_{x}}{\partial r}\right) \psi^{\prime}, ?, R u_{p}
$$

In the above relation, which is presented for fully . 'vesuped flow in a horizontal tube, the nanoparticle distribution has been considered as a functirn of radius within the tube. The approach for obtaining $\phi(r)$ is not presented here, but the ru ders $\mathrm{c} n$ refer to Refs.[165-167] which discuss particle distribution in the tube due to migratio . E E iective parameters that can be considered for migration are Brownian motion, non-uniform shea ral, vir cosity gradient, and thermophoresis.

Several researchers employed the siro ${ }^{\circ}{ }^{-}$-phase thermal dispersion model to simulate nanofluid flow and heat transfer. Kumar et al [1,9] carried out an analysis of flow and thermal field in $\mathrm{Cu} / \mathrm{water}$ nanofluid in a thermally driv^n th -dimensional cavity using a single-phase thermal dispersion model. Özerinç et al. [169] consid red nor ogenous model to simulate the $\mathrm{Al}_{2} \mathrm{O}_{3}$ /water nanofluid inside a tube with various boundary $r$ undition. They found that the estimated values of heat transfer rate with this numerical method are 'ower han experiments. Therefore, the thermal dispersion model was also examined and goor agrec nent with the experimental data was achieved. Heris et al. [170] showed the high ability of ther. 11 spersion model to predict the heat transfer rate due to nanofluids flow in circular tubes by cr.nparing the simulation results against tests data. Ameri et al. [171] investigated the capacity of nano. Yuids for heat transfer enhancement in a metal foam tube where dispersion model was used in the modeling. In this article, the distribution of nanoparticles was assumed to be non- 
uniform. In another research, Bahiraei and Vasefi [172] simulated laminar flow of di ferent nanofluids in a horizontal tube using both the homogenous and thermal dispersion models wh $\bullet$ non-uniform distribution of nanoparticles was included in the dispersion model. They found t at vith an increase in Re and particle loading, the thermal dispersion model is more suitable than homve nous technique for predicting experimental outcomes. Bahiraei and Hosseinalipour [173] util -1 the thermal dispersion model for simulation of convective heat transfer of $\mathrm{TiO}_{2} /$ water nanofluic ${ }^{{ }^{9}} \mathrm{O} v$ in a circular tube using non-uniform concentration distribution. In another study, Bahiraei an' Hoss ${ }^{\wedge}$ inalipour [165] compared the efficacy of thermal dispersion (non-uniform concentration di 'ribut' on) and Euler-Lagrange

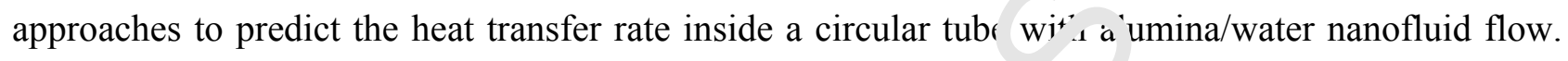
The results revealed that in terms of both computational accura.: an: . .me of calculation, employing the thermal dispersion model is affordable. Akbaridoust ei $1.17 \%$ ] investigated nanofluid flow in helically coiled tubes using both the homogenous and therma ${ }^{\prime}$ ispersion models. The results revealed higher accuracy of thermal dispersion model compared to $\mathrm{s} \cdot$ mogenous model.

\subsubsection{Buongiorno model}

In 2006, Buongiorno [21] proposed a model to $\mathrm{in}_{\mathrm{L}_{\mathrm{Y}}}$ "ove the homogenous single phase and thermal dispersion models. Buongiorno studied the ttec of seven slip mechanisms including: 1- the inertia, 2Brownian diffusion, 3- thermophoresis, $\Lambda_{-} \mathrm{a}_{1}{ }^{2}{ }^{{ }_{1}}{ }_{1} s^{i}$ phoresis, 5- Magnus effect, 6- fluid drainage, and 7gravity and concluded that Browni $1 \mathrm{~d}$ ifus on and thermophoresis are the most important slip mechanisms in nanofluids, in agree aent whi. our arguments in Section 2 of this article. In this model, the effect of the base fluid and the narı particle relative velocity is described more mechanistically than in the thermal dispersior mo el. Based on the findings of Buongiorno [21], a two-component four-equation nonhomoger sous eyxilibrium model for transport equations in nanofluids was developed. By taking into av unt Brownian and the thermophoresis effects, the transport equations in the homogenous model are co. verted to:

Continuity equation:

$$
\nabla \cdot\left(\rho_{n f} \mathbf{V}\right)=0
$$

Momentum equ 'tur

$$
\rho_{n f}(\mathbf{V} \cdot \nabla) \mathbf{V}=-\nabla p+\nabla \cdot\left[\mu_{n f}\left(\nabla \mathbf{V}+\nabla \mathbf{V}^{T}\right)\right]
$$


Energy equation:

$$
\nabla \cdot\left(\rho_{n f} c_{p, n f} \boldsymbol{V T}\right)=\nabla \cdot\left(k_{n f} \nabla T\right)+\left(\rho c_{p}\right)_{p}\left[D_{B} \nabla \phi \cdot \nabla T+D_{T} \frac{\nabla T \cdot \nabla T}{T}\right]
$$

Conservation equation for the nanoparticles:

$$
\mathbf{V} \cdot \nabla \phi=\nabla \cdot\left[D_{B} \nabla \phi+D_{T} \nabla T / T\right]
$$

In Eq. (139) Brownian diffusion and thermophoresis (or thermal : :ffus $\eta$ coefficient) can be expressed respectively as:

$$
\begin{gathered}
D_{B}=\frac{k_{B} T}{3 \pi \mu_{n f} d_{p}} \\
D_{T}=0.26 \frac{k_{n f}}{2 k_{n f}+k_{p}} \frac{\mu_{n f}}{\rho_{n f}} \phi
\end{gathered}
$$

where $k_{B}$ is the Boltzmann constant.

Several studies have been conducted regarding the analysis $\iota^{c}$ convection heat transfer of nanofluids based on Buongiorno's model. Sheikholeslami et al. $[1,5]$ studied heat and mass transfer characteristic of unsteady nanofluid flow between parallel pla's 'nder the effect of a magnetic field using Buongiorno model. Sheikholeslami and Rokni [n] arplied the Buongiorno model for evaluation of nanofluid flow and radiation and melting heat transfer over a stretching plate in the presence of a magnetic field. Garoosi et al. [177] carrie out a 1 umerical simulation of natural convection of waterbased $\mathrm{Cu}, \mathrm{Al}_{2} \mathrm{O}_{3}$, and $\mathrm{TiO}_{2}$ nanofluid $\mathrm{n}$ a $2 \mathrm{~L}$ cavity having several pairs of heater and coolers by Buongiorno approach. In other sturies, Ga sosi et al. [177,178] analyzed natural convection and mixed convection of $\mathrm{Al}_{2} \mathrm{O}_{3}$ /water lás. fluid in a square cavity using Buongiorno model. Malvandi et al. [179] studied the fully-deve' spc 1 mixed convective through an annulus with vertical position. The employed approach for the moa : $1 \mathrm{~g}$ of nanofluid included the modified two-component four-equation non-homogeneous equilib' um molel. Moreover, Malvandi and Ganji [180] evaluated the mixed convective heat transfer of als ina/water nanofluid inside a vertical microchannel and modified Buongiorno's model wi s empl'yed which fully accounted for the effect of the nanoparticle migration. Shehzad et al. [181, carried out the study of convective heat transfer of nanofluid in a wavy channel and the mathematic. ${ }^{1}$ forr ulation was processed utilizing the Buongiorno's model. Sheremet and Pop [182] investiga 'd w steady-state natural convection in a square porous enclosure filled by a nanofluid using Buc giorno model considering the Brownian diffusion and thermophoresis effects. 


\subsection{Two-phase approaches}

Nanofluids act like two-phase fluids. In the two-phase approaches, the base $\operatorname{lig}^{\cdot} \cdot d$ and nanoparticles are modeled as two individual phases with different velocities and possible iff srent temperatures, such that the particles may move relative to the base fluid (the relative velocity of particles through a fluid is called the particle slip velocity, although it is not related to the $10-5 . \mathrm{p}$ - oundary condition). Although the two-phase approaches may get more realistic results $\%$ con dering the movement between the fluid and nanoparticles, but they require longer simulat on tim s for simulation and the models are more complex. The two-phase approaches are categori ed in two general groups, known as Eulerian-Eulerian and Eulerian-Lagrangian models. In the Eularian-Eu ${ }^{1}$.rian approach, both the base fluid and the nanoparticles phases are considered as interasting co. tinua. On the other hand, in the Eulerian-Lagrangian approach, the base fluid is considerea - be $\ldots$ continuum while the nanoparticles are considered as a discrete phase. (Eulerian-Lagrang: . approach sometimes also called discretephase approach). In the Eulerian-Lagrangian approac , the natn of nanoparticles is determined [183]. Figure 20 illustrates the concept of Eulerian-Euleri` $\eta$ anc Eulerian-Lagrangian approaches, where blue arrows indicates the fluid path and red arrow sho v we particle path. For a given problem, the Eulerian-Lagrangian generally takes a longer t11. to perform the computation than the EulerianEulerian approach, but the Eulerian-Lagrar jim results are more accurate and the model can be used for a much broader range of problems.

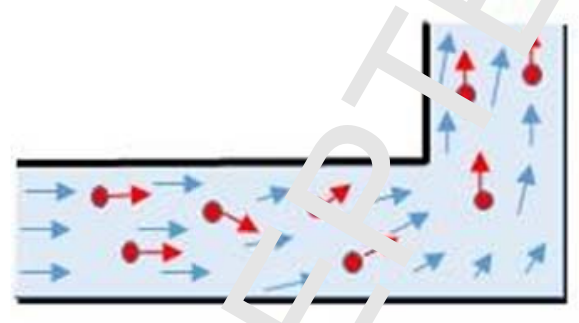

Eule ian-La rangian

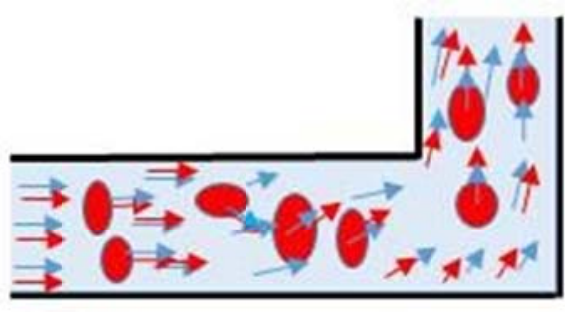

Eulerian-Eulerian

Figure 20. Concept , Eule: 'xn-Lagrangian and Eulerian-Eulerian approaches, blue arrow indicates fluid path and red arrow shows, ${ }^{\text {rrticl }}$, path. 


\subsubsection{Eullerian-Eulerian}

Eulerian-Eulerian models (e.g. two-phase approaches) cannot be assigned for tr? $\mathrm{k}_{\mathrm{L}}$ - the trajectory of suspended particles in fluid [184]. These models can be categorized as (i) v slu te of fluid (VOF), (ii) mixture, and (iii) Eulerian models. Among them, mixture model is mos nopular as will be discussed.

\subsubsection{Volume of fluid (VOF) model}

The VOF model is applicable for multiphase immiscible fluid regimes. wh th the interface between fluid phases should be tracked. Some applications of this model a e s; . nu ttion of bubble growth, free surface flows, stratified flows and liquid-gas surface tracking pru ${ }^{1}{ }^{2} m_{1 s}$. This model is not most convenient for application to nanofluid flows, since nanopartı ' ${ }^{\prime}$ s are iypically much smaller than the computational cell and are dispersed in the base fluid. Therefor for nanofluid-flow simulations (typically assuming well-mixed nanoparticle-dispersion) $\mathrm{el}_{\mathrm{L}_{-}}$loying the VOF method would be inappropriate, compared to the faster/cheaper Euler-El' ${ }^{\circ} r$ ' $\rho \mu_{\text {r }}$ oach (provided that the nanoparticles are $<100 \mathrm{~nm}$ ). However, in cases of nanoparticle-str $n$ in, ction into a moving fluid, VOF approach would be the way to simulate the two-fluid mix $; n$ rnc ss. Nevertheless, some authors used the VOF for nanofluid flow simulations and therefore it is incluled here for completeness.

The VOF model has been used to track the noparticle concentration by solving the continuity equation for the base fluid over the dor ain $\omega^{-}$ct $\lambda$ dy using a single set of Navier-Stokes equations for the base liquid and particle phases $: d$ cerr ine the values of velocity shared by the two phases. Similarly, a shared temperature is $c$ tained tıom a single energy equation [185].

The continuity equation can be evnressed ds:

$$
\nabla \cdot\left(\phi_{q} \rho_{q} \mathbf{V}_{q}\right)=0
$$

where $q$ indicates the phasf. Fo ex rmple, $q$ is equal to 1 for the base fluid and 2 for the nanoparticles. The summation of the $\mathrm{vr}^{1}$...me 1 . tions of phases is one, or $\sum_{q=1}^{n} \phi_{q}=1$.

The momentum and en argy e ${ }_{1}$ uations are identical to the momentum and energy equations for the single-phase homo', enous model.

Naphon and Nakhaintr $[86]$ considered the flow and heat transfer of $\mathrm{TiO}_{2}$ nanofluid through minichannel heat sit's. 1 IIC model predictions compared well with experimental results, indicating the effectiveness of the VOF model. Akbari et al. [185] compared the accuracy of single-phase and the three Eulerian-Eulerian models in the estimation of experimental data for combined convection and 
laminar flow. First, they pointed out that the three two-phase models provide simi'ar predictions of experimental data and are more accurate than single-phase. Second, among two- hav models, VOF was suggested since it needed the lowest computational time.

Rashidi et al. [187] compared two-phase and single-phase approaches for the $\mathrm{Cu} /$, ater nanofluid flow in a channel with wavy walls. The single-phase model and three different tr - phas model predictions (VOF, mixture, and Eulerian) were studied, and their results were ' ${ }^{\prime}$. pared. Davarnejad and Jamshidzadeh [188] analyzed turbulent heat transfer behavior of the $\mathrm{NgU/w}$ ?ter nanofluid in a circular tube using three individual models including single phase, VOF and $m_{\text {. }}$ vture It was concluded that the VOF model and the mixture model were more accurate than the $\sin ^{r}, \mathrm{e}$-, hase model for heat transfer prediction.

\subsubsection{Mixture model}

The mixture model can be implemented for flows with two or more phases, considering $n$ as the number of phases. In this model it is assumed that each; a lase has different velocity and concentration fields. The mixture model accounts for the coupıng 'etween fluid phases and is applicable for dispersed particulate fluids with low interphas coupling, low concentration bubbly flows and separators. Hence, this model has been emp ${ }^{1} \because$ ad for nanofluid flows when a nanoparticle phase exists and nanoparticles closely track the fluid $\mathrm{f}_{\mathbf{r}} \cdot \mathrm{w}$. Thr base fluid influences the nanoparticles via drag and turbulence, while the nanoparticles $:$ fec the base fluid via reduction in mean momentum and enhanced turbulence dissipation. $A^{1}, 0,1, \mathbf{s h}^{\prime}$ uld be noted that the model requires less run time and CPU usage than some competing $\mathrm{noi}^{-1} \mathrm{~s}$ and it sounds precise for a large group of multi-phase flow problems [26]. The mixture $\mathrm{m}$ Jde, in contrast to the VOF model, can model the interpenetrating phases and allows the phaser to . ve different velocities. As can be seen in the following equations, the mass conservation and en $\mathrm{gy}_{\text {g }}$ quations of the mixture model are similar to those of the singlephase model. However . me mon entum equation in the mixture model has an additional term to take into account the relativ velor ty (also known as drift velocity) between the phases. In addition, the volume fraction eq ation : also solved for the secondary phases:

Continuity equation.

$$
\nabla \cdot\left(\rho_{m} \mathbf{V}_{m}\right)=0
$$

Momentum equation: 


$$
\rho_{m}\left(\mathbf{V}_{m} \cdot \nabla\right) \mathbf{V}_{m}=-\nabla p+\nabla \cdot\left[\mu_{m}\left(\nabla \mathbf{V}_{m}+\nabla \mathbf{V}_{m}^{T}\right)\right]+\nabla \cdot\left(\sum_{k=1}^{n} \phi_{k} \rho_{k} \mathbf{V}_{d r, k} \mathbf{V}_{d r, k}\right)+F
$$

Energy equation:

$$
\nabla \cdot \sum_{k=1}^{n}\left(\phi_{k} \rho_{k} c_{p, k} \mathbf{V}_{k} T_{k}\right)=\nabla \cdot\left(\sum_{k=1}^{n} k_{e f f} \nabla T_{k}\right)
$$

Volume fraction equation for a secondary phase $p$ :

$$
\nabla \cdot\left(\phi_{p} \rho_{p} \mathbf{V}_{m}\right)=-\nabla \cdot\left(\phi_{p} \rho_{p} \mathbf{V}_{d r, p}\right)
$$

where $\mathbf{V}_{d r, k}$ is the drift velocity of phase $k$, which is defined as $\mathbf{V}_{a} \cdot \boldsymbol{r}=\mathbf{V}-\mathbf{V}_{m}$. The mixture velocity $V_{m}$ is given by:

$$
\boldsymbol{V}_{m}=\frac{\sum_{k=1}^{n} \phi_{k} \rho_{k} \boldsymbol{V}_{k}}{\rho_{m}}
$$

The other mixture properties such as $\rho_{m}, \mu_{m}$ and $k_{\text {eff }} \operatorname{con}^{1} \gamma$ be evaluated using the common singlephase correlations. The following relations could provı ${ }^{1} e$ ? ppıopriate estimations, as well:

$$
\begin{gathered}
\rho_{m}=\sum_{k=1}^{n} \phi_{k} \rho_{k} \\
\mu_{m}=\sum_{n=1}^{n} \phi_{k}{ }^{\prime} l_{k} \\
k_{e f f}=\sum_{k=1}^{n} \phi\left(k_{k}+k_{t}\right)
\end{gathered}
$$

where $k_{t}$ represents the turbulent therma sonductivity.

The above mentioned equatic as z.e not closed and another equation is required to find the drift velocity:

$$
\boldsymbol{V}_{a_{i}, p}=\boldsymbol{V}_{p q}-\sum_{k=1}^{n} \frac{\phi_{k} \rho_{k}}{\rho_{m}} \boldsymbol{V}_{q k}
$$

where $\boldsymbol{V}_{p q}$ is the slir. elocicy between the secondary phase $p$ and the primary phase $q$, and for laminar flow can be modelt ${ }^{\mathcal{A}}$ usins the correlation proposed by Manninen et al.[189]:

$$
\boldsymbol{V}_{p q}=\boldsymbol{V}_{p}-\boldsymbol{V}_{q}=\frac{\tau_{p}}{f_{\text {drag }}} \frac{\left(\rho_{p}-\rho_{m}\right)}{\rho_{p}} \boldsymbol{a}
$$


In the above equation, $\tau_{p}, \boldsymbol{a}$ and $f_{d r a g}$ are the particle relaxation time, acceleratio vector and drag function, respectively. $\tau_{p}$ and $\boldsymbol{a}$ are defined by:

$$
\begin{gathered}
\tau_{p}=\frac{\rho_{p} d_{p}^{2}}{18 \mu_{q}} \\
\boldsymbol{a}=\boldsymbol{g}-\left(\boldsymbol{V}_{m} \cdot \nabla\right) \boldsymbol{V}_{m}
\end{gathered}
$$

Schiller and Naumann [190] suggested the following relation for $f_{\text {drag }}$ :

$$
f_{\text {drag }}=\left\{\begin{array}{cc}
1+0.15 R e^{0.687} & R e \leq 1000 \\
0.0183 R e & R e>1000
\end{array}\right.
$$

Other scientists have also suggested some correlations to accu nt $f_{\text {arag }}$, and among them the work done by Morsi and Alexander [191] can be mentioned.

Most of the numerical nanofluid studies in the literature have _ nployed the mixture model because it is relatively accurate and requires less computational pow $\sim r$ than many other methods. Labib et al. [192] studied the convective heat transfer coefficie $+r_{2} \mathrm{ll}_{2} \mathrm{O}_{3} /$ water-ethylene glycol and $\mathrm{Al}_{2} \mathrm{O}_{3}$ CNTs/water nanofluids flowing in horizontal circh is tul a using the mixture model. Safikhani et al. [193] used the mixture model to calculate $\cdots$ ht. t transfer coefficient and pressure drop of $\mathrm{Al}_{2} \mathrm{O}_{3}$ /water nanofluid flow in horizontal flat tubes. The same configuration has been examined for water-based $\mathrm{Al}_{2} \mathrm{O}_{3}$ and $\mathrm{Al}_{2} \mathrm{O}_{3}-\mathrm{Cu}$ hybrid nanoi tids by Moghadassi et al. [194]. Mirmasoumi and Behzadmehr [195] evaluated laminar fl $r \mathrm{w}(\mathrm{h} \cdot \mathrm{v} f \mathfrak{d}$ convection) of a nanofluid composed of water and $\mathrm{Al}_{2} \mathrm{O}_{3}$ nanoparticles flowing in a tub $\mathrm{us} \mathrm{ng}$ ' wo-phase mixture model. A two-phase mixture model was employed by Goodarzi et al. r 96] to investigate mixed convection of $\mathrm{Cu}$ /water nanofluids in a rectangular shallow enclosure. Sirvashi and Jamali [197] analyzed entropy generation due to turbulent flow of $\mathrm{TiO}_{2}$ /water dispersion. in .n annulus by using two-phase mixture model. In another study on the application of two-pha,e r-ixture models, Siavashi et al., in three different works [198-200], investigated nanofluid flow nsi e a porous tube and annulus [198]. Toosi and Siavashi [201] employed the two-phas 2 mixtı re model for numerical simulation of $\mathrm{Cu}$-water nanofluid flow inside a partially porous cav $\div$. Ingioubi Emami et al.[202] used the mixture model to simulate two-phase $\mathrm{Cu}$-water nanofluic flow ir side an inclined cavity with different hot wall configurations. Siavashi et al. [203] used the .... model to solve $\mathrm{Cu}$-water nanofluid natural convection inside an enclosure using porous fins. Later, Siavashi and Rostami [204] employed a two-phase mixture model to model nonNewtonian nanofluid in a porous annulus and presented the mixture equations in the non-dimensional 
form. Moraveji and Ardehali [205] performed CFD modeling of laminar forced cor vection on $\mathrm{Al}_{2} \mathrm{O}_{3}$ nanofluid in minichannel heat sink by four individual models of single phase, VOF, ni- ture, Eulerian. It was concluded that the best approach for modeling was the mixture mr der. considering both accuracy and computational speed. Shariat et al. [206] evaluated the particle s1s impact on laminar mixed convection of $\mathrm{Al}_{2} \mathrm{O}_{3}$ /water nanofluids in a duct with elliptic cross .. tion mploying the two phase mixture model. Recently, Maghsoudi and Siavashi [207] employe. a' wo-phase mixture model for simulating mixed convection of nanofluid flow in a porous lid-c iven avity to find the optimal pore size configuration.

\subsubsection{Eulerian model}

The Eulerian approach is the most complex multi-phase mo del $u_{-}-\mathrm{o}$ the strong coupling between the phases. The Eulerian model supports volume fraction va' _...ming ng from dilute to dense, and can also be used with low to high values of particulate mas lnadin $_{5}$. In the Eulerian model, the transport equations are solved independently for each phase, ${ }^{\prime}$ 'ich is the primary difference between the Eulerian approach and the mixture model[208]. The ${ }_{1} \mathrm{re}_{\mathrm{u}}$ ure and interphase exchange coefficients are utilized for coupling of the equations, depending $n$ une type of fluid phases (such as fluid-fluid or fluid-solid). This model is appropriate for similation of bubbly flows, fluidized beds and particulate flows, and can also be implemented for na. nfluid low simulation.

Ignoring the interphase mass transfer the governing equations of a particulate laminar flow (fluidsolid) for the Eulerian model is presf ateu ' $f$ sllows.

The continuity equation for phase $1 \mathrm{ca}$. he expressed as:

$$
\nabla \cdot\left(\phi_{q} \rho_{q} \mathbf{V}_{q}\right)=0
$$

Obviously, the summation c volunı fraction of all the $n$ phases is $\sum_{q=1}^{n} \phi_{q}=1$.

The momentum equation is $y^{\cdot}$ ' en ', $y$ :

$\rho_{q} \phi_{q}\left(\mathbf{V}_{q} \cdot \nabla\right) \mathbf{V}_{q}=-\phi_{q} \nabla_{l}+\nabla \cdot\left[/{ }_{q} \phi_{q}\left(\nabla \mathbf{V}_{q}+\nabla \mathbf{V}_{q}^{T}\right)\right]+\sum_{p=1}^{n} R_{p q}+\left(F+F_{L}+F_{w l}+F_{A}\right)_{q}$

where $\boldsymbol{R}_{p q}$ is the $\mathrm{i}$ teracti $\mathrm{n}$ force between the fluid phase $q$ and the particulate phase $p, \boldsymbol{F}, \boldsymbol{F}_{L}, \boldsymbol{F}_{w l}$ and $\boldsymbol{F}_{A}$ are bod.,$\because{ }^{\circ}$ wall lubrication and virtual mass forces, respectively. It should be noted other forces may be pul $d$ in the above equation as explained in section 2 . The interaction force $\boldsymbol{R}_{p q}$ is calculated by: 


$$
\boldsymbol{R}_{p q}=\sum_{p=1}^{n} K_{p q}\left(\boldsymbol{V}_{p}-\boldsymbol{V}_{q}\right)
$$

in which, $K_{p q}$ is the interphase momentum exchange coefficient.

For a nanofluid flow, $K_{p q}$ should be defined according to the relation prop sec ${ }^{\cdots}:$ Wen and $\mathrm{Yu}$ [209] for dilute fluid-solid flows.

$$
K_{p q}=\frac{3}{4} C_{d} \frac{\phi_{p} \phi_{q} \rho_{q}\left|\boldsymbol{V}_{p}-\boldsymbol{V}_{q}\right|}{d_{p}} \phi_{q}^{-265}
$$

The drag coefficient, $C_{d}$, is given by:

$$
C_{D}=\frac{24\left(1+0.15\left(\phi_{q} R e_{p}\right)^{0.678)}\right.}{\phi_{q} R e_{p}}
$$

where $R e_{p}=\rho_{q} d_{p}\left|\boldsymbol{V}_{p}-\boldsymbol{V}_{q}\right| / \mu_{q}$.

The lift force, $\boldsymbol{F}_{L}$, acting on the particles is caused $\because$ the velocity gradient inside the primary phase $q$,

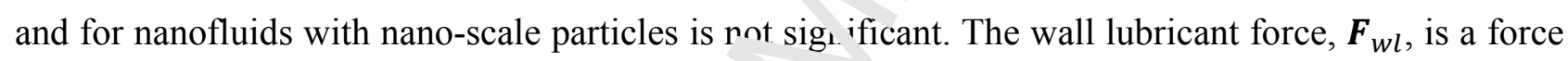
acting on the secondary phase $p$ and takes it away $\mathrm{n} \cdot \mathrm{m}$ the wall. This force is important in gas-liquid flows and has negligible effect on nanofl a 1 h w w . The virtual mass force, $\boldsymbol{F}_{A}$, should be included when the particulate phase $p$ accelerates $w_{2}$ h re pect to the fluid phase $q$. This force should not be respected for steady flows or nanoflu $1 \mathrm{fl}$, ws since the nanoparticle density is much greater than the base fluid density [210].

The energy equation is given by:

$$
\nabla \cdot\left(\phi_{q} \rho_{q} c_{p, q} \mathbf{V}_{q} T_{q}\right)=\vee\left({ }_{q} \nabla T_{q}\right)-\left[\mu_{q} \phi_{q}\left(\nabla \mathbf{V}_{q}+\nabla \mathbf{V}_{q}^{T}\right)\right]: \nabla \mathbf{V}_{q}+\sum_{p=1}^{n} Q_{p q}
$$

where $Q_{p q}=h_{p q}\left(T_{p}-T_{q}\right):$ th ; interphase heat exchange coefficient. $h_{p q}$ is the heat transfer coefficeint between ph ises al 1 can be specified as a constant value or be defined as a function of Nusselt number, $h_{p} \longrightarrow\left(\cup_{\sim_{q}} \varphi_{q} \phi_{p} N u_{p}\right) / d_{p}^{2} . N u_{p}$ can also be calculated from the Ranz and Marshall [211] model as:

$$
N u_{p}=2+0.6 \operatorname{Re}_{p}^{0.5} \operatorname{Pr}^{0.333}
$$

$\operatorname{Pr}$ is the Prandtl number of phase $q$ and is given by: 


$$
\operatorname{Pr}=\frac{c_{p, q} \mu_{q}}{k_{q}}
$$

As can be seen in the above mentioned equations, the Eulerian model considers ${ }^{\cdots} \cdot{ }^{\circ}$ erent temperatures for the particulate and fluid phases. Concerning nanofluid flows, nanoparticle $h$, ve very small size and could be considered to be in local thermal equilibrium with the base fluid. 1 sance, the solution of an additional energy equation for nanoparticles is not beneficial and doe, no $1 \mathrm{n}_{\mathrm{r}_{\mathrm{r}}}$ rove the simulation accuracy. Anyway, the Eulerian method has been used in a few inv sigatı os of nanofluid flows. Kalteh et al. [210] studied the prediction of $\mathrm{Cu} /$ water nanofluid ${ }^{7} \mathrm{ow}$ ir an isothermally heated microchannel using the Eulerian approach. Using the same appro ch, $\boldsymbol{D}-\mathrm{o}$, et al. [212] studied the flow and heat transfer of bio-nanofluid in circular channel. Predictic 'ns show' $\mathrm{d}$ that the difference between results of Eulerian approach and experiments was only $7 \%$ while it vas $35 \%$ for single phase model. Lotfi et al. [213] examined alumina nanofluid flow with : arceu convection in horizontal conduits employing two-phase Eulerian model. It was shown thw ootn single-phase and the Eulerian models underestimate the $\mathrm{Nu}$ number. Hejazian et al. [214 r r formed a comparative study of Euler and mixture models for nanofluid turbulent flow insi ${ }^{\mathrm{j}} \mathrm{e}, \mathrm{a}$, orizontal conduit. They found that the two models almost showed the same results. Sabaghan et c'. L 15] employed Eulerian two-phase model for the simulation of $\mathrm{TiO}_{2}$ nanofluid flow in micro 'annels with six longitudinal vortex generators. Ebrahimnia-Bajestan et al.[216] analyzer in heat transfer characteristics of water-based $\mathrm{TiO}_{2}$ nanofluid for application in solar heat exc. 'nger using single-phase, Eulerian-Eulerian, and mixture models. They revealed that Eulerian $\mathrm{r}$ ode is not able to predict the experimental data accurately, so they modified the common mixtr e mu. ${ }^{\circ}$. Behroyan et al. [217] compared the predictions of numerical models to evaluate turb.lenı ' $\mathrm{n}$ (gravity influence was neglected) of $\mathrm{Cu} /$ water nanofluid in a pipe under fixed value of heat flus and illustrated that the Eulerian model gives inaccurate results.

\subsubsection{Eulerian-Lagrangia 1}

In the Eulerian-Lagrar gian $\mathrm{m}$ del, the fluid phase is considered as a continuum medium by solving the momentum equ unns and the particle phase is modeled by solving for individual particle motion using the particle $\mathrm{n}$ tion $\uparrow$ eeory in the Lagrangian reference frame [208]. The influence of particles in the fluid is intr un as source terms in the momentum and energy equations. The dispersed phase can exchange mor antum, mass, and energy with the fluid phase. Our presentation of the EulerianLagrangian method makes the common assumption that the dispersed second phase occupies a small 
volume fraction; however, the model can be easily extended to dense flows. A limita ion of this model is that it requires high memory and computational time. Not only are the number $c$. na. nparticles very large, but the small value of Stokes number for nanoparticle flows introduces $\mathrm{r}\lrcorner \mathrm{m}$. rical stiffness that necessitates use of small time steps, which is a stability requirement in explicit nu. erical methods and necessary for accurate computation of particle drift in implicit numeric - neth $1 \mathrm{~s}$. The governing equations are written for the base liquid as follows.

Continuity equation:

$$
\nabla \cdot\left(\rho_{f} \mathbf{V}_{f}\right)=0
$$

Momentum equation:

$$
\rho_{f}\left(\mathbf{V}_{f} \cdot \nabla\right) \mathbf{V}_{f}=-\nabla p+\nabla \cdot\left[\mu_{f}\left(\nabla \mathbf{V}_{f}+\nabla \mathbf{V}_{f}^{T}\right)\right]+\curvearrowright
$$

Energy equation:

$$
\nabla \cdot\left(\rho_{f} c_{p, f} \mathbf{V}_{f} T_{f}\right)=\nabla \cdot\left(k_{f} \nabla T_{j} \cdot r \nu_{e}\right.
$$

where $S_{m}$ is the momentum source term vector which $u_{\mu_{-}}$- nants the momentum transfer between fluid and particles, and $S_{e}$ is the energy source term $r$ hich 2 ives the energy transfer between fluid and particles. These source terms can be computed bv ave nging over a grid cell as

$$
\begin{gathered}
\boldsymbol{S}_{m}=\frac{1}{\delta} \sum_{p=1}^{n_{p}} m_{p} \boldsymbol{F}_{\boldsymbol{p}} \\
S_{e}=\frac{1}{\sigma_{\cdot}} \sum_{p}^{n_{p}} r^{\prime} c_{p} c_{p, p} \frac{d T_{p}}{d t}
\end{gathered}
$$

where the subscript $p$ refers to par.rcle,, and $\boldsymbol{F}_{\boldsymbol{p}}$ respectively denote mass of the particle and the total force per unit mass of the part' de : cting on the fluid, $\delta V$ represents the grid cell volume and $n_{p}$ is the number of solid particles $w^{i}$. nin a -11 volume. The particle force on the fluid (i.e. F) in Eq. (168) is the negative of the sum of is vari us hydrodynamic forces acting on the particle, including Brownian motion, drag, Saffman 'nd M: onus lift, pressure gradient force, thermophoretic force, and virtual mass force, which were discus. ad iv. Section 2.

The energy equatic 1 for th : particle can be written as

$$
m_{p} c_{p, p} \frac{d T_{p}}{d t}=N u_{p} \pi d_{p} k_{f}\left(T_{f}-T_{p}\right)
$$

where the Nusselt, umber $N u_{p}$ for heat transfer to the particle was evaluated using the Ranz and Marshall correlation presented in Eq. (163). 
Particle trajectory motion equation could also be written as follows to find the particl position:

$$
m_{p} \frac{d \boldsymbol{V}_{p}}{d t}=\boldsymbol{F}_{p}
$$

A large number of research studies have been conducted to simulate nanofluiu ${ }^{f_{C}} \mathcal{N}$ and heat transfer using the Eulerian-Lagrangian approach. Due to the limitation on the number c. narcicles that can be handled, this method is particularly well suited for modeling the microm sch alc of a nanofluid flow field for problems on a scale of up to about one million particles.

Rashidi et al. [218] employed Eulerian- Lagrangian approach (two-vay co ıpling) to simulate fluid flow and heat transfer inside a channel equipped with two square oloclrs where the working fluid was a mixture of water and alumina particles (sizes between $30 \mathrm{~nm}$ ^na $u .5 \mu \mathrm{n}$ and a concentration of 1\%). They used ANSYS-Fluent software to solve the problem. Figure $\_1$ displays the algorithm for the CFD simulation of the mixture fluid flow in the channel usiı, Euı Ian-Lagrangian approach. 


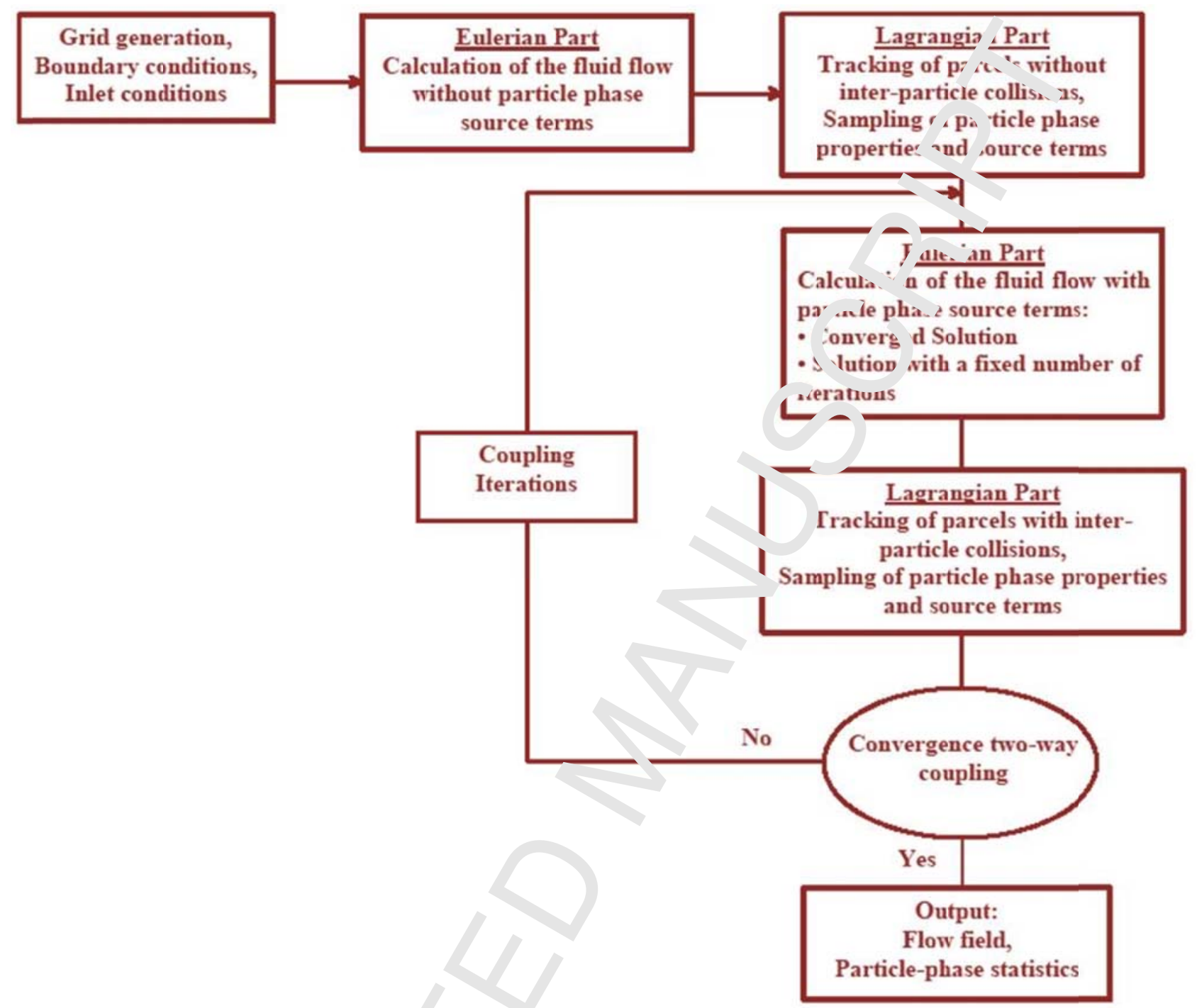

Figure 21. Numerical procedure to $s^{1}{ }^{1}$ ve mixture flow using Eulerian-Lagrangian approach [218].

He et al. [219] studied $\mathrm{TiO}_{2}$ r anoı id flow(laminar regime) through a tube using both the single phase method and the Eulerian-L 'or ngir a method. The numerical results were compared with experimental data and reasonably gor $a$ agreement was achieved. Bianco et al. [220] used the same model to study the laminar forced conv ction of $\mathrm{Al}_{2} \mathrm{O}_{3}$ nanofluid in a tube and mentioned that there is a difference of $11 \%$ comparing th : heat ansfer coefficient resulting of the Eulerian-Lagrangian model and that of the single phase mo: 1 sahiraei [221] used two-phase Eulerian-Lagrangian method to evaluate the effects of adding $\mathrm{J} \mathrm{J}$ nanoparticles to pure water on the rate of heat transfer in a straight tube. It was found that the Euler- Lagrange method gives more accurate predictions of heat transfer rate compared to the single-phase homogenous approach. In another study, Bahiraei [222] focused on particle 
migration effects on heat transfer rate through simulations done by Eulerian-Lagra igian simulation. By employing the Eulerian-Lagrangian approach, Kumar and Puranik [223, s. nulated forced convection heat transfer of $\mathrm{Al}_{2} \mathrm{O}_{3}, \mathrm{TiO}_{2}$ and $\mathrm{Cu}$ nanoparticles dispersed in water anc ir fully-developed turbulent flow in a circular tube where its surface was heated uniformly. Th " results were also compared with the single phase model. The comparison indicated the the :lerian-Lagrangian

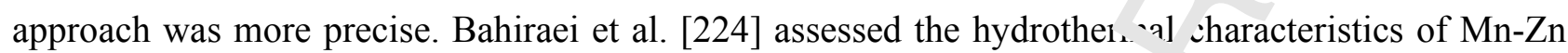
ferrite nanofluid under a magnetic field using the Eulerian-Lagrangi a methoc. Ghasemi et al. [225] evaluated the laminar forced convection heat transfer of the $\mathrm{w} \cdot \mathrm{er}-\mathrm{b}$ sed nanofluid inside a minichannel heat sink using the Eulerian-Eulerian two-phase $\mathrm{mr}$ del $1 \mathrm{t}$ ir simulation results were in excellent agreement with the experimental data and the maxin. $m c_{\ldots}$. ration from experimental data was 5\%. Sonawane et al. [226] employed Eulerian-Lagı ngian 1 lodel to study turbulent forced convection flow using nanofluids at low concentration and $1 \mathrm{~s}$ n nrecision was confirmed. Rostami and Abbassi [227] studied conjugate heat transfer of nanoflu. ${ }^{\top}$ in wavy microchannels using EulerianLagrangian approach. The results again showed a goo ags _...ent with experimental results.

In earlier studies on the Eulerian-Lagrangian app in $h t_{t}$ " nanofluid flow and heat transfer analysis, the boundary conditions for nanoparticle interartinn with the wall are not typically discussed. In some cases reflection boundary conditions were assumeu, while not explicitly stated. The influence of particle-wall boundary condition on the anol id flows was studied by Rashidi et al. [228] and Bovand et al. [229] where both reflectir $n$ an. ${ }^{\prime}+{ }^{\prime}$ ' pping boundary conditions were used. It was shown that the particle-wall boundary conc tio' sis nificantly affects the near-wall flow behavior of the nanofluids and the nanoparticle cor entrativis.

\subsection{Comparison of differer $\_$app. naches}

In the majority of numeriral su 'r ies on the flow and convective heat transfer of nanofluids, the slip velocity between nano, article and the bulk fluid is neglected and accordingly the effective singlephase model is usf $\mathrm{d}$. However, it is clear that the corresponding results of this model have some errors, such as una restir ation of the heat transfer rate, which has been widely reported for studies using the homo $\varepsilon^{\text {ant }}$.n model. These errors, of course, can be significantly reduced by employing the temperature-depen, nt thermophysical properties. Regarding the more advanced models like the twophase, Buongiorno, and thermal dispersion, the thermal dispersion model is more preferred due to its 
lower computational time. However, two-phase models provide most reliable resul's by considering major influential parameters including thermophoresis, Brownian motion, and sli, vu' rcity concepts. Two-phase models comprise of different approaches, including the Euleri $n-1$ dlerian, EulerianLagrangian, mixture, and VOF models. The Eulerian-Lagrangian and mixture mu als are mostly used in heat transfer studies of nanofluids compared to VOF and Eulerian mode', - ince 'here are numerous investigations indicating the superiority of these models regarding the $\mathrm{n}^{\mathrm{r}}$ Jvision of more precise results. It should be noted that the CPU and memory requirement is $\mathrm{m}$.ch hir her, and consequently the computational time is much longer in the Eulerian-Lagrangian model c e to equirement of computing the trajectories of each particle, which affects its range of app' cat' $\mathrm{s}$ ' or numerical investigations.

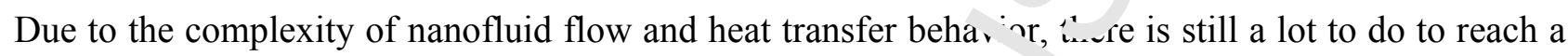
final conclusion on the precision of different models for diffe. 'nt cas's.

Table 3 provides a collection of comparative studies in $w$ : ich the results of different modeling approaches have been compared with experimental data : $>r$ nanofluid flow in a circular tube under various regimes and boundary conditions.

As can be seen, there are inconsistencies among th suı of the researchers and it is not clear at this time which model is the best choice. However, the for in wing notes can be considered when modeling approaches are compared with each other and with $\mathrm{e}_{\boldsymbol{\lambda}_{\mathrm{r}}}$ erimental data:

- Using temperature-dependent the mop. ${ }_{\text {. }}$ sical relations for properties may increase the accuracy of the homogenous mor'el su thr. the deviation with experimental data decreases.

- Two-phase models involve mc e nysical phenomena compared to the single-phase homogenous model, so nat ally their corresponding results should be closer to experimental data. In some cases that has bet.l reported results of the homogenous model are closer to experimental data; hov. 've', we note that both the experimental data and the numerical model are subject to uns stanties of various types. Some factors such as sedimentation of nanoparticles, aggreg ion of nanoparticles and uncertainties in measurements which are not considered in tl e matt smatical modeling may be the reason for high deviation of two-phase model results $\varkappa_{0}$ on _...perimental data.

Ta. 'e J a mparison of various nanofluid modeling approaches in a circular tube. 


\begin{tabular}{|c|c|c|c|c|}
\hline $\begin{array}{c}\text { Kumar and Puranik } \\
{[223]}\end{array}$ & $\begin{array}{c}\mathrm{Al}_{2} \mathrm{O}_{3} / \text { water } \\
\mathrm{TiO}_{2} / \text { water } \\
\mathrm{Cu} / \text { water }\end{array}$ & $\begin{array}{l}\text { Fully developed turbulent } \\
\text { forced convection }\end{array}$ & $\begin{array}{l}\text { Constant wall } \\
\text { heat flux }\end{array}$ & $\begin{array}{l}\text { Euler-Lagrange }>\text { Homogenous for } \\
\text { lower } \mathrm{r} \text { "'me fractions }(<0.5 \%) \\
\text { Homogenous - Juler-Lagrange for } \\
\text { hig' er v lume fractions }(>0.5 \%)\end{array}$ \\
\hline $\begin{array}{l}\text { Moraveji and } \\
\text { Esmaeili [230] }\end{array}$ & $\mathrm{Al}_{2} \mathrm{O}_{3} /$ water & $\begin{array}{l}\text { Fully developed laminar } \\
\text { forced convection }\end{array}$ & $\begin{array}{l}\text { Constant wall } \\
\text { heat flux }\end{array}$ & Eun agrange $>$ Homogenous \\
\hline Bianco et al. [220] & $\mathrm{Al}_{2} \mathrm{O}_{3} /$ water & $\begin{array}{l}\text { Developing laminar forced } \\
\text { convection }\end{array}$ & $\begin{array}{l}\text { Constant wall } \\
\text { heat flux }\end{array}$ & E ıler-Lagrange $>$ Homogenous \\
\hline $\begin{array}{c}\text { Moghadassi et al. } \\
\text { [194] }\end{array}$ & $\begin{array}{c}\mathrm{Al}_{2} \mathrm{O}_{3} / \text { water } \\
\mathrm{Al}_{2} \mathrm{O}_{3}-\mathrm{Cu} / \text { water }\end{array}$ & $\begin{array}{l}\text { Fully developed laminar } \\
\text { forced convection }\end{array}$ & $\begin{array}{l}\text { Constant wa'1 } \\
\text { heat flux }\end{array}$ & Mixt \\
\hline Akbari et al. [185] & $\mathrm{Al}_{2} \mathrm{O}_{3} /$ water & $\begin{array}{l}\text { Fully developed laminar } \\
\text { mixed convection }\end{array}$ & $\begin{array}{l}\text { Constant wa } \\
\text { heat ilux }\end{array}$ & $\begin{array}{l}\text {-Eulerian, Mixture, VOF }> \\
\text { Homogenous -VOF is the best since } \\
\text { lowest running expense }\end{array}$ \\
\hline Akbari & $\begin{array}{c}\mathrm{Al}_{2} \mathrm{O}_{3} / \text { water } \\
\mathrm{Cu} / \text { water }\end{array}$ & $\begin{array}{l}\text { Fully developed turbulent } \\
\text { forced convection }\end{array}$ & $\begin{array}{l}\text { Consta. wall } \\
\text { heat flu: }\end{array}$ & $\begin{array}{c}\text { Homogenous }>\text { Eulerian, Mixture, } \\
\text { VOF }\end{array}$ \\
\hline $\begin{array}{l}\text { Albojamal and Vafai } \\
\qquad[232]\end{array}$ & $\mathrm{Al}_{2} \mathrm{O}_{3} /$ water & $\begin{array}{l}\text { Developing laminar forced } \\
\text { convection }\end{array}$ & $\begin{array}{l}\text { `ทnsta... wall } \\
\text { hor. flux }\end{array}$ & $\begin{array}{c}\text { Homogenous }>\text { Euler-Lagrange }> \\
\text { Mixture }\end{array}$ \\
\hline $\begin{array}{c}\text { Bahiraei and } \\
\text { Hosseinalipour [165] }\end{array}$ & $\mathrm{Al}_{2} \mathrm{O}_{3} /$ water & $\begin{array}{l}\text { Developing laminar forced } \\
\text { convection }\end{array}$ & $\begin{array}{l}\text { Tnstant wall } \\
\text { heat flux }\end{array}$ & $\begin{array}{c}\text { Euler-Lagrange }>\text { Dispersion }> \\
\text { Homogenous }\end{array}$ \\
\hline Bahiraei [233] & $\mathrm{CuO} /$ water & $\begin{array}{l}\text { Developing laminar force } \\
\text { convection }\end{array}$ & $\begin{array}{l}\text { Constant wall } \\
\text { heat flux }\end{array}$ & Euler-Lagrange $>$ Homogenous \\
\hline Göktepe et al. [234] & $\mathrm{Al}_{2} \mathrm{O}_{3} /$ water & $\begin{array}{l}\text { Developing laminar fol ed } \\
\text { convection }\end{array}$ & $\begin{array}{l}\text { Constant wall } \\
\text { heat flux }\end{array}$ & $\begin{array}{c}\text { Eulerian }>\text { Mixture }>\text { Dispersion }> \\
\text { Homogenous }\end{array}$ \\
\hline $\begin{array}{c}\text { Hejazian and } \\
\text { Moraveji [235] }\end{array}$ & $\mathrm{TiO}_{2} /$ water & $\begin{array}{l}\text { Developing turbulent } \\
\text { forcer' conve, tion }\end{array}$ & $\begin{array}{l}\text { Constant wall } \\
\text { temperature }\end{array}$ & Mixture $>$ Homogenous \\
\hline Hejazian et al. [236] & $\mathrm{TiO}_{2} /$ water & $\begin{array}{l}\text { Develop. } \checkmark \text { tur' ulent } \\
\text { fo ced zonvection }\end{array}$ & $\begin{array}{l}\text { Constant wall } \\
\text { heat flux }\end{array}$ & $\begin{array}{c}\text { VOF }>\text { Mixture }>\text { Homogenous }> \\
\text { Eulerian }\end{array}$ \\
\hline $\begin{array}{c}\text { Haghshenas Fard et } \\
\text { al. [237] }\end{array}$ & $\begin{array}{c}\mathrm{Al}_{2} \mathrm{O}_{3} / \text { water } \\
\mathrm{Cu} / \text { water } \\
\mathrm{CuO} / \text { water }\end{array}$ & $\begin{array}{l}\text { Deve }_{1}{ }^{-i} \text { g la ninar forced } \\
\text { con, ection }\end{array}$ & $\begin{array}{l}\text { Constant wall } \\
\text { temperature }\end{array}$ & Euler-Lagrange $>$ Homogenous \\
\hline Lotfi et al. [213] & $\mathrm{Al}_{2} \mathrm{O}_{3} /$ water & $\begin{array}{l}\text { Teveloping turbulent } \\
\text { forced convection }\end{array}$ & $\begin{array}{l}\text { Constant wall } \\
\text { heat flux }\end{array}$ & Mixture $>$ Homogenous, Eulerian \\
\hline Mojarrad et al. [164] & $\mathrm{Al}_{2} \mathrm{O}_{3} /$ wate & $\begin{array}{l}\text { Uu loping laminar forced } \\
\text { convection }\end{array}$ & $\begin{array}{l}\text { Constant wall } \\
\text { temperature }\end{array}$ & $\begin{array}{c}\text { Dispersion }>\text { Euler-Lagrange }> \\
\text { Mixture }>\text { Homogenous }\end{array}$ \\
\hline
\end{tabular}

\section{Conclusions}

It has been more than two decades since the discovery of nanofluids. As a type of colloidal suspension, nanofluids are typically employed as heat transfer fluids due to their higher thermal 
conductivity compared conventional liquids. Many numerical studies have been don on nanofluids in recent years. In this paper, a comprehensive review (in two parts) was presenter $\mathrm{co}$, ring the latest developments in modeling of nanofluid flows in different passages and flow $r$ g11 es, with emphasis on the underlying physical aspects and three dimensional studies. In the first $\sec _{i} \cdot \eta$ of Part I, general descriptions of nanofluids, their applications and the research trends in this $\cdots 1 \mathrm{~d} w \bullet \cdot 2$ described. In the second section, various forces and physical phenomena in nanofluid flc s vere reviewed. Next, the main models for properties of nanofluids, including thermal cond stıvitr, viscosity, density, heat capacity, and thermal expansion coefficient, were presented. In the - vurth section, physical models that are used for prediction of flow and heat transfer characteris ics $\int \mathrm{I}$ lanofluids were reviewed by dividing these models into two general groups: single-phas anc .wo-phase approaches. In the following, the main points of Part I are summarized:

- In nanofluid flow, forces including Brownian $\mathrm{mr}$..... ...u thermophoretic force play a primary role in balancing the drag force to determine narticle s.iotion and bulk fluid heat transfer rate. Other forces, such as lift and Basset history ice, are negligible because of the ultrafine particle sizes.

- Typically the two-phase approaches give - cults that are generally closer to experimental data than the single-phase model. Uncertrintv in the experimental studies, due to phenomena such as sedimentation of nanoparticles, -ggreg: tion of particles, and errors in measurements, must also be considered when using a d data to evaluate the accuracy of computational models.

- In geometrically simple pror ems Mr $\mathrm{A}$ as natural convection in cavities, instead of employing

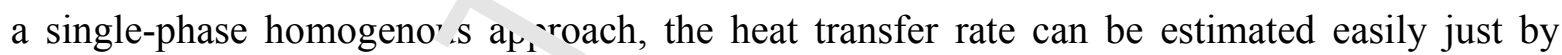
using accurate models $f{ }^{\prime} \mathrm{f}$ th : nanofluid thermophysical properties in the classical correlations.

- Review of the literat re $\mathrm{su}_{-}-{ }^{-}$ests that the two-phase mixture model is the easiest approach to apply among two-p ' 'os' mo iels.

- In a single-phas apprnacı, using novel models for thermophysical properties instead of classic models can redu $\cdot$ erre $\mathrm{s}$ in predictions of heat and mass flow characteristics.

- Adding nar spartic es and using nanoparticles with a smaller size usually provides higher heat transfer enhain.....ent rates.

In Part II, the prim. ry CFD approaches for solution of the governing equations given in Part I will be investigated. Next, three dimensional studies on modeling of nanofluid flow will be reviewed by 
indicating the flow regime and geometry, the nanofluid type, the method of solution and the physical phenomena responsible for heat transfer enhancement.

\section{Acknowledgment}

Omid Mahian and Somchai Wongwises acknowledge the support prov" «d by ine "Research Chair Grant” National Science and Technology Development Agency (NST, 'A), th: Thailand Research Fund (TRF), and King Mongkut's University of Technology Thor ouri $\therefore$ ough the "KMUTT 55

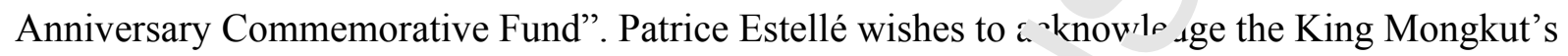
University of Technology Thonburi as well as Professor Worowises or support during his visit as an invited Professor from the university. R.A.T. would like to ac-nowredge support financial support from the Australian Research Council in the form of a D $\iota_{\llcorner}$'nvery Early Career Researcher Award (DE160100131). The authors also would like to thank nom Lian-Ping Wang from Southern University of Science and Technology, China and $\Gamma \cdot$ Eh. ₹n Ebrahimnia Bajestan from University of Calgary, Canada for their valuable comments. 


\section{Appendix A: Extended form of transport equations}

Extended form of governing equations for conventional fluids in different coordincie sy ${ }^{\star} \bullet \mathrm{ms}$ shown in Fig. 1.A.

\section{Cartesian / Rectangular Coordinates $P(x, y, z)$}

\section{Cylindrical Coordinates $P(x, \theta, z)$ $\mathrm{X}=\mathrm{r} \operatorname{Cos} \theta$ \\ $\mathrm{Y}=\mathrm{r} \operatorname{Sin} \theta$ $Z=z$}

\section{Spherical Coordinates $P(r, \theta, \varphi)$ $\mathrm{X}=\mathrm{r} \operatorname{Sin} \theta \operatorname{Cos} \varphi$ \\ $\mathrm{Y}=\mathrm{r} \operatorname{Sin} \Theta \operatorname{Sin} \varphi$ $\mathrm{Z}=\mathrm{z} \operatorname{Cos} \theta$}
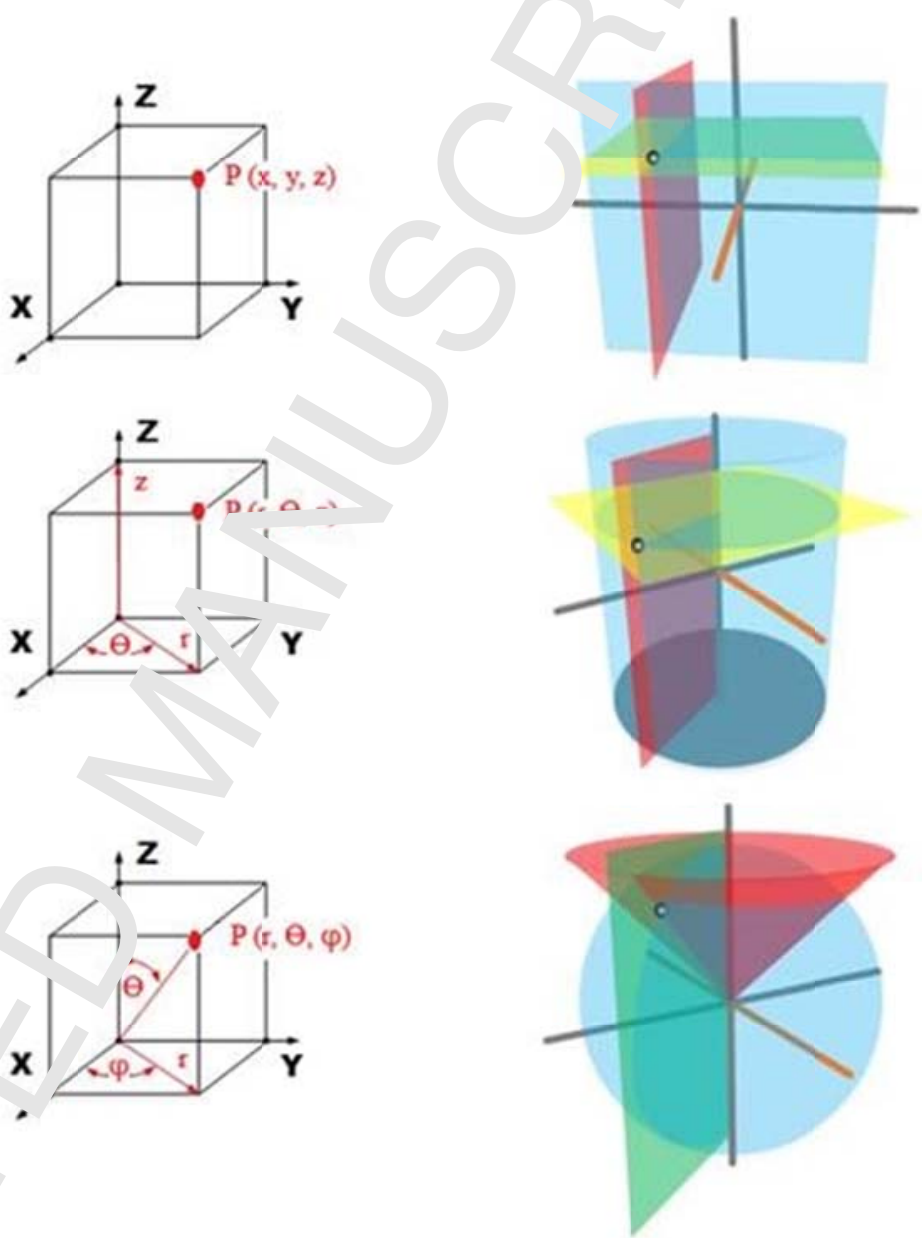

Figure 1 1. Cartesian, cylindrical, and spherical coordinate systems.

in Cartesian coordinate

Continuity:

$$
\frac{\partial v_{x}}{\partial x}+\frac{\partial v_{y}}{\partial y}+\frac{\partial v_{z}}{\partial z}=0
$$

Momemtum in $x$ direction: 


$$
\rho\left(\frac{\partial v_{x}}{\partial t}+v_{x} \frac{\partial v_{x}}{\partial x}+v_{y} \frac{\partial v_{x}}{\partial y}+v_{z} \frac{\partial v_{x}}{\partial z}\right)=-\frac{\partial p}{\partial x}+\mu\left(\frac{\partial^{2} v_{x}}{\partial x^{2}}+\frac{\partial^{2} v_{x}}{\partial y^{2}}+\frac{\partial^{2} v_{x}}{\partial z^{2}}\right)+F_{x}
$$

Momemtum in $y$ direction:

$$
\rho\left(\frac{\partial v_{y}}{\partial t}+u \frac{\partial v_{y}}{\partial x}+v \frac{\partial v_{y}}{\partial y}+w \frac{\partial v_{y}}{\partial z}\right)=-\frac{\partial p}{\partial y}+\mu\left(\frac{\partial^{2} v_{y}}{\partial x^{2}}+\frac{\partial^{2} v_{y}}{\partial y^{2}}+\frac{\partial^{2} v_{y}}{\partial z^{2}}\right)+F_{y}
$$

Momemtum in $z$ direction:

$$
\rho\left(\frac{\partial v_{z}}{\partial t}+u \frac{\partial v_{z}}{\partial x}+v \frac{\partial v_{z}}{\partial y}+w \frac{\partial v_{z}}{\partial z}\right)=-\frac{\partial p}{\partial z}+\mu\left(\frac{\partial^{2} v_{z}}{\partial x^{2}}+\frac{\partial^{2} v_{z}}{\partial y}+\frac{\partial^{2} v_{z}}{v z}\right)+F_{z}
$$

Energy equation:

$$
\begin{aligned}
& \rho c_{p}\left(\frac{\partial T}{\partial t}+v_{x} \frac{\partial T}{\partial x}+v_{y} \frac{\partial T}{\partial y}+v_{z} \frac{\partial T}{c}\right) \\
& \frac{\partial}{\partial x}\left(k \frac{\partial T}{\partial x}\right)+\frac{\partial}{\partial y}\left(k \frac{\partial T}{\partial y}\right)+\frac{c}{\partial_{7}}\left(\begin{array}{c}
\partial_{1} \\
\partial z
\end{array}\right)+\mu \Phi
\end{aligned}
$$

Where

$$
\begin{aligned}
\Phi= & 2\left[\left(\frac{\partial v_{x}}{\partial x}\right)^{2}+\left(\frac{\partial v_{y}}{\partial y}\right)^{2}+\left(\frac{\partial v_{z}}{\partial z}\right)^{2}\right]+\left[\left(\frac{i v_{x}}{\partial_{y}}-\frac{\partial v_{y}}{\hat{c}_{i}}\right)^{-}+\left(\frac{\partial v_{y}}{\partial z}+\frac{\partial v_{z}}{\partial y}\right)^{2}+\left(\frac{\partial v_{z}}{\partial x}+\frac{\partial v_{x}}{\partial z}\right)^{2}\right]- \\
& \frac{2}{3}\left(\frac{\partial v_{x}}{\partial x}+\frac{\partial v_{y}}{\partial y}+\frac{\partial v_{z}}{\partial z}\right)^{2}
\end{aligned}
$$

in Cylindrical coordinat $r$ systen.

Continuity:

$$
\frac{1}{r} \frac{\partial}{\partial r}\left(r v_{r}\right)+\frac{1}{r} \frac{\partial}{\partial \theta}\left(v_{\theta}\right)+\frac{\partial}{\partial z}\left(v_{z}\right)=0
$$

Momemtum in $r$ dirtction: 


$$
\begin{aligned}
& \rho\left(\frac{\partial v_{r}}{\partial t}+v_{r} \frac{\partial v_{r}}{\partial r}+\frac{v_{\theta}}{r} \frac{\partial v_{\theta}}{\partial \theta}-\frac{v_{\theta}^{2}}{r}+v_{z} \frac{\partial v_{r}}{\partial \mathbf{z}}\right)= \\
& r-\frac{\partial p}{\partial r}+\mu\left[\frac{\partial}{\partial r}\left(\frac{1}{r} \frac{\partial}{\partial r}\left(r v_{r}\right)\right)+\frac{1}{r^{2}} \frac{\partial^{2} v_{r}}{\partial \theta^{2}}-\frac{2}{r^{2}} \frac{\partial v_{r}}{\partial \theta}+\frac{\partial^{2} v_{r}}{\partial z^{2}}\right]+F_{r}
\end{aligned}
$$

Momemtum in $\theta$ direction:

$$
\begin{aligned}
& \rho\left(\frac{\partial v_{\theta}}{\partial t}+v_{r} \frac{\partial v_{\theta}}{\partial r}+\frac{v_{\theta}}{r} \frac{\partial v_{\theta}}{\partial \theta}-\frac{v_{r} v_{\theta}}{r}+v_{z} \frac{\partial v_{\theta}}{\partial z}\right)= \\
& \rho g_{\theta}-\frac{1}{r} \frac{\partial p}{\partial \theta}+\mu\left[\frac{\partial}{\partial r}\left(\frac{1}{r} \frac{\partial}{\partial r}\left(r v_{\theta}\right)\right)+\frac{1}{r^{2}} \frac{\partial^{2} v_{\theta}}{\partial \theta^{2}}+\frac{2}{r^{2}} \frac{\partial v_{r}}{\partial \theta}+\frac{\rho^{2} v_{\theta}}{v_{\nu}}\right]+F_{\theta}
\end{aligned}
$$

Momemtum in $z$ direction:

$$
\begin{aligned}
\rho\left(\frac{\partial v_{z}}{\partial t}+\right. & \left.v_{r} \frac{\partial v_{z}}{\partial r}+\frac{v_{\theta}}{r} \frac{\partial v_{z}}{\partial \theta}+v_{z} \frac{\partial v_{z}}{\partial z}\right)= \\
& -\frac{\partial p}{\partial z}+\mu\left[\frac{1}{r} \frac{\partial}{\partial r}\left(r \frac{\partial v_{z}}{\partial r}\right)+\frac{1}{r} \frac{\partial \cdot}{i \partial^{2}}+\frac{\partial^{2} v_{z}}{\partial z^{2}}\right]+F_{z}
\end{aligned}
$$

Energy equation:

$$
\begin{aligned}
& \rho c_{P}\left(\frac{\partial T}{\partial t}+v_{r} \frac{\partial T}{\partial r}+\frac{v_{\theta}}{r} \frac{\partial^{\prime}}{\partial \theta}, \cdot \frac{\partial^{\prime}}{z z}\right)= \\
& {\left[\frac{1}{r} \frac{\partial}{\partial r}\left(k r \frac{\partial T}{\partial r}\right)-\frac{1}{r^{2}}-\frac{\partial}{\partial \theta}\left(k \frac{\partial T}{\partial \theta}\right)+\frac{\partial}{\partial z}\left(k \frac{\partial T}{\partial z}\right)\right]+\mu \Phi}
\end{aligned}
$$

where:

$$
\begin{aligned}
& \Phi=2\left(\frac{\partial v_{r}}{\partial r}\right)^{2}+2\left(\frac{1}{r} \frac{\partial v_{\theta}}{\partial \theta}+{ }^{1} r\right)^{2}+2\left(\frac{\partial v_{z}}{\partial z}\right)^{2}+ \\
& \left(\frac{\partial v_{\theta}}{\partial r}-\frac{v_{\theta}}{r}+\frac{1}{r} \frac{\partial v_{r}}{\partial \theta}\right)^{2}+\left(\frac{1}{-} \frac{\partial v_{z}}{\partial \theta}+\frac{\partial v_{\theta}}{\partial z}\right)^{2}+\left(\frac{\partial v_{r}}{\partial z}+\frac{\partial v_{z}}{\partial r}\right)^{2}
\end{aligned}
$$

In spherical coor “ $"$ ^te system:

Continuity: 


$$
\frac{\partial \rho}{\partial t}+\frac{1}{r^{2}} \frac{\partial}{\partial r}\left(\rho r^{2} v_{r}\right)+\frac{1}{r \sin \theta} \frac{\partial}{\partial \theta}\left(\rho v_{\theta} \sin \theta\right)+\frac{1}{r \sin \theta} \frac{\partial}{\partial \varphi}\left(\rho v_{\varphi}\right)=0
$$

Momemtum in $r$ direction:

$$
\begin{aligned}
& \rho\left(\frac{\partial v_{r}}{\partial t}+v_{r} \frac{\partial v_{r}}{\partial r}+\frac{v_{\theta}}{r} \frac{\partial v_{r}}{\partial \theta}+\frac{v_{\varphi}}{r \sin \theta} \frac{\partial v_{r}}{\partial \varphi}-\frac{v_{\theta}^{2}+v_{\phi}^{2}}{r}\right)= \\
& F_{r}-\frac{\partial p}{\partial r}+\mu\left(\nabla^{2} v_{r}-\frac{2}{r^{2}} v_{r}-\frac{2}{r^{2}} \frac{\partial v_{\theta}}{\partial \theta}-\frac{2 v_{\theta} \cot \theta}{r^{2}}-\frac{2}{r^{2} \sin \theta} \frac{v_{\varphi}}{r_{n}}\right)
\end{aligned}
$$

Momemtum in $\theta$ direction:

$$
\begin{aligned}
& \rho\left(\frac{\partial v_{\theta}}{\partial t}+v_{r} \frac{\partial v_{\theta}}{\partial r}+\frac{v_{\theta}}{r} \frac{\partial v_{\theta}}{\partial \theta}-\frac{v_{\varphi}}{r \sin \theta} \frac{\partial v_{\theta}}{\partial \varphi}+\frac{v_{r} v_{\theta}}{r} \frac{{ }^{2}{ }^{2} \cot }{r}\right)= \\
& F_{\theta}-\frac{1}{r} \frac{\partial p}{\partial \theta}+\mu\left(\nabla^{2} v_{\theta}+\frac{2}{r^{2}} \frac{\partial v_{r}}{\partial \theta}-\frac{v_{\theta}}{r^{2} \sin ^{2} \imath^{?}}-\frac{\cos \theta}{\sin ^{2} \theta} \frac{\partial v_{\varphi}}{\partial \varphi}\right)
\end{aligned}
$$

Momemtum in $\varphi$ direction:

$$
\begin{aligned}
& \rho\left(\frac{\partial v_{\theta}}{\partial t}+v_{r} \frac{\partial v_{\varphi}}{\partial r}+\frac{v_{\theta}}{r} \frac{\partial v_{\varphi}}{\partial \theta}+\frac{v}{r \sin \theta} \frac{\partial v_{\varphi}}{\rho}+\frac{v_{\varphi} v_{r}}{r}+\frac{v_{\theta} v_{\varphi}}{r} \cot \theta\right)= \\
& F_{\varphi}-\frac{1}{r \sin \theta} \frac{\partial p}{\partial \varphi}+ \\
& \mu\left(\nabla^{2} v_{\varphi}-\frac{v_{\varphi}}{r^{2} \sin ^{2} \theta} \cdot \frac{2}{r-\operatorname{in}^{2} \theta} \frac{\partial v_{r}}{\partial \varphi}+\frac{2 \cos \theta}{r^{2} \sin ^{2} \theta} \frac{\partial v_{\theta}}{\partial \varphi}\right)
\end{aligned}
$$

Energy equation: 


$$
\begin{aligned}
\rho c_{p}\left(\frac{\partial T}{\partial t}+\right. & \left.v_{r} \frac{\partial T}{\partial r}+\frac{v_{\varphi}}{r} \frac{\partial T}{\partial \varphi}+\frac{v_{\theta}}{r \sin \varphi} \frac{\partial T}{\partial \theta}\right)=\frac{1}{r^{2}} \frac{\partial}{\partial r}\left(k r^{2} \frac{\partial T}{\partial r}\right)+ \\
& \frac{1}{r^{2} \sin ^{2} \theta} \frac{\partial}{\partial \varphi}\left(k \frac{\partial T}{\partial \varphi}\right)+\frac{1}{r^{2} \sin \theta} \frac{\partial}{\partial \theta}\left(k \sin \theta \frac{\partial T}{\partial \theta}\right)+\mu \Phi
\end{aligned}
$$

where:

$$
\begin{aligned}
\Phi=2 & {\left[\left(\frac{\partial v_{r}}{\partial r}\right)^{2}+\left(\frac{1}{r} \frac{\partial v_{\varphi}}{\partial \varphi}+\frac{v_{r}}{r}\right)^{2}+\left(\frac{1}{r \sin \varphi} \frac{\partial v_{\theta}}{\partial \theta}+\frac{v_{r}}{r}+\frac{v_{\varphi} \cot \varphi}{r}\right)^{2}\right]+} \\
& {\left[r \frac{\partial}{\partial r}\left(\frac{v_{\varphi}}{r}\right)+\frac{1}{r} \frac{\partial v_{r}}{\partial \varphi}\right]^{2}+} \\
& {\left[\frac{\sin \varphi}{r} \frac{\partial}{\partial \varphi}\left(\frac{v_{\theta}}{r \sin \varphi}\right)+\frac{1}{r \sin \varphi} \frac{\partial v_{\theta}}{\partial \theta}\right]^{2}+\left[\frac{1}{r \sin \varphi} \frac{\partial v_{r}}{\partial \varphi}+r \frac{\partial}{\partial r}\left|v_{\theta}\right|^{7^{2}}\right.}
\end{aligned}
$$

\section{References}

[1] H. Masuda, A. Ebata, K. Teramae, N i.. hinuma, Alteration of Thermal Conductivity and Viscosity of Liquid by Dispersing L : " Ultra-Fine Particles, Netsu Buss ii. 7 (1993) 227-233. doi:10.2963/jjtp.7.227.

[2] S.U.S. Choi, J.A. Eastman, F hancing thermal conductivity of fluids with nanoparticles, ASME Int. Mech. Eng. Congr. Ey $>66$ (1995) 99-105. doi:10.1115/1.1532008.

[3] A. Ghadimi, R. Saidur, H.S. ' Metselaar, A review of nanofluid stability properties and characterization in s ^tir nar conditions, Int. J. Heat Mass Transf. 54 (2011) 4051-4068. doi:10.1016/j.ijhr atmasstransfer.2011.04.014.

[4] R. Saidur, K.r. Leong, H.A. Mohammad, A review on applications and challenges of nanofluids, 1 enew. justain. Energy Rev. 15 (2011) 1646-1668. doi:10.1016/j.rser.2010.11.035.

[5] R. Taylor, S. Loulombe, T. Otanicar, P. Phelan, A. Gunawan, W. Lv, G. Rosengarten, R. Prasher, H. Ty agi, Small particles, big impacts: A review of the diverse applications of 
nanofluids, J. Appl. Phys. 113 (2013). doi:10.1063/1.4754271.

[6] Z. Zhien, C. Jianchao, C. Feng, L. Hao, Z. Wenxian, Q. Wenjie, Progress in enhanc.ment of $\mathrm{CO}_{2}$ absorption by nanofluids: A mini review of mechanisms and curren stat $\lrcorner$, Renew. Energy. 118 (2018) 527-535. doi:10.1016/j.renene.2017.11.031.

[7] O. Mahian, A. Kianifar, S.Z. Heris, D. Wen, A.Z. Sahin, S. Wongr 'se', Nanofluids effects on the evaporation rate in a solar still equipped with a heat exchan r, rr, Nrno Energy. 36 (2017) 134-155. doi:10.1016/j.nanoen.2017.04.025.

[8] D.K. Devendiran, V.A. Amirtham, A review on preparatior, , lara terization, properties and applications of nanofluids, Renew. Sustain. Energy Rev. 60 (¿ר16) 21-40. doi:10.1016/j.rser.2016.01.055.

[9] G. Colangelo, E. Favale, M. Milanese, A. de Risi, L I aforgia, Cooling of electronic devices: Nanofluids contribution, Appl. Therm. Eng. 12, ( $\angle 4,4), 421-435$. doi:10.1016/j.applthermaleng.2017.08.042.

[10] A. Kasaeian, A.T. Eshghi, M. Sameti, A ru ${ }^{-e w}$ wn the applications of nanofluids in solar energy systems, Renew. Sustain. Enerov Rev. 43 (2015) 584-598. doi:10.1016/j.rser.2014.11.020.

[11] S. Rashidi, O. Mahian, E.M. La 'gu' ', A' plications of nanofluids in condensing and evaporating systems: A review, J. Therm Anal. ᄂ. iorim. (2017). doi:10.1007/s10973-017-6773-7.

[12] S. Rashidi, M. Eskandari ^, T. Mahian, S. Poncet, Combination of nanofluid and inserts for heat transfer enhancemetı, Therm. Anal. Calorim. (2018). doi:10.1007/s10973-018-7070-9.

[13] A. Kasaeian, R.D. A_'r an, J. Mahian, L. Kolsi, A.J. Chamkha, S. Wongwises, I. Pop, Nanofluid flow s id hec transfer in porous media: A review of the latest developments, Int. J. Heat Mass Transt. 107 2017). doi:10.1016/j.ijheatmasstransfer.2016.11.074.

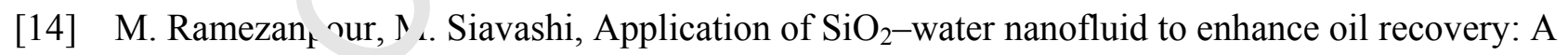
new hybi $\tau 01$... ization approach using pattern search and PSO algorithms, J. Therm. Anal. Calorim. (26 8) 1-16. doi:10.1007/s10973-018-7156-4. 
[15] O. Mahian, A. Kianifar, A.Z. Sahin, S. Wongwises, Heat Transfer, Pressure Dr sp, and Entropy Generation in a Solar Collector Using $\mathrm{SiO}_{2} /$ Water Nanofluids: Effects of $\mathrm{Na} 10 \mu$. "ticle Size and pH, J. Heat Transfer. 137 (2015). doi:10.1115/1.4029870.

[16] S.S. Meibodi, A. Kianifar, O. Mahian, S. Wongwises, Second law analy - ot a nanofluid-based solar collector using experimental data, J. Therm. Anal. Calorim. 17 o (2 : $:$ ) 617-625.

[17] A. Kasaeian, S.M. Hosseini, M. Sheikhpour, O. Mahian, W.M. . an, S Wongwises, Applications of eco-friendly refrigerants and nanorefrigerants: $t$. revie $v$, Renew. Sustain. Energy Rev. 96 (2018) 91-99. doi:10.1016/j.rser.2018.07.( 33.

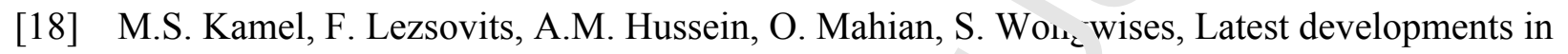
boiling critical heat flux using nanofluids: A concise "evı * '.t. Commun. Heat Mass Transf. 98 (2018) 59-66. doi:https://doi.org/10.1016/j.ichentman ansfer.2018.08.009.

[19] O. Mahian, A. Kianifar, S.A. Kalogirou, I. Pop, >. $>$ gwises, A review of the applications of nanofluids in solar energy, Int. J. Heat Mass -ansi 57 (2013) 582-594. doi:10.1016/j.ijheatmasstransfer.2012.10 237 .

[20] W. Daungthongsuk, S. Wongwises, A rritical review of convective heat transfer of nanofluids, Renew. Sustain. Energy Rev. 11 (2'07) 79 -817. doi:10.1016/j.rser.2005.06.005.

[21] J. Buongiorno, Convective Trar 'po ، in Nanofluids, J. Heat Transfer. 128 (2006) 240. doi:10.1115/1.2150834.

[22] M. Sheikholeslami, D.D. Ja ji, eds., Front matter, in: Appl. Nanofluid Heat Transf. Enhanc., William Andrew Publish.. 2017: p. iii-. doi:https://doi.org/10.1016/B978-0-08-1021729.00011-3.

[23] M.R. Safaei, A. dhanb ๆ, A. Kianifar, S. Gharehkhani, A.S. Kherbeet, M. Goodarzi, M. Dahari, Mathematical Mo ilin for Nanofluids Simulation: A Review of the Latest Works, in: N.S. Akbar, O.A. Beg (E 1s.), Model. Simul. Eng. Sci., InTech, Rijeka, 2016. doi:10.5772/64154.

[24] M. Bahir، 91, . . omprehensive Review on Different Numerical Approaches for Simulation in Nanofluids: raditional and Novel Techniques, J. Dispers. Sci. Technol. 35 (2014) 984-996. doi:10.1080/01932691.2013.825210. 
[25] N.A.C. Sidik, M.N.A.W.M. Yazid, S. Samion, M.N. Musa, R. Mamat, Latest r'velopment on computational approaches for nanofluid flow modeling: Navier-Stokes base . mı. ${ }^{1}$ iphase models, Int. Commun. Heat Mass Transf. 74 (2016) 114-124. doi:10.1016/j.icheatmasstransfer.2016.03.007.

[26] S.M. Vanaki, P. Ganesan, H.A. Mohammed, Numerical study of co sver : a heat transfer of nanofluids: A review, Renew. Sustain. Energy Rev. 54 (2016) 1212-1.29. doi:10.1016/j.rser.2015.10.042.

[27] S. Kakaç, A. Pramuanjaroenkij, Single-phase and two-phas e tre $\Perp$ u ents of convective heat transfer enhancement with nanofluids - A state-of-the-an , vie , int. J. Therm. Sci. 100 (2016) 75-97. doi:10.1016/j.ijthermalsci.2015.09.021.

[28] G. Ahmadi, J.B. McLaughlin, Transport, Depositinn and d _moval of Fine Particles Biomedical Applications, in: E. Matijević (Ed.) Med. r.spl. Colloids, Springer US, New York, NY, 2008: pp. 92-173. doi:10.1007/978-0-387-\%०८1-9_4.

[29] J.S. Marshall, S. Li, Adhesive Particle Flnхx: A . Tiscrete-Element Approach, Cambridge University Press, 2014. doi:10.1017/CBO978, 139424547.

[30] R. Clift, J.R. Grace, M.E. Weber, P ıbbles, )rops, and Particles, Academic Press, 1978. https://books.google.co.th/books ${ }^{r} \mathrm{~d}=\eta 8 \mathrm{~g}_{1}$ AQAAIAAJ.

[31] G. Sekrani, S. Poncet, P. Pro .1x, Colı, dgated heat transfer and entropy generation of Al2O3-water nanofluid flows over a heat . ${ }^{1}$ wall-mounted obstacle, J. Therm. Anal. Calorim. (2018). doi:10.1007/s10973-018.734)-x.

[32] M.A. E. Cunninghar \&, O t the velocity of steady fall of spherical particles through fluid medium, Proc. R. ㄷc. Lc - Jon A Math. Phys. Eng. Sci. 83 (1910) 357-365. doi:10.1098/rspá 1910.024.

[33] H. Brenner, The slo $v$ motion of a sphere through a viscous fluid towards a plane surface, Chem. Eno. Scl. 10 (1961) 242-251. doi:10.1016/0009-2509(61)80035-3.

[34] P.G. Saffmal. The lift on a small sphere in a slow shear flow, J. Fluid Mech. 22 (1965) 385400. doi:10.1017/S0022112065000824. 
[35] P.G. Saffman, Corrigendum to "The lift force on a small sphere in a slow shea' flow.," J. Fluid Mech. (1968).

[36] S.I. Rubinow, J.B. Keller, The transverse force on a spinning sphere mo ng $n$ a viscous fluid, J. Fluid Mech. 11 (1961) 447-459. doi:10.1017/S0022112061000640.

[37] O. Mahian, A. Kianifar, A.Z. Sahin, S. Wongwises, Performance a $9 / \mathbf{v}$, is of a minichannelbased solar collector using different nanofluids, Energy Conver . Marıg. 88 (2014) 129-138. doi:10.1016/j.enconman.2014.08.021.

[38] R.I.A.V.P.L.S. Robert Brown, XXVII. A brief account of n. . oser pical observations made in the months of June, July and August 1827, on the particles cu.tained in the pollen of plants; and on the general existence of active molecules in orgar: ${ }^{\prime}$ an. ${ }^{1}$ in sganic bodies, Philos. Mag. 4 (1828) 161-173. doi:10.1080/1478644280867476º

[39] E.E.S. Michaelides, Heat and Mass Transfer in 'aı ı...' ate Suspensions, Springer-Verlag New York, 2013.

[40] A. Li, G. Ahmadi, Dispersion and deposilı ${ }^{n}$ o w wherical particles from point sources in a turbulent channel flow, Aerosol Sci. Technol. 16 (1992) 209-226. doi:10.1080/02786829208959550.

[41] A. Einstein, Über die von der $m$,lek dlar'-inetischen Theorie der Wärme geforderte Bewegung von in ruhenden Flüssigkeite ، suspe ı , ierten Teilchen, Ann. Phys. 322 (1905) 549-560. doi:10.1002/andp.1905322u806.

[42] M. von Smoluchowski, Lı- kinetischen Theorie der Brownschen Molekularbewegung und der Suspensionen, Ann. hy . 325 (1906) 756-780. doi:10.1002/andp.19063261405.

[43] O. Abouali, A. N ‘kbak! +, G. Ahmadi, S. Saadabadi, Three-dimensional simulation of Brownian

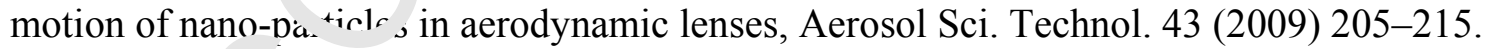
doi:10.1080. J2786¿?0802587888.

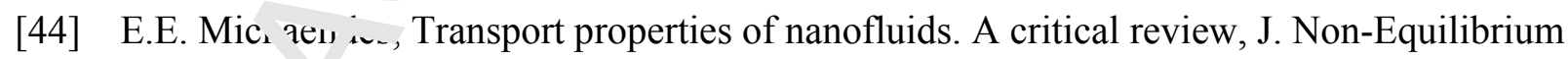
Thermodyn. '8 (2013) 1-79. doi:10.1515/jnetdy-2012-0023. 
[45] P.S. Epstein, Zur Theorie des Radiometers, Zeitschrift Für Phys. 54 (1929) 537-563. doi:10.1007/BF01338485.

[46] J.R. Brock, On the theory of thermal forces acting on aerosol particles, J Co' oid Sci. 17 (1962) 768-780. doi:10.1016/0095-8522(62)90051-X.

[47] L. Talbot, R.K. Cheng, R.W. Schefer, D.R. Willis, Thermophoresi of articles in a heated boundary layer, J. Fluid Mech. 101 (1980) 737-758. doi:10.101'//>00?2112080001905.

[48] C. He, G. Ahmadi, Particle Deposition with Thermophoresi in Lammar and Turbulent Duct Flows, Aerosol Sci. Technol. 29 (1998) 525-546. doi:10.16?,027,6829808965588.

[49] E.E. Michaelides, Brownian movement and thermoph "esis of lanoparticles in liquids, Int. J. Heat Mass Transf. 81 (2015) 179-187. doi:10.1016/j.11^ 'atmasstransfer.2014.10.019.

[50] S. Savithiri, A. Pattamatta, S.K. Das, Scaling analysis s the investigation of slip mechanisms in nanofluids, Nanoscale Res. Lett. 6 (2011) 1-1_ „ „oi:10.1186/1556-276X-6-471.

[51] S. Elghobashi, On predicting particle-laden turt lent flows, Appl. Sci. Res. 52 (1994) 309-329. doi:10.1007/BF00936835.

[52] C.T. Crowe, J.D. Schwarzkopf, M. romme feld, Y. Tsuji, Multiphase Flow with Droplets and Particles, CRC Press Taylor Fr. C.r. (?01 i, 209.

[53] C. Tropea, A.L. Yarin, J.F. F ss, Spı ger Handbook of Experimental Fluid Mechanics, AIAA J. 46 (2007) 2653-2655. do1:10.2.'14/1.38773.

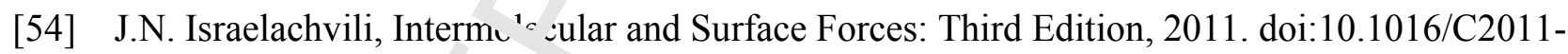
0-05119-0.

[55] D. Guo, G. Xie, . Luo, Mechanical properties of nanoparticles: Basics and applications, J. Phys. D. Appl. $\mathrm{Ph}_{\downarrow}{ }^{\top} 47$ (2014). doi:10.1088/0022-3727/47/1/013001.

[56] H.C. Hamakı * The London-van der Waals attraction between spherical particles, Physica. 4 (1937) $1 \iota>0-272$.

[57] R. Hogg, T.W. Healy, D.W. Fuerstenau, Mutual coagulation of colloidal dispersions, Trans. 
Faraday Soc. 62 (1966) 1638-1651.

[58] J.A. Lewis, Colloidal Processing of Ceramics, J. Am. Ceram. Soc. 83 (n.d.) 2341-_.59. doi:10.1111/j.1151-2916.2000.tb01560.x.

[59] L.P. Aoki, H.E. Schulz, M.G. Maunsell, An MHD Study of the Beha '>r or . n Electrolyte Solution using 3D Numerical Simulation and Experimental results, $\eta$ : roceeding COMSOL Conf., 2013: pp. 1-7. doi:10.13140/2.1.1398.6082.

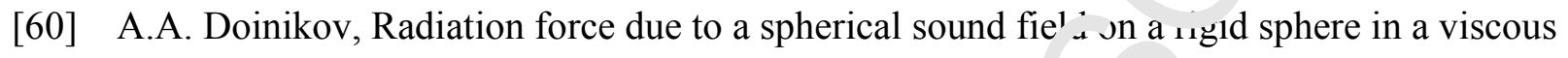
fluid, J. Acoust. Soc. Am. 96 (1994) 3100-3105. doi:10.11 $1 \quad 1.41247$.

[61] M. Settnes, H. Bruus, Forces acting on a small particlc in an ac sustical field in a viscous fluid, Phys. Rev. E - Stat. Nonlinear, Soft Matter Phys. 85 ( $\angle u^{1}$ ? $)$. doi:10.1103/PhysRevE.85.016327.

[62] Y. Zhao, J.S. Marshall, Spin coating of a colloidal susp nsion, Phys. Fluids. 20 (2008) 43302. doi:10.1063/1.2896601.

[63] J.D.S. Efstathios Michaelides, Clayton T. Crow ed., Multiphase Flow Handbook, Second, CRC Press, 2016.

[64] C. Jin, I. Potts, M.W. Reeks, A sim le stocı astic quadrant model for the transport and deposition of particles in turbuler c bruna.ry layers, Phys. Fluids. 27 (2015). doi:10.1063/1.4921490.

[65] K. Khanafer, K. Vafai, A critical s, nthesis of thermophysical characteristics of nanofluids, Int. J. Heat Mass Transf. 54 201 . 4410-4428. doi:10.1016/j.ijheatmasstransfer.2011.04.048.

[66] J.C. Maxwell, A tres .ise sn electricity and magnetism Vol.II, Oxford Clarendon Press. (1873) 360-366. doi:10.1 n1 6/u' '-0032(54)90053-8.

[67] Bruggema, D.A.C N F erechnung von verschiedener physikalischer Konstanten von Heterogener Substá izen, Ann. Phys. 24 (1935) 636-664. doi:10.1115/1.4006796.

[68] R.L. Har. 'lw, Thermal conductivity of heterogeneous two-component systems, Ind. Eng. Chem. Fund ` ๆ. 1 (1962) 187-191. doi:10.1021/i160003a005. 
[69] W. Yu, S.U.S. Choi, The role of interfacial layers in the enhanced thermal con'uctivity of nanofluids: A renovated Maxwell model, J. Nanoparticle Res. 5 (2003) 167- i/. doi:10.1023/A:1024438603801.

[70] Y. Xuan, Q. Li, W. Hu, Aggregation structure and thermal conductivity ` ${ }^{c}$ nanufluids, AIChE J. 49 (2003) 1038-1043. doi:10.1002/aic.690490420.

[71] J. Koo, C. Kleinstreuer, A new thermal conductivity model for ' dnofl'ids, J. Nanoparticle Res. 6 (2004) 577-588. doi:10.1007/s11051-004-3170-5.

[72] U. Lee, J. (NC State University, Raleigh, NC, Computation. ‘ anal sis of nanofluid flow in microchannels with applications to micro-heat sinks and bio-. 'EMS, NC State University, Raleigh, NC, USA, 2008.

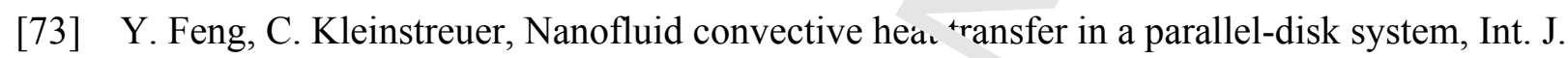
Heat Mass Transf. 53 (2010) 4619-4628. doi:1, iv ". jijheatmasstransfer.2010.06.031.

[74] Z. Xu, C. Kleinstreuer, Concentration photove' ta: -tnermal energy co-generation system using nanofluids for cooling and heating, Energy 'Our rs. Manag. 87 (2014) 504-512. doi:10.1016/j.enconman.2014.07.047.

[75] C.-W. Nan, R. Birringer, D.R. Clarke, ㄱ. C ceiter, Effective thermal conductivity of particulate composites with interfacial ther al esis ance, J. Appl. Phys. 81 (1997) 6692-6699. doi:10.1063/1.365209.

[76] R. Prasher, P. Bhattachar a, '.E. Phelan, Thermal conductivity of nanoscale colloidal solutions (nanofluids), Phys. Rev. L`i. 94 (2005). doi:10.1103/PhysRevLett.94.025901.

[77] S.K. Das H.E. Patel, ' 'rar 'ep, T. Sundararajan, A. Dasgupta, N. Dasgupta, A microconvection mode: for thermal conductivity of nanofluid, Pramana-Journal Phys. 65 (2005) 863-869.

[78] A. Amiri, K. 'afai Analysis of dispersion effects and non-thermal equilibrium, non-Darcian, variable Pru $_{i}$, , incompressible flow through porous media, Int. J. Heat Mass Transf. 37 (1994) 939-; 54. doi:10.1016/0017-9310(94)90219-4. 
[79] K. Khanafer, K. Vafai, M. Lightstone, Buoyancy-driven heat transfer enhancer ent in a twodimensional enclosure utilizing nanofluids, Int. J. Heat Mass Transf. 46 (20 3 3) _ ‘39-3653. doi:10.1016/S0017-9310(03)00156-X.

[80] Q.Z. Xue, Model for thermal conductivity of carbon nanotube-based col...-nsilus, Phys. B Condens. Matter. 368 (2005) 302-307. doi:10.1016/j.physb.2005.0־.02。

[81] H.E. Patel, K.B. Anoop, T. Sundararajan, S.K. Das, Model for t' erma' conductivity of CNTnanofluids, in: Bull. Mater. Sci., 2008: pp. 387-390. doi:10.100 :'s120 ,4-008-0060-y.

[82] C.-W. Nan, G. Liu, Y. Lin, M. Li, Interface effect on therm. ' ond ictivity of carbon nanotube composites, Appl. Phys. Lett. 85 (2004) 3549-3551. doi:10.1 `53/1.1808874.

[83] B. Lamas, B. Abreu, A. Fonseca, N. Martins, M. Olive - Critical analysis of the thermal conductivity models for CNT based nanofluids, Inı. ' Therm. Sci. 78 (2014) 65-76. doi:10.1016/j.ijthermalsci.2013.11.017.

[84] S.M.S. Murshed, K.C. Leong, C. Yang, Invesi ${ }^{-}{ }_{a}:$ ins of thermal conductivity and viscosity of nanofluids, Int. J. Therm. Sci. 47 (2008) د'-sü. doi:10.1016/j.jithermalsci.2007.05.004.

[85] S.M.S. Murshed, C.A. Nieto De Cas' o, D nerior thermal features of carbon nanotubes-based nanofluids - A review, Renew. Sustaı. En rgy Rev. 37 (2014) 155-167. doi:10.1016/j.rser.2014.05.017,

[86] P. Estellé, S. Halelfadl, T. N à' Thermal Conductivity of CNT Water Based Nanofluids: Experimental Trends and ir dels Overview, J. Therm. Enginnering. 1 (2015) 381-390. doi:10.13140/2.1.2173.90

[87] S. El Bécaye Maïga, ' ' '. Pa' n, C.T. Nguyen, G. Roy, N. Galanis, Heat transfer enhancement by using nanofluids in for `d convection flows, Int. J. Heat Fluid Flow. 26 (2005) 530-546. doi:10.1016/j.iihe ${ }_{a}$ flıi fflow.2005.02.004.

[88] M. Corcione, Heat + ansfer features of buoyancy-driven nanofluids inside rectangular enclosurt a1s ... ntially heated at the sidewalls, Int. J. Therm. Sci. 49 (2010) 1536-1546. doi:10.1016/J ijthermalsci.2010.05.005. 
[89] C.H. Chon, K.D. Kihm, S.P. Lee, S.U.S. Choi, Empirical correlation finding th z role of temperature and particle size for nanofluid $\left(\mathrm{Al}_{2} \mathrm{O}_{3}\right)$ thermal conductivity ent inc - nent, Appl. Phys. Lett. 87 (2005) 1-3. doi:10.1063/1.2093936.

[90] C.J. Ho, W.K. Liu, Y.S. Chang, C.C. Lin, Natural convection heat transı - of aiumina-water nanofluid in vertical square enclosures: An experimental study, Int. J. T _. m. Sci. 49 (2010) 1345-1353. doi:10.1016/j.ijthermalsci.2010.02.013.

[91] K. V Sharma, P.K. Sarma, W.H. Azmi, R. Mamat, K. Kadirgan. Cor elations To Predict Friction and Forced Convection Heat Transfer Coefficients of $v$ at $r$ Based Nanofluids for Turbulent Flow in a Tube, Int. J. Microscale Nanoscale 1. rrm. T.uid Transp. Phenomena, Suppl. Spec. Issue Heat Mass Transf. Nanofluids; Haı `nauge. 3 (2012) 283-307.

[92] W.H. Azmi, K. V. Sharma, R. Mamat, S. Anuar, Tumh 1 forced convection heat transfer of nanofluids with twisted tape insert in a plain tuhe. in: ... argy Procedia, 2014: pp. 296-307. doi:10.1016/j.egypro.2014.07.081.

[93] G. Zyła, J. Fal, Experimental studies on viccosi_; thermal and electrical conductivity of aluminum nitride-ethylene glycol (AlN-EG) 1tm ^ofluids, Thermochim. Acta. 637 (2016) 11-16. doi:10.1016/j.tca.2016.05.006.

[94] G. Zyła, Thermophysical proper ${ }^{+}$es $\cap \mathrm{f}$ etıylene glycol based yttrium aluminum garnet $\left(\mathrm{Y}_{3} \mathrm{Al}_{5} \mathrm{O}_{12}-\mathrm{EG}\right)$ nanofluids, In+ J. : eat Mass Transf. 92 (2016) 751-756. doi:10.1016/j.ijheatmasstrar sic -2015.09.045.

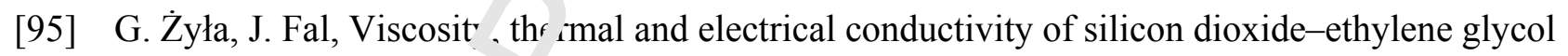
transparent nanofluid . An $\mathrm{e}_{\lambda_{\mathrm{r}}}$ arimental studies, Thermochim. Acta. 650 (2017) 106-113. doi:10.1016/j.tca.201 ? r 2.0r 1 .

[96] G. Żyła, J. Fal, J Tracia ., M. Gizowska, K. Perkowski, Huge thermal conductivity enhancemen ${ }^{+}$in boron nitride - ethylene glycol nanofluids, Mater. Chem. Phys. 180 (2016) 250-255. do1. ${ }^{10.10}$ 6/j.matchemphys.2016.06.003.

[97] G. Żyła, J. `. I, P. Estellé, The influence of ash content on thermophysical properties of ethylene glycol based graphite/diamonds mixture nanofluids, Diam. Relat. Mater. 74 (2017) 81-89. 
doi:10.1016/j.diamond.2017.02.008.

[98] G. Żyła, J. Fal, P. Estellé, Thermophysical and dielectric profiles of ethylene glycoı 'Jased titanium nitride (TiN-EG) nanofluids with various size of particles, Int. $\quad$ He tt Mass Transf. 113 (2017) 1189-1199. doi:10.1016/j.ijheatmasstransfer.2017.06.032.

[99] G. Żyła, J.P. Vallejo, J. Fal, L. Lugo, Nanodiamonds - Ethylene G. 'rco nanofluids: Experimental investigation of fundamental physical properties, nt. J. Heat Mass Transf. 121 (2018) 1201-1213. doi:10.1016/j.ijheatmasstransfer.2018.01.0\%

[100] M.H. Ahmadi, M.A. Ahmadi, M.A. Nazari, O. Mahian, R. $\complement^{{ }^{\prime}}$.dser pour, A proposed model to

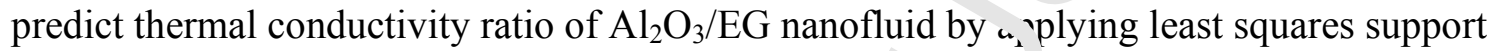

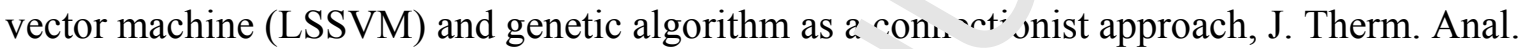
Calorim. (2018). doi:10.1007/s10973-018-7035-z

[101] M. Hemmat Esfe, S. Saedodin, M. Bahiraei, D. 'oz … ¿, O. Mahian, S. Wongwises, Thermal conductivity modeling of $\mathrm{MgO} / \mathrm{EG}$ nanoflui. . 'sin _ experimental data and artificial neural network, J. Therm. Anal. Calorim. 118 (2n14). i ivi:10.1007/s10973-014-4002-1.

[102] M. Hemmat Esfe, P.M. Behbahani, A.A A. Arani, M.R. Sarlak, Thermal conductivity enhancement of $\mathrm{SiO}_{2}-\mathrm{MWCNT}$ ( 8 ₹ $15 \%$ )- EG hybrid nanofluids : ANN designing, experimental investigation, cost erfrrma 128 (2017) 249-258. doi:10.1no,' 109’3-016-5893-9.

[103] M. Hemmat Esfe, H. Rostamian, L Toghraie, W.-M. Yan, Using artificial neural network to predict thermal conducti vity sf ethylene glycol with alumina nanoparticle, J. Therm. Anal. Calorim. (2016) 1-6. ^oi:10.1 07/s10973-016-5506-7.

[104] M. Vakili, M. Kar ${ }^{\sim}$ רi, S. `elfani, S. Khosrojerdi, K. Kalhor, Experimental investigation and modeling of ther nal cor luctivity of $\mathrm{CuO}$-water/EG nanofluid by FFBP-ANN and multiple regressions, . I herm. Anal. Calorim. 129 (2017) 629-637. doi:10.1007/s10973-017-6217-4.

[105] M.H. Esfe S. Sauuodin, O. Mahian, S. Wongwises, Thermal conductivity of $\mathrm{Al}_{2} \mathrm{O}_{3} /$ water nanofluids. ' 1 easurement, correlation, sensitivity analysis, and comparisons with literature reports, J. Therm. Anal. Calorim. 117 (2014). doi:10.1007/s10973-014-3771-x. 
[106] M. Hemmat Esfe, S. Saedodin, O. Mahian, S. Wongwises, Thermophysical prr perties, heat transfer and pressure drop of COOH-functionalized multi walled carbon nar stuc $₫ /$ water nanofluids, Int. Commun. Heat Mass Transf. 58 (2014). doi:10.1016/j.icheatmasstransfer.2014.08.037.

[107] M. Hemmat Esfe, S. Saedodin, O. Mahian, S. Wongwises, Heat tra sfe $\therefore$ aracteristics and pressure drop of of $\mathrm{COOH}$-functionalized DWCNTs/water nanoflıid 1 . turbulent flow at low concentrations, Int. J. Heat Mass Transf. 73 (2014). doi:10.1016/j.ijheatmasstransfer.2014.01.069.

[108] M. Amani, P. Amani, A. Kasaeian, O. Mahian, S. Wongw ' es, Trermal conductivity measurement of spinel-type ferrite $\mathrm{MnFe}_{2} \mathrm{O}_{4}$ nanofluic in the resence of a uniform magnetic field, J. Mol. Liq. 230 (2017) 121-128. doi:10.1016/j.nı 11iq.2016.12.013.

[109] M. Amani, P. Amani, A. Kasaeian, O. Mahian, I Pop, , Wongwises, Modeling and optimization of thermal conductivity and viscosil; $\mathrm{f} \mathrm{MnFe}_{2} \mathrm{O}_{4}$ nanofluid under magnetic field using an ANN, Sci. Rep. 7 (2017) 17369. doi: ‘.. ‘`38/s41598-017-17444-5.

[110] S.M.S. Murshed, K.C. Leong, C. Yang, Enhan ad thermal conductivity of $\mathrm{TiO}_{2}-$ Water based nanofluids, Int. J. Therm. Sci. 44 (2C J5) J 7-373. doi:10.1016/j.ijthermalsci.2004.12.005.

[111] A. Turgut, I. Tavman, M. Chirto', H P. Sunuchmann, C. Sauter, S. Tavman, Thermal

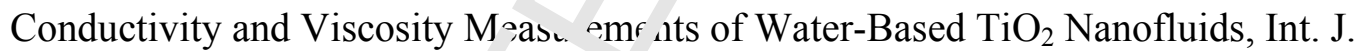
Thermophys. 30 (2009) 121 ,-: 26. doi:10.1007/s10765-009-0594-2.

[112] S. Wang, Y. Li, H. Zhar s, Y Lin, Z. Li, W. Wang, Q. Wu, Y. Qian, H. Hong, C. Zhi, Enhancement of therr al conc ctivity in water-based nanofluids employing $\mathrm{TiO}_{2}$ reduced graphene oxide comp • tes. J. Mater. Sci. 51 (2016) 10104-10115. doi:10.1007/s10853-0160239-3.

[113] M. Zadkhast N. Trghraie, A. Karimipour, Developing a new correlation to estimate the thermal conductivity f MV CNT-CuO/water hybrid nanofluid via an experimental investigation, J. Therm. A ‘al. _norim. 129 (2017) 859-867. doi:10.1007/s10973-017-6213-8.

[114] P.K. Singh, D. Khandelwal, C. Sidhant, A. Shubham, N. Priyanshu, G. Rasu, Nanofluid heat 
transfer mechanism and thermo-physical properties: A review, Int. J. Mech. Er g. Technol. 8 (2017) 156-164.

[115] K.Y. Leong, K.Z. Ku Ahmad, H.C. Ong, M.J. Ghazali, A. Baharum, Syr hes's and thermal

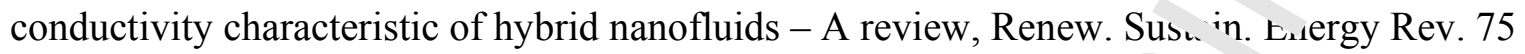
(2017) 868-878. doi:10.1016/j.rser.2016.11.068.

[116] A. Kotia, S. Borkakoti, P. Deval, S.K. Ghosh, Review of interfe _lal laver s effect on thermal conductivity in nanofluid, Heat Mass Transf. Und Stoffuebertra ${ }^{\prime}$ 'ng. ‘ 3 (2017) 2199-2209. doi:10.1007/s00231-016-1963-6.

[117] M.I. Pryazhnikov, A. V Minakov, V.Y. Rudyak, D. V Guze,, Thermal conductivity measurements of nanofluids, Int. J. Heat Mass Trans ${ }^{c}$ 1U. ' or 17) 1275-1282. doi:10.1016/j.ijheatmasstransfer.2016.09.080.

[118] P.C. Mishra, S.K. Nayak, S. Mukherjee, Therm. ' u. ...' 1 ictivity of Nanofluids-An Extensive Literature Review, Int. J. Eng. Res. Technol. : (20, 3) 734-745.

[119] H. Younes, G. Christensen, D. Li, H. Hon, A. . . Ghaferi, Thermal Conductivity of Nanofluids: Review, J. Nanofluids. 4 (ग015) 107-132. doi:10.1166/jon.2015.1151.

[120] P.M. Kumar, J. Kumar, R. Tamilarasa. S. Jendhilnathan, S. Suresh, Review on nanofluids theoretical thermal conductivity mo ،els Eng. J. 19 (2015) 67-83. doi:10.4186/ej.2015.19.1.67.

[121] S.A. Angayarkanni, J. Philir , 1 vview on thermal properties of nanofluids: Recent developments, Adv. Collr « 'nterface Sci. 225 (2015) 146-176. doi:10.1016/j.cis.2015.08.014.

[122] M.H. Ahmadi, A. Mir ohi, Nı. 1. Nazari, R. Ghasempour, A review of thermal conductivity of various nanofluids, J. '⿳ol. J.ıq. 265 (2018) 181-188. doi:https://doi.or $s / 10.1 \sim 16 / j . m o l l i q .2018 .05 .124$.

[123] C. Kleinstrer sr, Y. Feng, Experimental and theoretical studies of nanofluid thermal conductivity nhan ement: a review, Nanoscale Res. Lett. 6 (2011) 439. doi:10.1186/1556276X-6-4 ‘y.

[124] H.C. Birkman, The viscosity of concentrated suspensions and solution, J. Chem. Phys. 20 
(1952) 571. doi:doi: 10.1063/1.1700493.

[125] I.M. Krieger, T.J. Dougherty, A Mechanism for Non Newtonian Flow in Suspensı ns of Rigid Spheres, Trans. Soc. Rheol. 3 (1959) 137-152. doi:10.1122/1.548848.

[126] S.H. Maron, P.E. Pierce, Application of ree-eyring generalized flow t' ' ory a suspensions of spherical particles, J. Colloid Sci. 11 (1956) 80-95. doi:10.1016/0C $15-522(56) 90023-X$.

[127] S. Halelfadl, P. Estellé, B. Aladag, N. Doner, T. Maré, Viscosi1 $r$ of cal on nanotubes waterbased nanofluids: Influence of concentration and temperatur _, int. J. 1 herm. Sci. 71 (2013) 111-117. doi:10.1016/j.ijthermalsci.2013.04.013.

[128] H. Chen, Y. Ding, C. Tan, Rheological behaviour of n. nofluid, New J. Phys. 9 (2007). doi:10.1088/1367-2630/9/10/367.

[129] J. Chevalier, O. Tillement, F. Ayela, Structure and rhev' gy of $\mathrm{SiO}_{2}$ nanoparticle suspensions under very high shear rates, Phys. Rev. E - Stat. I'` ılinear, Soft Matter Phys. 80 (2009). doi:10.1103/PhysRevE.80.051403.

[130] N. Masoumi, N. Sohrabi, A. Behzadmehr, A 1 'v model for calculating the effective viscosity of nanofluids, J. Phys. D. Appl. Phys. 4L (?009). doi:10.1088/0022-3727/42/5/055501.

[131] P.K. Singh, K.B. Anoop, T. Sun' ararajaı, S.K. Das, Entropy generation due to flow and heat transfer in nanofluids, Int. J. Heat" Iass Transf. 53 (2010) 4757-4767. doi:10.1016/j.ijheatmasstrar sis-2010.06.016.

[132] U. Rea, T. McKrell, L. $\mathrm{v}$ en I ، $\mathrm{u}, \mathrm{J}$. Buongiorno, Laminar convective heat transfer and viscous pressure loss of alumi ıa-wal and zirconia-water nanofluids, Int. J. Heat Mass Transf. 52 (2009) 2042-2048. u $\therefore .0 .1$, 16/j.ijheatmasstransfer.2008.10.025.

[133] W. Williams, J. . 'uongiı nno, L.-W. Hu, Experimental Investigation of Turbulent Convective Heat Transfe and Pressure Loss of Alumina/Water and Zirconia/Water Nanoparticle Colloids (Nanofluids) in Hor zontal Tubes, J. Heat Transfer. 130 (2008) 42412. doi:10.1115/1.2818775.

[134] S.P. Jang, , I. Lee, K.S. Hwang, S.U.S. Choi, Particle concentration and tube size dependence of viscosities of $\mathrm{Al}_{2} \mathrm{O}_{3}$-water nanofluids flowing through micro- and minitubes, Appl. Phys. 
Lett. 91 (2007). doi:10.1063/1.2824393.

[135] K. Bashirnezhad, S. Bazri, M.R. Safaei, M. Goodarzi, M. Dahari, O. Mahian. A.S. ¿alkiliça, S. Wongwises, Viscosity of nanofluids: A review of recent experimental st dies, Int. Commun. Heat Mass Transf. 73 (2016) 114-123. doi:10.1016/j.icheatmasstransfer..ำ16.ı2.005.

[136] S.M.S. Murshed, P. Estellé, A state of the art review on viscosity c na ofluids, Renew. Sustain. Energy Rev. 76 (2017) 1134-1152. doi:10.1016/j.rser.2017.03.'13.

[137] J.P. Meyer, S.A. Adio, M. Sharifpur, P.N. Nwosu, The Visc sity or vanofluids: A Review of the Theoretical, Empirical, and Numerical Models, Heat Tru si. Er g. 37 (2016) 387-421. doi:10.1080/01457632.2015.1057447.

[138] H.D. Koca, S. Doganay, A. Turgut, I.H. Tavman, R. Sa ' 'י 1 Ir, I.M. Mahbubul, Effect of particle size on the viscosity of nanofluids: A review, Rene、. Sustain. Energy Rev. 82 (2018) 16641674. doi:10.1016/j.rser.2017.07.016.

[139] M. Amani, P. Amani, A. Kasaeian, O. Mahiar r. Kasaeian, S. Wongwises, Experimental study on viscosity of spinel-type manganese fer. " rlanvfluid in attendance of magnetic field, J. Magn. Magn. Mater. 428 (2017) 457-463.

[140] T. Yiamsawas, A.S. Dalkilic, O. Manı. n. S. Wongwises, Measurement and Correlation of the Viscosity of Water-Based $\mathrm{Al}_{2} \mathrm{O}$ an $\mathrm{TiC}_{2}$ Nanofluids in High Temperatures and Comparisons with Literature Reports, J. D; ,pers. D... Technol. 34 (2013) 1697-1703. doi:10.1080/01932691.2013.7644i?

[141] T. Yiamsawas, O. Mahiaı, I.S. Dalkilic, S. Kaewnai, S. Wongwises, Experimental studies on the viscosity of $\mathrm{TiO}^{-}$an $\mathrm{A}^{\wedge} \mathrm{Al} \mathrm{O}_{3}$ nanoparticles suspended in a mixture of ethylene glycol and water for high tem-: >ratu` applications, Appl. Energy. 111 (2013) 40-45. doi:10.1016/j.ap nergy.' 013.04.068.

[142] G.M. Moldc veanu, I.A. Minea, M. Iacob, C. Ibanescu, M. Danu, Experimental study on viscosity of staumzed $\mathrm{Al}_{2} \mathrm{O}_{3}, \mathrm{TiO}_{2}$ nanofluids and their hybrid, Thermochim. Acta. 659 (2018). doi:10.101“'tca.2017.12.008.

[143] G.M. Moldoveanu, C. Ibanescu, M. Danu, A.A. Minea, Viscosity estimation of $\mathrm{Al}_{2} \mathrm{O}_{3}, \mathrm{SiO}_{2}$ 
nanofluids and their hybrid: An experimental study, J. Mol. Liq. 253 (2018). doi:10.1016/j.molliq.2018.01.061.

[144] G. Zyła, M. Cholewa, On unexpected behavior of viscosity of diethylen€ oly' ol-based MgAl2O4nanofluids, RSC Adv. 4 (2014) 26057-26062. doi:10.1039/c4ı. 73143a.

[145] O. Mahian, A. Kianifar, C. Kleinstreuer, M.A. Al-Nimr, I. Pop, A.. S nin, S. Wongwises, A review of entropy generation in nanofluid flow, Int. J. Heat Mar, I rar sf. 65 (2013). doi:10.1016/j.ijheatmasstransfer.2013.06.010.

[146] P. Estellé, D. Cabaleiro, G. Żyła, L. Lugo, S.M.S. Murshea, ‘urre' t trends in surface tension and wetting behavior of nanofluids, Renew. Sustain. Energy i ev. 94 (2018) 931-944. doi:https://doi.org/10.1016/j.rser.2018.07.006.

[147] N. Ahammed, L.G. Asirvatham, S. Wongwises, Etı 't of volume concentration and temperature on viscosity and surface tension of graphene-wc *er 1 .... fluid for heat transfer applications, $\mathrm{J}$. Therm. Anal. Calorim. 123 (2016). doi:10.1 $: 7 / \mathrm{s} 1,973-015-5034-\mathrm{x}$.

[148] D. Cabaleiro, P. Estellé, H. Navas, A. Des: ‘rges, B. Vigolo, Dynamic Viscosity and Surface Tension of Stable Graphene Oxide and Reduced Graphene Oxide Aqueous Nanofluids, J. Nanofluids. 7 (2018) 1081-1088. d i:10.11 i6/jon.2018.1539.

[149] J. Chinnam, D.K. Das, R.S. Va. na, ,.R. Satti, Measurements of the surface tension of nanofluids and development f a new correlation, Int. J. Therm. Sci. 98 (2015) 68-80. doi:10.1016/j.ijthermalsci.2015.0, 908.

[150] O. Mahian, A. Kianifar, _־ - Sahin, S. Wongwises, Entropy generation during $\mathrm{Al}_{2} \mathrm{O}_{3} /$ water nanofluid flow in as slar iollector: Effects of tube roughness, nanoparticle size, and different thermophysical $\mathrm{m}^{\mathrm{N}} \mathrm{d}$ els, . .`. J. Heat Mass Transf. 78 (2014). doi:10.1016/j.ijh 'atmass ransfer.2014.06.051.

[151] O. Mahian, Mahı ud, S. Zeinali Heris, Effect of Uncertainties in Physical Properties on Entropy Feneraıun Between Two Rotating Cylinders With Nanofluids, J. Heat Transfer. 134 (2012) 101 ' 4 . doi:10.1115/1.4006662.

[152] O. Mahian, A. Kianifar, S.Z. Heris, S. Wongwises, Natural convection of silica nanofluids in 
square and triangular enclosures: Theoretical and experimental study, Int. J. Hr at Mass Transf. 99 (2016). doi:10.1016/j.ijheatmasstransfer.2016.03.045.

[153] E. Abu-Nada, A.J. Chamkha, Effect of nanofluid variable properties on ! xtur ، convection in enclosures filled with a CuO-EG-Water nanofluid, Int. J. Therm. Sci. 4y ? (1v, 2339-2352. doi:10.1016/j.ijthermalsci.2010.07.006.

[154] E. Abu-Nada, Effects of variable viscosity and thermal conduct $\sqrt{ }$ tty of $\mathrm{A}_{\iota_{2}} \mathrm{O}_{3}$-water nanofluid on heat transfer enhancement in natural convection, Int. J. Heat . ${ }^{\top 1}$ uid $\boldsymbol{\top}$ low. 30 (2009) 679-690. doi:10.1016/j.ijheatfluidflow.2009.02.003.

[155] G. Saha, M.C. Paul, Investigation of the characteristics of naı fluids flow and heat transfer in a pipe using a single phase model, Int. Commun. Heat Mas Tr.nsf. 93 (2018) 48-59. doi:https://doi.org/10.1016/j.icheatmasstransfer.2010 $n \cdots$ i.

[156] H. Demir, A.S. Dalkilic, N.A. Kürekci, W. Dua 'gu, ... suk, S. Wongwises, Numerical investigation on the single phase forced con. ation heat transfer characteristics of $\mathrm{TiO}_{2}$ nanofluids in a double-tube counter flow heat e hanger, Int. Commun. Heat Mass Transf. 38 (2011) 218-228. doi:10.1016/j.icheatmasstran ${ }^{c_{\text {er. }} 2010.12 .009 .}$

[157] P.K. Namburu, D.K. Das, K.M. Ta' outuri, ?.S. Vajjha, Numerical study of turbulent flow and heat transfer characteristics of n? lof liids jonsidering variable properties, Int. J. Therm. Sci. 48 (2009) 290-302. doi:10.1016/:,ijı. rm rs sci.2008.01.001.

[158] M.K. Moraveji, M. Darabi, S.M.t. Haddad, R. Davarnejad, Modeling of convective heat transfer of a nanofluid ir the developing region of tube flow with computational fluid dynamics, Int. Commun. Heat $\mathrm{N}^{\prime}$ ass Tra.. ff. 38 (2011) 1291-1295. doi:10.1016/j.icheatı.'stra'sfer.2011.06.011.

[159] O. Manca, S. Na dini, D Ricci, A numerical study of nanofluid forced convection in ribbed channels, Ar s. Therm. Eng. 37 (2012) 280-292. doi:10.1016/j.applthermaleng.2011.11.030.

[160] M.A. Ahmed, Nı..v1. Yaseen, M.Z. Yusoff, Numerical study of convective heat transfer from tube bank 1. -ross flow using nanofluid, Case Stud. Therm. Eng. 10 (2017) 560-569. doi:10.1016/j.csite.2017.11.002. 
[161] R.S. Vajjha, D.K. Das, P.K. Namburu, Numerical study of fluid dynamic and 1 eat transfer performance of $\mathrm{Al}_{2} \mathrm{O}_{3}$ and $\mathrm{CuO}$ nanofluids in the flat tubes of a radiator, Int J. I. at Fluid Flow. 31 (2010) 613-621. doi:10.1016/j.ijheatfluidflow.2010.02.016.

[162] O. Abouali, G. Ahmadi, Computer simulations of natural convection of s ' ngle phase nanofluids in simple enclosures: A critical review, Appl. Therm. Eng. 36 (201 , 1- : doi:10.1016/j.applthermaleng.2011.11.065.

[163] Y. Xuan, W. Roetzel, Conceptions for heat transfer correlation $\iota^{\complement}$ nanr iluids, Int. J. Heat Mass Transf. 43 (2000) 3701-3707. doi:10.1016/S0017-9310(99 002 נצ. 5.

[164] M.S. Mojarrad, A. Keshavarz, A. Shokouhi, Nanofluids therı. al behavior analysis using a new dispersion model along with single-phase, Heat Mas Tra. \& Jnd Stoffuebertragung. 49 (2013). doi:10.1007/s00231-013-1182-3.

[165] M. Bahiraei, S.M. Hosseinalipour, Thermal Dis, 'ers ... Model Compared with Euler-Lagrange Approach in Simulation of Convective Heat $\neg$ ans $r$ for Nanoparticle Suspensions, J. Dispers. Sci. Technol. 34 (2013) 1778-1789. doi:1n 108i'01932691.2012.751339.

[166] M. Amani, P. Amani, A. Kasaeian, O. Mahian, W.-M. Yan, Two-phase mixture model for nanofluid turbulent flow and heat $\mathrm{t} r$.nsfer: 'ffect of heterogeneous distribution of nanoparticles, Chem. Eng. Sci. 167 (2017). doi 10.1010, J.ces.2017.03.065.

[167] Y. Ding, D. Wen, Particle mi ration ... a flow of nanoparticle suspensions, Powder Technol. 149 (2005) 84-92. doi:10.1016/j.p - wtec.2004.11.012.

[168] S. Kumar, S.K. Prasad, J. ? nerjee, Analysis of flow and thermal field in nanofluid using a single phase thermal disr ersion model, Appl. Math. Model. 34 (2010) 573-592. doi:10.1016/j.apm ค909.i‘.026.

[169] S. Özerinç, A.G. I vor slu, S. Kakaç, Numerical analysis of laminar forced convection with temperature depena nt thermal conductivity of nanofluids and thermal dispersion, in: Int. J. Therm. Sri. 2U1 . pp. 138-148. doi:10.1016/j.ijthermalsci.2011.10.007.

[170] S.Z. Heris, N. N. Esfahany, G. Etemad, Numerical investigation of nanofluid laminar convective heat transfer through a circular tube, Numer. Heat Transf. Part A Appl. 52 (2007) 
1043-1058. doi:10.1080/10407780701364411.

[171] M. Ameri, M. Amani, P. Amani, Thermal performance of nanofluids in metal foanı ube: Thermal dispersion model incorporating heterogeneous distribution of n nop rticles, Adv. Powder Technol. 28 (2017) 2747-2755. doi:10.1016/j.apt.2017.07.028.

[172] M. Bahiraei, S.I. Vasefi, A novel thermal dispersion model to impi ve prediction of nanofluid convective heat transfer, Adv. Powder Technol. 25 (2014) 1772 - / /79 doi:10.1016/j.apt.2014.07.005.

[173] M. Bahiraei, S.M. Hosseinalipour, Accuracy enhancement $\iota^{c}$. nerr al dispersion model in prediction of convective heat transfer for nanofluids conside, ' $g$ the effects of particle migration, Korean J. Chem. Eng. 30 (2013) 1552-1558. u. : ' J.1007/s1 1814-013-0087-7.

[174] F. Akbaridoust, M. Rakhsha, A. Abbassi, M. Saffa ^vval, Experimental and numerical investigation of nanofluid heat transfer in helic ' ' 1 y. .1 d tubes at constant wall temperature using dispersion model, Int. J. Heat Mass Tr. ff. 5. (2013) 480-491. doi:https://doi.org/10.1016/j.ijheatmasstransfer.2 912.11 .064 .

[175] M. Sheikholeslami, D.D. Ganji, M.M. Rashidi, Magnetic field effect on unsteady nanofluid flow and heat transfer using Buong irno mı del, J. Magn. Magn. Mater. 416 (2016) 164-173. doi:10.1016/j.jmmm.2016.05.02' .

[176] M. Sheikholeslami, H.B. Rol ،i, Efte. of melting heat transfer on nanofluid flow in existence of magnetic field considering Buv. giorno Model, Chinese J. Phys. 55 (2017) 1115-1126. doi:10.1016/j.cjph.2017 J4.C 9.

[177] F. Garoosi, L. Jahan nal o, M.M. Rashidi, A. Badakhsh, M.E. Ali, Numerical simulation of natural convection - $f$ the - nofluid in heat exchangers using a Buongiorno model, Appl. Math. Comput. 254 (2(15) 18:-203. doi:10.1016/j.amc.2014.12.116.

[178] F. Garoosi, : . Garo si, K. Hooman, Numerical simulation of natural convection and mixed convection of tIı Ilanofluid in a square cavity using Buongiorno model, Powder Technol. 268 (2014) 279. 92. doi:10.1016/j.powtec.2014.08.006.

[179] A. Malvandi, S.A. Moshizi, E.G. Soltani, D.D. Ganji, Modified Buongiorno's model for fully 
developed mixed convection flow of nanofluids in a vertical annular pipe, Cor put. Fluids. 89 (2014) 124-132. doi:10.1016/j.compfluid.2013.10.040.

[180] A. Malvandi, D.D. Ganji, Mixed convective heat transfer of water/alumi a n' nofluid inside a vertical microchannel, Powder Technol. 263 (2014) 37-44. doi:https://doi.org/10.1016/j.powtec.2014.04.084.

[181] N. Shehzad, A. Zeeshan, R. Ellahi, K. Vafai, Convective heat tr ،nsfer of nanofluid in a wavy channel: Buongiorno’s mathematical model, J. Mol. Liq. $222(2 \backslash 16) 4$ ، $4-455$. doi:10.1016/j.molliq.2016.07.052.

[182] M.A. Sheremet, I. Pop, Conjugate natural convection in a squ re porous cavity filled by a nanofluid using Buongiorno's mathematical model, Int. J. Je .i Mass Transf. 79 (2014) 137145. doi:10.1016/j.ijheatmasstransfer.2014.07.092

[183] Z. Zhang, Q. Chen, Comparison of the Euleriar चाI - zrangian methods for predicting particle transport in enclosed spaces, Atmos. Enviro $11(\angle$ 107) 5236-5248. doi:10.1016/j.atmosenv.2006.05.086.

[184] S. Kakaç, A. Pramuanjaroenkij, Analysis of Convective Heat Transfer Enhancement by Nanofluids: Single-Phase and Two 'hase 1 eatments, J. Eng. Phys. Thermophys. 89 (2016) 758-793. doi:10.1007/s10891-01 J-1437-1.

[185] M. Akbari, N. Galanis, A. Bf .zadme: , Comparative analysis of single and two-phase models for CFD studies of nanofluid heal . ansfer, Int. J. Therm. Sci. 50 (2011) 1343-1354. doi:10.1016/j.ijthermals 1.20 \& 1.03.008.

[186] P. Naphon, L. Nakh rint, Trrbulent two phase approach model for the nanofluids heat transfer analysis flowing th trough $^{2} \mathrm{e}$ minichannel heat sinks, Int. J. Heat Mass Transf. 82 (2015) 388395. doi:10.101t 'i.ijhea' nasstransfer.2014.11.024.

[187] M.M. Rashi i, A. h isseini, I. Pop, S. Kumar, N. Freidoonimehr, Comparative numerical study of single and twu-phase models of nanofluid heat transfer in wavy channel, Appl. Math. Mech. (English Ei 35 (2014) 831-848. doi:10.1007/s10483-014-1839-9.

[188] R. Davarnejad, M. Jamshidzadeh, CFD modeling of heat transfer performance of MgO-water 
nanofluid under turbulent flow, Eng. Sci. Technol. an Int. J. 18 (2015) 536-54^? doi:10.1016/j.jestch.2015.03.011.

[189] M. Manninen, V. Taivassalo, S. Kallio, On the mixture model for multip ase ilow, Vtt Publ. (1996) 1-67.

[190] L. Schiller, Z. Naumann, A drag coefficient correlation, Z.Ver.Deu ^ch ing. 77 (1933) 318-320. doi:10.1016/j.ijheatmasstransfer.2009.02.006.

[191] S.A. Morsi, A.J. Alexander, An investigation of particle trai uories in two-phase flow systems, J. Fluid Mech. 55 (1972) 193-208. doi:10.1017/S00221126 ?^J018 J6.

[192] M. Nuim Labib, M.J. Nine, H. Afrianto, H. Chung, H. 'eong, I umerical investigation on effect of base fluids and hybrid nanofluid in forced convectivu heat transfer, Int. J. Therm. Sci. 71

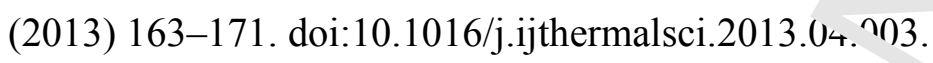

[193] H. Safikhani, A. Abbassi, A. Khalkhali, M. Kalte Modeling and Optimization of Nanofluid Flow in Flat Tubes Using a Combination of C $L$ nd Response Surface Methodology, Heat Transf. Res. (2014) n/a-n/a. doi:10.1002/hy,11zj.

[194] A. Moghadassi, E. Ghomi, F. Parviz an, 5 , numerical study of water based $\mathrm{Al}_{2} \mathrm{O}_{3}$ and $\mathrm{Al}_{2} \mathrm{O}_{3}-\mathrm{Cu}$ hybrid nanofluid effect on forced con vetiv e heat transfer, Int. J. Therm. Sci. 92 (2015) 50-57.

[195] S. Mirmasoumi, A. Behzadmehr, a ım rical study of laminar mixed convection of a nanofluid in a horizontal tube using tv $\mathrm{J}-\mathrm{r}^{-}$hase mixture model, Appl. Therm. Eng. 28 (2008) 717-727. doi:10.1016/j.appltherma' $-\mathrm{H}_{2}: 2007.06 .019$.

[196] M. Goodarzi, M.R. S raei, K. Vafai, G. Ahmadi, M. Dahari, S.N. Kazi, N. Jomhari, Investigation of nanu? $\mathrm{d} \mathrm{w}$ ixed convection in a shallow cavity using a two-phase mixture model, Int. J. Th rm. S. i. 75 (2014) 204-220. doi:10.1016/j.ijthermalsci.2013.08.003.

[197] M. Siavashi, v1. Jamali, Heat transfer and entropy generation analysis of turbulent flow of $\mathrm{TiO}_{2}$ water nanoflı $: d$ ins $i$ le annuli with different radius ratios using two-phase mixture model, Appl. Therm. E. 'g. i in (2016) 1149-1160. doi:10.1016/j.applthermaleng.2016.02.093.

[198] M. Siavashi, H.R. Talesh Bahrami, H. Saffari, Numerical investigation of flow characteristics, 
heat transfer and entropy generation of nanofluid flow inside an annular pipe $\mathrm{p}$ irtially or completely filled with porous media using two-phase mixture model, Energ. . ל. (2015). doi:10.1016/j.energy.2015.10.100.

[199] M. Siavashi, H.R. Talesh Bahrami, E. Aminian, Optimization of heat tra.-fer c. pumping power of a heat exchanger tube using nanofluid with grad $\mathrm{nt}^{\prime}$. $^{1}{ }^{1}$ multi-layered porous foams, Appl. Therm. Eng. 138 (2018) 465-474.

doi:10.1016/j.applthermaleng.2018.04.066.

[200] M. Siavashi, H.R.T. Bahrami, H. Saffari, Numerical invest gati fl porous rib arrangement on heat transfer and entropy generation of nanofluid flow in " n an a us using a two-phase mixture model, Numer. Heat Transf. Part A Appl. 71 (2017) 1乞₹1-127. doi:10.1080/10407782.2017.1345270.

[201] M.H. Toosi, M. Siavashi, Two-phase mixture nיumericia simulation of natural convection of nanofluid flow in a cavity partially filled with por ${ }^{\prime} \mathrm{s}$ media to enhance heat transfer, J. Mol. Liq. 238 (2017) 553-569. doi:10.1016/j.mollı, <i'7.05.015.

[202] R. Yaghoubi Emami, M. Siavashi, G. Shahriaı: Moghaddam, The effect of inclination angle and hot wall configuration on $\mathrm{Cu}$-water $r$ anor id natural convection inside a porous square cavity, Adv. Powder Technol. 29 (2018) 51y- $\$ 36$ doi:10.1016/j.apt.2017.10.027.

[203] M. Siavashi, R. Yousofvand, S. n. 'anf , ad, Nanofluid and porous fins effect on natural convection and entropy gen ra. 'n of flow inside a cavity, Adv. Powder Technol. 29 (2018) 142-156. doi:10.1016/j.a , l.L 17.10.021.

[204] M. Siavashi, A. Rostr ni, Tw phase simulation of non-Newtonian nanofluid natural convection in a circular annulus $r$ ial $/$ or completely filled with porous media, Int. J. Mech. Sci. 133 (2017) 689-703. doi:1C 1016/j.ijmecsci.2017.09.031.

[205] M.K. Morav' J1, R.M. Ardehali, CFD modeling (comparing single and two-phase approaches) on thermal $\mathrm{pc}$ form nce of $\mathrm{Al}_{2} \mathrm{O}_{3}$ /water nanofluid in mini-channel heat sink, Int. Commun. Heat Mass Tra. st. 2013) 157-164. doi:10.1016/j.icheatmasstransfer.2013.02.012.

[206] M. Shariat, R.M. Moghari, A. Akbarinia, R. Rafee, S.M. Sajjadi, Impact of nanoparticle mean 
diameter and the buoyancy force on laminar mixed convection nanofluid flow in an elliptic duct employing two phase mixture model, Int. Commun. Heat Mass Transf. 50 (ว J1 , 15-24. doi:10.1016/j.icheatmasstransfer.2013.11.003.

[207] P. Maghsoudi, M. Siavashi, Application of nanofluid and optimization v' nore vize arrangement of heterogeneous porous media to enhance mixed convection inside a tv - rided lid-driven cavity, J. Therm. Anal. Calorim. (2018) 1-15. doi:10.1007/s10973-01c 7335-3.

[208] R.M.C. Mourad Rebay, Sadik Kakaç, Microscale and Nanoscalc Heat 'iransfer: Analysis, Design, and Application, 1st ed., CRC Press, 2016.

[209] C.Y. Wen, Y.H. Yu, Mechanics of fluidization, Chem. Eng. । ogress, Symp. Ser. 62 (1966) 100-111. doi:10.1016/S0032-0633(98)00014-2.

[210] M. Kalteh, A. Abbassi, M. Saffar-Avval, J. Harting, Fulerian-Eulerian two-phase numerical simulation of nanofluid laminar forced convect, $n_{1}, \ldots$. nicrochannel, Int. J. Heat Fluid Flow. 32 (2011) 107-116. doi:10.1016/j.ijheatfluic ’’w.' ’10.08.001.

[211] W.E. Ranz, W.R. Marshall, Evaporation 1^ $m$ uı ps - Part 1, Chem. Eng. Prog. 48 (1952) 141148. doi:10.1016/S0924-7963(01)0003)-X.

[212] O.A. Beg, M.M. Rashidi, M. Akbari, ' Hr sseini, Comparative Numerical Study of SinglePhase and Two-Phase Models f ir B o-N inofluid Transport Phenomena, J. Mech. Med. Biol. 14 (2014) 1450011. doi:10.1142 s0219. 9414500110.

[213] R. Lotfi, Y. Saboohi, A.N. . a shidi, Numerical study of forced convective heat transfer of Nanofluids: Comparison ${ }^{c}$ different approaches, Int. Commun. Heat Mass Transf. 37 (2010) 74-78. doi:10.1016/..1ch atmasstransfer.2009.07.013.

[214] M. Hejazian, M.' .. Mo 'veji, A. Beheshti, Comparative study of Euler and mixture models for turbulent flow of $1, \cap$ nanofluid inside a horizontal tube, Int. Commun. Heat Mass Transf. 52 (2014) 152- 58. do $\cdot 10.1016 /$ j.icheatmasstransfer.2014.01.022.

[215] A. Sabag. 7n, : Edalatpour, M.C. Moghadam, E. Roohi, H. Niazmand, Nanofluid flow and heat transfer $\eta$ a microchannel with longitudinal vortex generators: Two-phase numerical simulation, Appl. Therm. Eng. 100 (2016) 179-189. doi:10.1016/j.applthermaleng.2016.02.020. 
[216] E. Ebrahimnia-Bajestan, M. Charjouei Moghadam, H. Niazmand, W. Daungth `ngsuk, S. Wongwises, Experimental and numerical investigation of nanofluids heat tr $\mathrm{As} \mathrm{s}$ characteristics for application in solar heat exchangers, Int. J. Heat Mass ' ' rat if. 92 (2016) 1041-1052. doi:10.1016/j.ijheatmasstransfer.2015.08.107.

[217] I. Behroyan, P. Ganesan, S. He, S. Sivasankaran, Turbulent forced r onv - inn of Cu-water nanofluid: CFD model comparison, Int. Commun. Heat Mass Transf. ¿ 7 (2015) 163-172. doi:10.1016/j.icheatmasstransfer.2015.07.014.

[218] S. Rashidi, J.A. Esfahani, R. Ellahi, Convective heat transf $r$ ar $+\mu$ trticle motion in an obstructed duct with two side by side obstacles by means , f DF” $:$ model, Appl. Sci. 7 (2017). doi:10.3390/app7040431.

[219] Y. He, Y. Men, Y. Zhao, H. Lu, Y. Ding, Numerimn in..... gation into the convective heat transfer of $\mathrm{TiO}_{2}$ nanofluids flowing through a straight $\mathrm{u}^{\text {' }}$ e under the laminar flow conditions, Appl. Therm. Eng. 29 (2009) 1965-1972. doi:10. '` 16/j.applthermaleng.2008.09.020.

[220] V. Bianco, F. Chiacchio, O. Manca, S. Nardini, Numerical investigation of nanofluids forced convection in circular tubes, Appl. Therm. Eng 29 (2009) 3632-3642. doi:10.1016/j.applthermaleng.2009.C J.01

[221] M. Bahiraei, A numerical study $r i$ heat ti $u n s f e r$ characteristics of $\mathrm{CuO}$-water nanofluid by Euler-Lagrange approach, J. The. A $A^{r}$ al. Calorim. 123 (2016) 1591-1599. doi:10.1007/s10973-015-50, 1 n

[222] M. Bahiraei, Studying $\mathrm{n}$ nor srticle distribution in nanofluids considering the effective factors on particle migration .nd del mination of phenomenological constants by Eulerian-Lagrangian simulation, Adv. Pow ' $i$ Te shnol. 26 (2015) 802-810. doi:10.1016/j.apt.2015.02.005.

[223] N. Kumar, B.P. s uranik Numerical study of convective heat transfer with nanofluids in turbulent flor , usin r a Lagrangian-Eulerian approach, Appl. Therm. Eng. (2016).

[224] M. Bahiraei. M. siangi, A. Monavari, Assessment of hydrothermal characteristics of Mn-Zn ferrite nanc " did as a functional material under quadrupole magnetic field, Powder Technol. 305 (2017) 174-182. doi:10.1016/j.powtec.2016.10.009. 
[225] S.E. Ghasemi, A.A. Ranjbar, M.J. Hosseini, Numerical study on the convectiv heat transfer of nanofluid in a triangular minichannel heat sink using the Eulerian-Eulerian ${ }^{4} \mathrm{NO}$. hase model, Numer. Heat Transf. Part A Appl. 72 (2017) 185-196. doi:10.1080/10407 / < 2017.1358990.

[226] S. Sonawane, U. Bhandarkar, B. Puranik, Modeling Forced Convection ‘ 'anolı did Heat Transfer Using an Eulerian-Lagrangian Approach, J. Therm. Sci. F ig. $r_{1}^{11} 8$ (2016) 31001. doi:10.1115/1.4032734.

[227] J. Rostami, A. Abbassi, Conjugate heat transfer in a wavy micrc hann , I using nanofluid by two-phase Eulerian-Lagrangian method, Adv. Powder Tecl nol L (2016) 9-18. doi:10.1016/j.apt.2015.10.003.

[228] S. Rashidi, M. Bovand, J. Abolfazli Esfahani, G. Ahmad, nir vrete particle model for

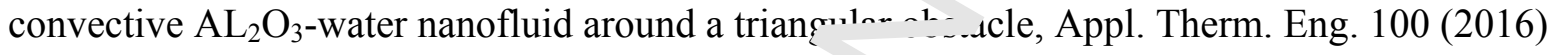
39-54. doi:10.1016/j.applthermaleng.2016.01.076.

[229] M. Bovand, S. Rashidi, G. Ahmadi, J.A. Esf : ani, . ffects of trap and reflect particle boundary conditions on particle transport and convertive $\perp_{1}$ at transfer for duct flow - A two-way coupling of Eulerian-Lagrangian model, Appl. Therm. Lng. 108 (2016) 368-377. doi:10.1016/j.applthermaleng.2016.C /.1 2 :

[230] M. Keshavarz Moraveji, E. Esm sili Com parison between single-phase and two-phases CFD modeling of laminar forced ccrve ion low of nanofluids in a circular tube under constant heat flux, Int. Commun. Heat Mrss Transf. 39 (2012) 1297-1302. doi:10.1016/j.icheatmass ${ }^{+}$al fer.2012.07.012.

[231] M. Akbari, N. Galani, A Bt. zadmehr, Comparative assessment of single and two-phase models for numerica ${ }^{+}$tdie of nanofluid turbulent forced convection, Int. J. Heat Fluid Flow. 37 (2012) 136-1 r6. do: 10.1016/j.ijheatfluidflow.2012.05.005.

[232] A. Albojama', K. Vatai, Analysis of single phase, discrete and mixture models, in predicting nanofluid tra sport int. J. Heat Mass Transf. 114 (2017) 225-237. doi:10.16 $\mathrm{O} / \mathrm{J}$ jinatmasstransfer.2017.06.030.

[233] M. Bahiraei, A numerical study of heat transfer characteristics of $\mathrm{CuO}$-water nanofluid by 
Euler-Lagrange approach, J. Therm. Anal. Calorim. 123 (2016) 1591-1599. doi:10.1007/s10973-015-5031-0.

[234] S. Göktepe, K. Atalık, H. Ertürk, Comparison of single and two-phase m ıdel, for nanofluid convection at the entrance of a uniformly heated tube, Int. J. Therm. Sc1. `n (८u14) 83-92. doi:10.1016/j.ijthermalsci.2014.01.014.

[235] M. Hejazian, M.K. Moraveji, A Comparative Analysis of Singl $r$ and Two-Phase Models of Turbulent Convective Heat Transfer in a Tube for $\mathrm{TiO}_{2} \mathrm{Nanofl}_{\text {' }} \mathrm{\gamma}$ wit' ${ }_{1} \mathrm{CFD}$, Numer. Heat Transf. Part A Appl. 63 (2013) 795-806. doi:10.1080/104C 178`.ム 13.756759.

[236] M. Hejazian, M.K. Moraveji, A. Beheshti, Comparative Nun r. rical Investigation on $\mathrm{TiO}_{2} /$ Water Nanofluid Turbulent Flow by Implementation of Sin_le r i as and Two Phase Approaches, Numer. Heat Transf. Part A Appl. 66 (2014) 330_210 A _.... 0.1080/10407782.2013.873271.

[237] M. Haghshenas Fard, M.N. Esfahany, M.R. Taı 1e, … herical study of convective heat transfer of nanofluids in a circular tube two-phase $m .1 \mathrm{vc}$ sus single-phase model, Int. Commun. Heat Mass Transf. 37 (2010) 91-97. doi:10.1016/i.icı. aatmasstransfer.2009.08.003. 